\author{
UNIVERSIDADE DE SÃO PAULO \\ ESCOLA DE ENGENHARIA DE SÃO CARLOS \\ DEPARTAMENTO DE ENGENHARIA ELÉTRICA
}

RAPHAEL GAVA DE ANDRADE

Classificação das Castanhas do Brasil por Origem e Seleção de Suas Amêndoas Utilizando Visão Computacional 


\author{
UNIVERSIDADE DE SÃO PAULO \\ ESCOLA DE ENGENHARIA DE SÃO CARLOS \\ DEPARTAMENTO DE ENGENHARIA ELÉTRICA
}

\title{
Classificação das Castanhas do Brasil por Origem e Seleção de Suas Amêndoas Utilizando Visão Computacional
}

\author{
Raphael Gava de Andrade
}

Dissertação apresentada à Escola de Engenharia de São Carlos da Universidade de São Paulo para obtenção do título de Mestre em Engenharia Elétrica.

Área de Concentração: Processamento de Sinais e Instrumentação

Orientador: Prof. Dr. Valentin Obac Roda 
AUTORIZO A REPRODUÇÃO E DIVULGAÇÄO TOTAL OU PARCIAL DESTE TRABALHO, POR QUALQUER MEIO CONVENCIONAL OU ELETROONICO, PARA FINS DE ESTUDO E PESQUISA, DESDE QUE CITADA A FONTE.

Ficha catalográfica preparacka pela Seçāo de Tratamento da Informação do Serviço de Biblioteca - EESC/USP

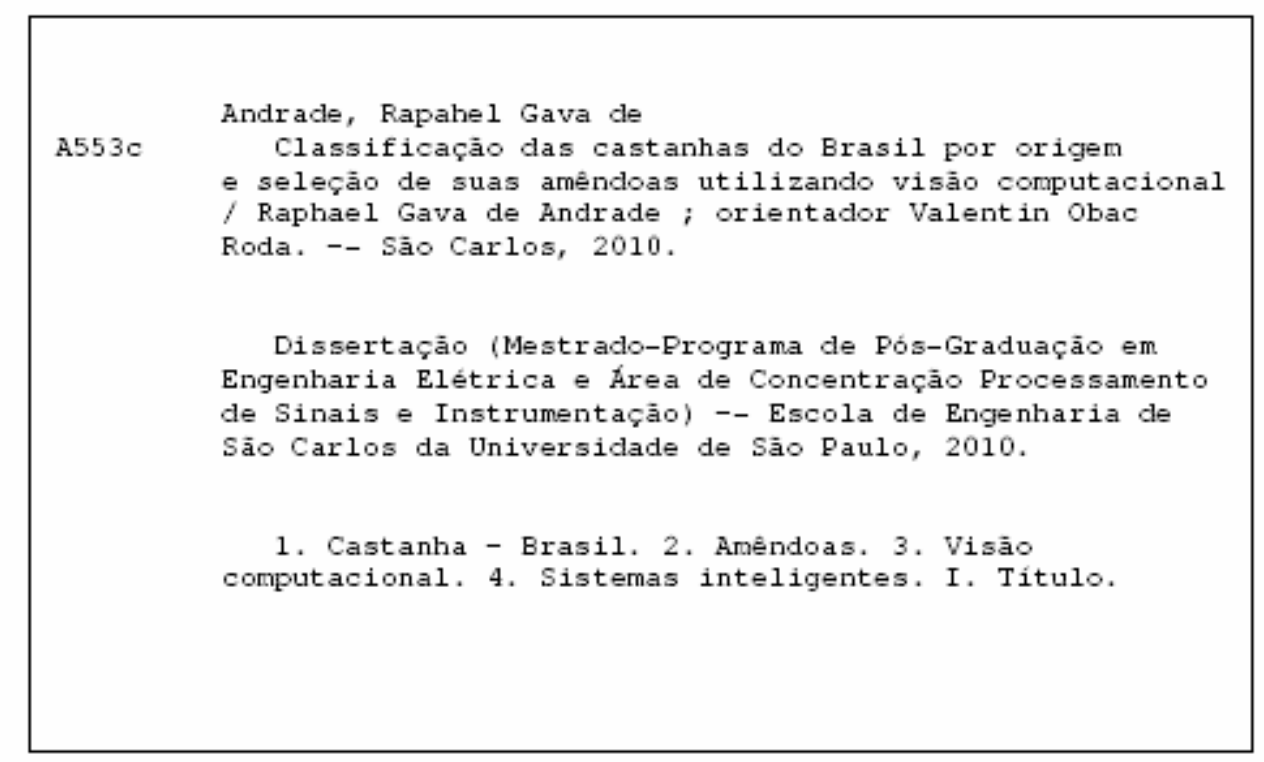




\section{FOLHA DE JULGAMENTO}

\section{Candidato(a): Bacharel RAPHAEL GAVA DE ANDRADE.}

Dissertação defendida e julgada em 10/06/2010 perante a Comissão Julgadora:

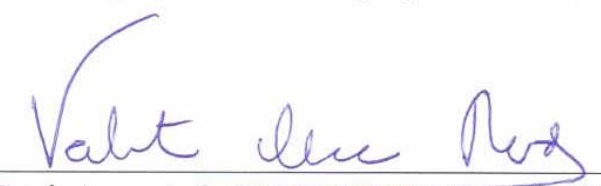

Prof. Associado VALENTIN OBAC RODA - (Orientador)

APROVADO

(Escola de Engenharia de São Carlos/USP)

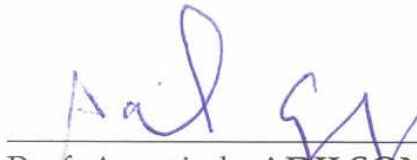

Prof. Associado ADILS $\varnothing$ GONZAGA

APROVADO

(Escola de Engenharia de \$ão Carlos/USP)

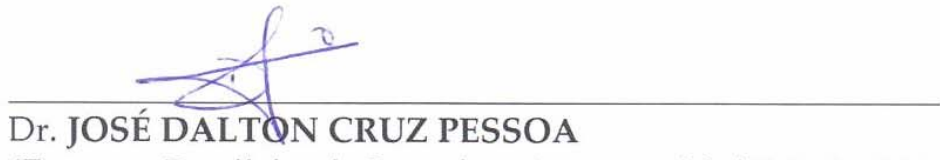

DPROUAOO

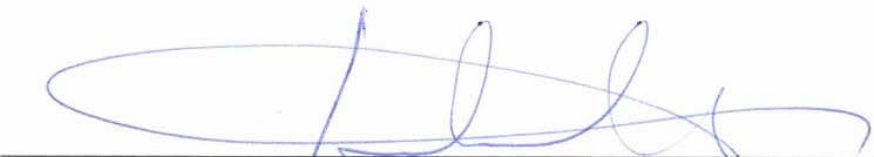

Prof. Titular GERALDO ROBERTO MARTINS DA COSTA

Coordenador do Programa de Pós-Graduação em Engenharia Elétrica e Presidente da Comissão de Pós-Graduação 
Dedico este trabalho para a pessoa mais importante e que com maestria contempla todos os significados da palavra mãe, a minha mãe Silvia. 


\section{AGRADECIMENTOS}

Primeiramente agradeço a minha família pelo apoio e por acreditar em mim. Sem ela nada disso teria acontecido. A minha namorada Juliana pela paciência e carinho neste período.

Ao professor Dr. Valentin pela valiosa oportunidade concedida. Aos meus amigos, professores e todo o departamento de Engenharia Elétrica da Escola de Engenharia de São Carlos por toda a ajuda, apoio e descontração.

Ao Dr. Dalton por todos esses anos de trabalho, discussões e principalmente aprendizado. A todo o pessoal do Laboratório de Inovação Pós Colheita, especialmente a Thais, Tatiane, Gisele, Danieli, Alan, Ana, Karina, Samuel, Cleia e a Sandra pelo apoio em alguns momentos críticos e pelos momentos de descontração durante esses anos.

A todo o corpo técnico da Embrapa Instrumentação Agropecuária que sempre foram prestativos e solidários, especialmente ao Ednaldo, Mariana, Lúcio, Washington, Godoy, Jorge, Adonai, a dupla de Andrés.

As pessoas que fazem parte do projeto Kamukaia pelas discussões e castanhas concedidas, principalmente a Dra. Lúcia Helena de Oliveira Wadt (Embrapa Acre).

Por último mas não menos importante, aos meus amigos sempre presentes Michel, José Augusto (Zinho), Anderson (Baixinho), Beto e a dupla de Anas. Aos meus amigos desde a faculdade Ricardão e Diego. E sobrevivendo aos tempos de cursinho, Digão, Allyson e Camila. Estes sempre estiveram comigo seja qual tenha sido a dificuldade ou a diversão. 
“Algumas pessoas rezam para Jesus, outras vão a Meca, outras estudam partículas subatômicas. No final, estamos todos apenas buscando a verdade, aquela que é maior do que nós mesmos."

Dan Brown 


\section{RESUMO}

ANDRADE, R. G. Classificação das Castanhas do Brasil por Origem e Seleção de Suas Amêndoas Utilizando Visão Computacional. Dissertação (Mestrado) - Departamento de Engenharia Elétrica, Escola de Engenharia, Universidade de São Paulo, São Carlos, 2010.

A extração e comercialização das castanhas do Brasil (Bertholletia excelsa H.B.K.) é uma importante fonte de renda na região norte do Brasil. O processamento das castanhas nas indústrias ainda necessita de melhorias. Por isso, o Brasil está atrasado na questão da qualidade do produto em relação às exigências feitas pelo mercado externo. A Bolívia, que é a maior exportadora de amêndoas, utiliza tecnologia para processamento das amêndoas e com isso consegue satisfazer as exigências impostas pelo mercado internacional, sendo mais competitiva do que o Brasil nesse segmento.

Sistemas de visão computacional e sistemas inteligentes estão sendo amplamente utilizados para melhoria dos processos de produção e dos produtos em diversas áreas do conhecimento. Visando a melhoria dos processos nas indústrias brasileiras de beneficiamento das castanhas, este trabalho utilizou conceitos de visão computacional com foco em duas das várias etapas de beneficiamento: classificação das castanhas e seleção de suas amêndoas.

Assim, esta dissertação apresenta o software desenvolvido para seleção das amêndoas e também uma metodologia de classificação por origem. O software desenvolvido para a seleção das amêndoas apresentou na distinção entre intactas e quebradas uma média de identificações corretas de 95,7\%. Já para a metodologia de classificação, teve $84 \%$ de identificações corretas na identificação das origens.

Palavras chaves: Castanhas-Brasil, amêndoas, visão computacional e sistemas inteligentes. 


\section{ABSTRACT}

ANDRADE, R. G. Classification of Brazil Nuts by Origin and Selection of Their Almonds Using Computer Vision. Dissertation (Master degree) - Department of Electrical Engineering, School of Engineering, University of São Paulo, São Carlos, 2010.

Extraction and trading of the Brazil nuts (Bertholletia excelsa H.B.K) is an important source of income for the northern region of Brazil. The factory processing of the Brazil nuts still needs improvements. This is in the mean reason why Brazil is losing ground in the foreign markets due to the demands made on the issue of product quality. Bolivia, today is the largest exporter of nuts, and uses technology for nuts processing satisfying the requirements imposed by the international market, being more competitive than Brazil in this segment.

Computer vision and intelligent systems are being widely used to improve production processes and products in many areas of technology. Aiming to improve the Brazilian industrial nuts processing, this study used computer vision concepts with focus on two of the various stages of processing: classification of nuts and selection of its almonds

Thus, this dissertation presents the software developed for the selection of almonds and also a method of classification by origin. The software developed for the selection of almonds showed the distinction between intact and broken with an average accuracy of $95.7 \%$. As for the methodology of classification, this had $84 \%$ accuracy in identifying the sources.

Keywords: Brazil nut, almond, computer vision and intelligent systems. 


\section{SUMÁRIO}

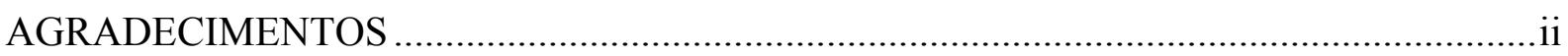

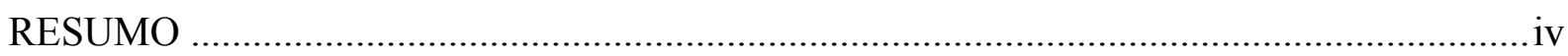

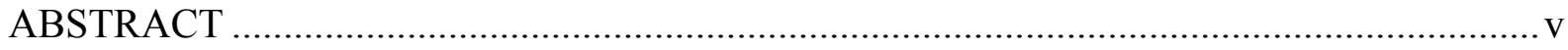

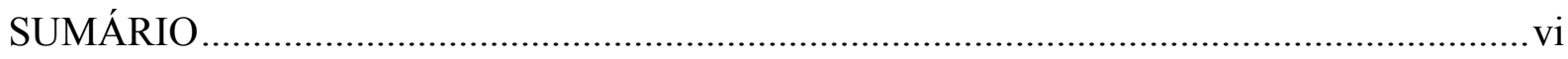

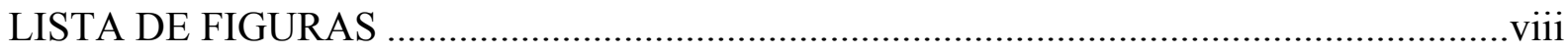

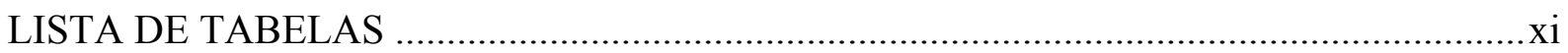

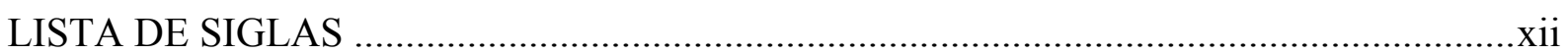

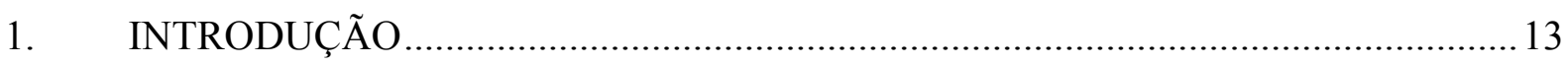

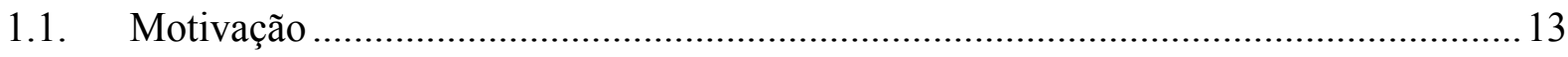

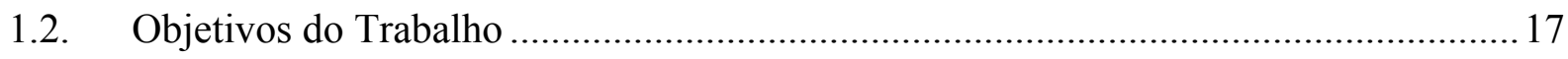

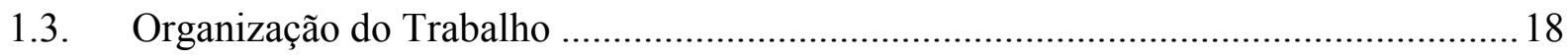

2. SISTEMAS DE CLASSIFICAÇÃO, SELEÇÃO OU CARACTERIZAÇÃO DE

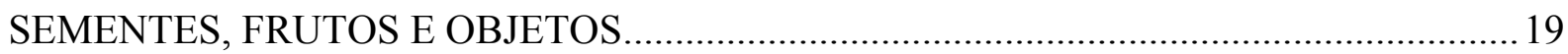

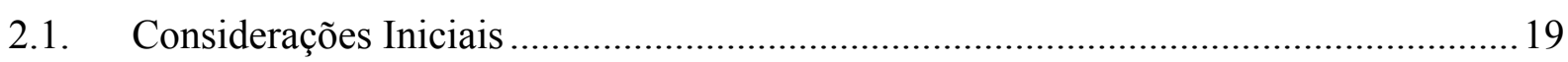

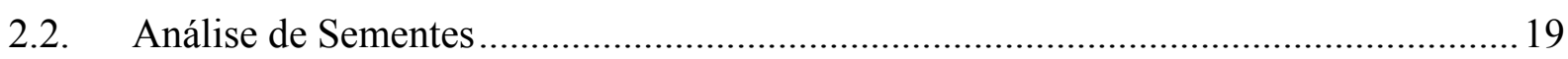

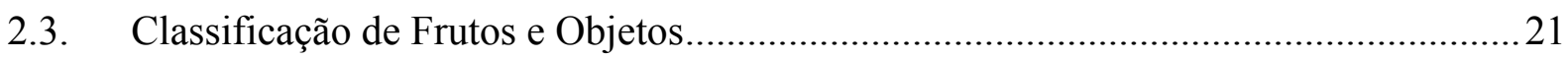

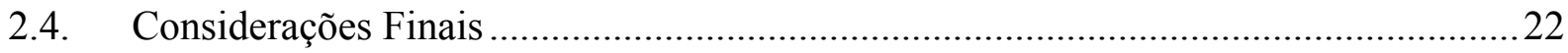

3. FUNDAMENTOS DE VISÃO COMPUTACIONAL E SISTEMAS INTELIGENTES

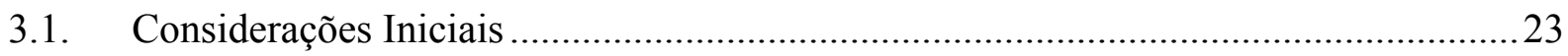

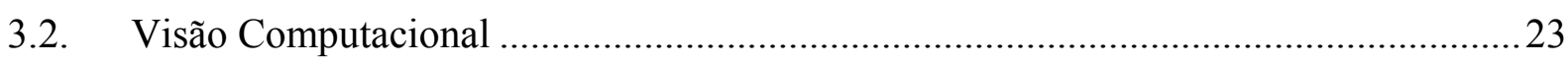

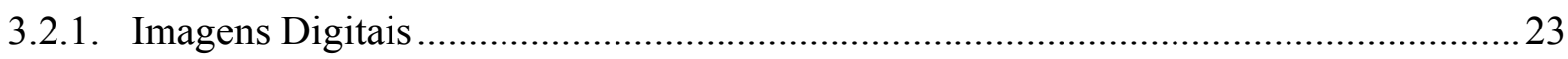

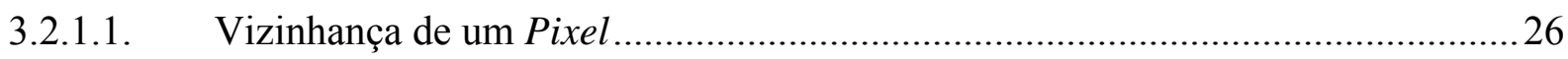

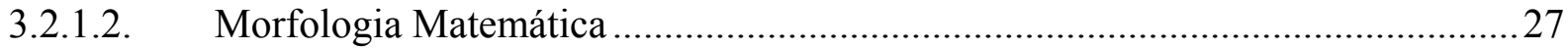

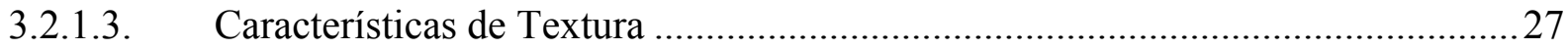

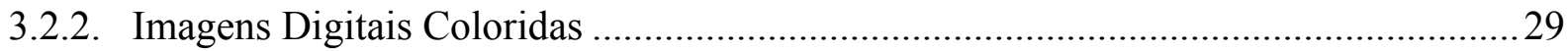

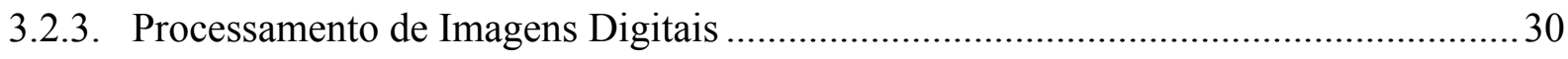

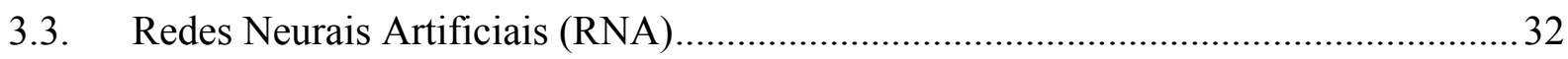

3.3.1. Neurônio Biológico x Neurônio Artificial.................................................................... 32

3.3.2. Rede neural artificial Perceptron Multicamadas ....................................................... 34

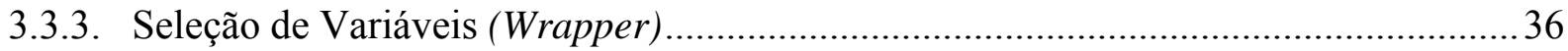




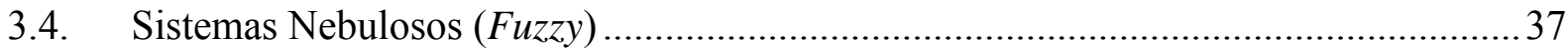

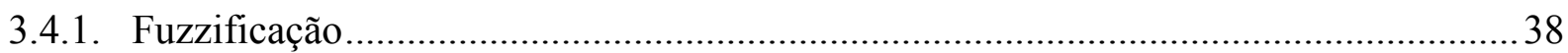

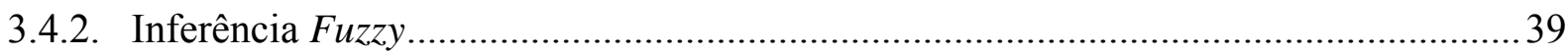

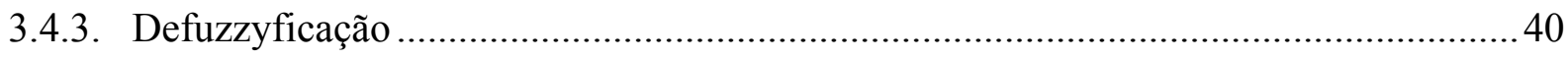

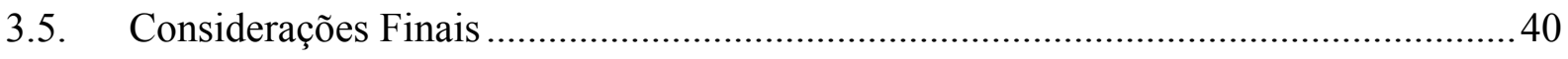

4. CLASSIFICAÇÃO DAS CASTANHAS DO BRASIL POR ORIGEM .....................41

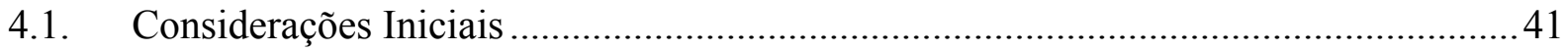

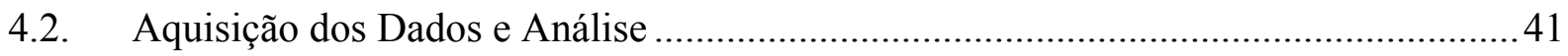

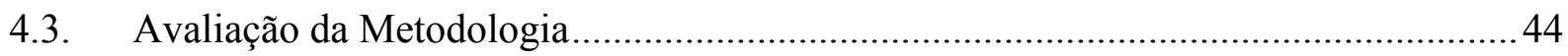

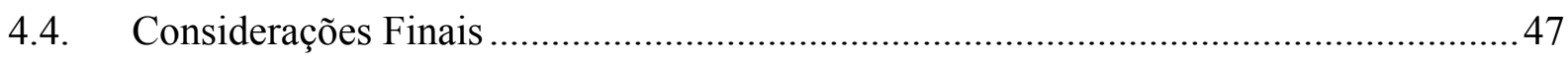

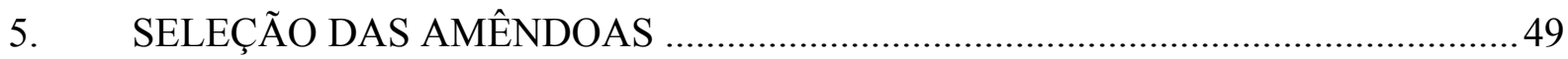

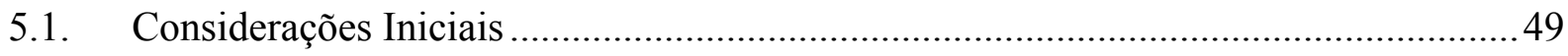

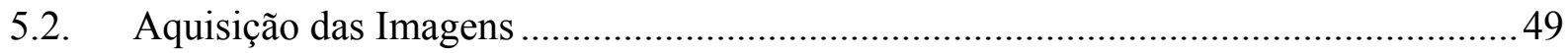

5.3. Pré-processamento e Segmentação das Imagens ........................................................... 51

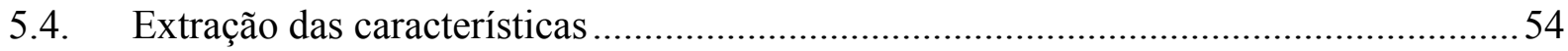

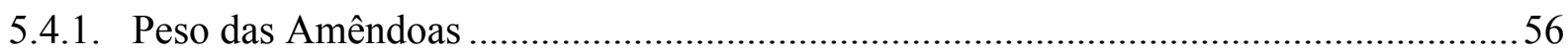

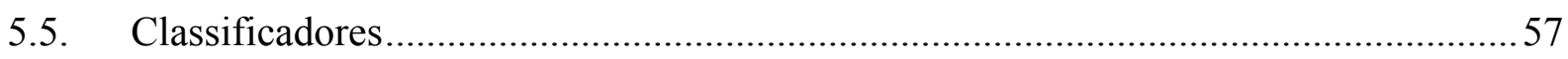

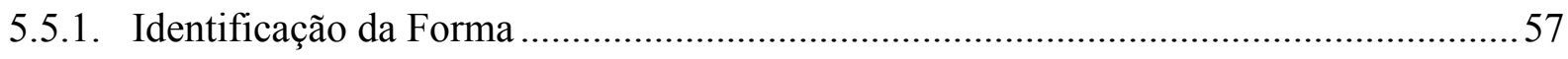

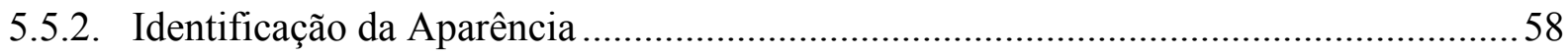

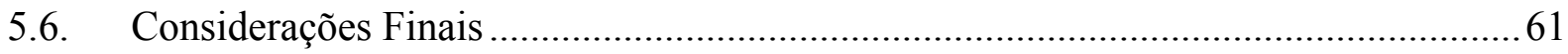

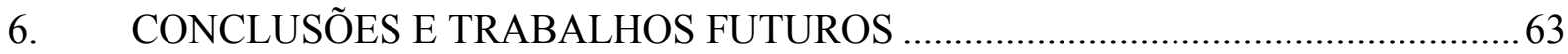

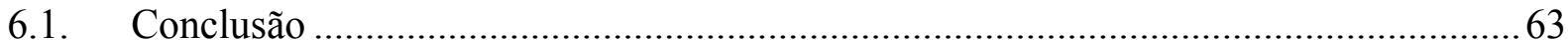

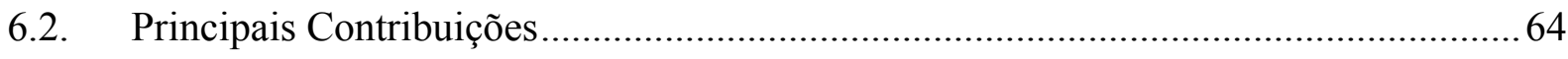

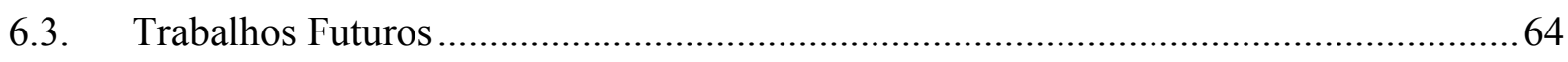

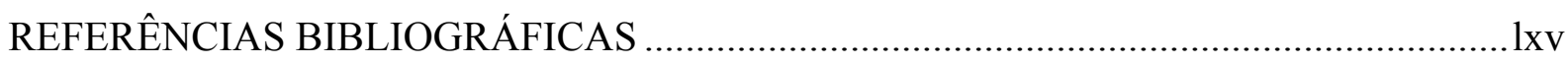

APÊNDICE A - Gráficos das Diversidades das Variáveis Para Cada Região .......................1xxi

APÊNDICE B - Imagens das Telas do Software Desenvolvido .........................................1xxvii APÊNDICE C - Imagens da Montagem Utilizada nos Testes Para Seleção das Amêndoas.

lxxxiii

APÊNDICE D - Fluxograma do Funcionamento do Software de Seleção das Amêndoas 1xxxv ANEXO A - Pseudocódigo de Conversão Entre os Espaços de Cores RGB e HSV ........1xxxvii 


\section{LISTA DE FIGURAS}

FIGURA 1 - IMAGEM DOS FRUTOS (OURIÇOS) E SEMENTES (CASTANHAS) DA CASTANHEIRA (VILELA, 2008) . . 13 FIGURA 2 - FluXograma da CADEIA PROdutiva da CASTANHA do BRasil (PROJETO FLORESTA VIVA, [2009]) 14

FIGURA 3 - QUANTIDADE DE CASTANHAS EXPORTADAS EM TONELADAS (SISTEMA..., [1989])........................ 15

FIGURA 4 - VALOR EM U\$ POR TONELADA DAS CASTANHAS EXPORTADAS (SISTEMA..., [1989]).................... 15

FIGURA 5 - SEQÜÊNCIA DE IMAGENS DIGITAIS, COM RESOLUÇÃO ESPACIAL CADA VEZ MENOR, MOSTRANDO O EFEITO DA RESOLUÇ̃̃o ESPACIAL SOBRE ELAS (GONZALEZ; WOODS, 2001). 25

FIGURA 6 - SEQÜÊNCIA DE IMAGENS DIGITAIS, COM RESOLUÇ̃̃o DE NÍVEL DE CINZA CADA VEZ MENOR, MOSTRANDO O EFEITO DA RESOLUÇÃO DE NÍVEL DE CINZA SOBRE ELAS (GONZALEZ; WOODS, 2001) ............ 25 FIGURA 7 - (A) VIZINHANÇA 4-ADJACENTES DE P; (B) VIZINHANÇA 8-ADJACENTES DE P................................... 26 FIGURA 8 - REPRESENTAÇÃO ESPAÇO DE COR RGB...................................................................................... 30

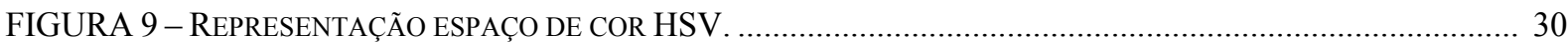

FIGURA 10 - ETAPAS BÁSICAS PARA O PROCESSAMENTO DE IMAGENS. ……....................................................... 31

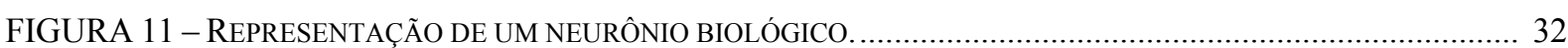

FIGURA 12 - REPRESENTAÇÃO DO NEURÔNIO ARTIFICIAL. ................................................................................ 33

FIGURA 13 - FunÇõES DE ATIVAÇ̃̃o COMUMENTE USADAS E SUAS EQUAÇÕES (SILVA, C. B. S, 2007)............ 34

FIGURA 14 - SENTIDOS DE PROCESSAMENTO DO ALGORITMO BACKPROPAGATION............................................... 35

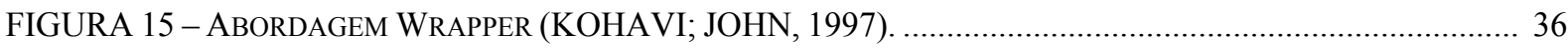

FIGURA 16 - REPRESENTAÇ̃̃o GRÁFICA DAS CLASSES ClARo (CINZA CLARO) E ESCURO (CINZA ESCURO) DA VARIÁVEL LINGUISTICA INTENSIDADE. 37

FIGURA 17 - ETAPAS DE FUNCIONAMENTO DE UM SISTEMA FUZZY (HENRIQUES, 2004)................................ 38

FIGURA 18 - (A) FUnÇão GAUSSIANA; (B) FUNÇão TRIANGULAR; (C) FUNÇ̃̃o TRAPEZOIDAL. ........................ 39 FIGURA 19 - IMAGENS DAS CASTANHAS DO BRASIl COM ORIGEM EM: (A) ACRE; (B) AMAPÁ; (C) Mato Grosso; (D) PARÁ; (E) RONDÔNIA.

FIGURA 20 - IMAGENS DAS CASTANHAS DO BRASIL COM DIMENSÃO DE 100X100 PIXELS COM ORIGEM EM: (A)

ACre; (B) AMAPÁ; (C) Mato Grosso; (D) PARÁ; (E) RondôniA. 42

FIGURA 21 - ARQUITETURA 1 DA MLP - TODAS AS VARIÁVEIS (15 NEURÔNIOS NA CAMADA DE ENTRADA; 5 NEURÔNIOS NA CAMADA INTERMEDIÁRIA; 5 NEURÔNIOS NA CAMADA DE SAÍDA). 43

FIGURA 22 - ARQUITETURA 2 DA MLP - APÓS SELEÇÃO DAS VARIÁVEIS (7 NEURÔNIOS NA CAMADA DE ENTRADA; 5 NEURÔNIOS NA CAMADA INTERMEDIÁRIA; 5 NEURÔNIOS NA CAMADA DE SAÍDA). .............................. 44

FIGURA 23 - ILUSTRAÇÃO DO SISTEMA UTILIZADO PARA SELECIONAR AS AMÊNDOAS. ...................................... 50

FIGURA 24 - EXEMPLO DE IMAGEM RGB CAPTURADA E UTILIZADA PELO SISTEMA (IMAGEM DE FUNDO).......... 50 FIGURA 25 - EXEMPLO DE IMAGEM RGB CAPTURADA E UTILIZADA PELO SISTEMA (IMAGEM COM AMÊNDOAS). 51 FIGURA 26 - IMAGEM REFERENTE AO CANAL R DO ESPAÇO DE COR RGB. ..................................................... 51

FIGURA 27 - IMAGEM REFERENTE AO CANAL G DO ESPAÇO DE COR RGB ........................................................... 52

FIGURA 28 - IMAGEM REFERENTE AO CANAL B DO ESPAÇO DE COR RGB. ...................................................... 52 
FIGURA 29 - RESULTADO DA SUBTRAÇÃO ENTRE O CANAL B DA IMAGEM DE FUNDO COM O CANAL B DO FRAME

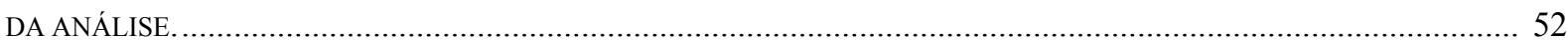

FIGURA 30 - IMAGEM BINARIZADA DAS AMÊNDOAS EM MOVIMENTO_......................................................... 53

FIGURA 31 - IMAGEM DAS AMÊNDOAS EM MOVIMENTO APÓS A UTILIZAÇÃO DO PROCESSO DE ABERTURA........ 53

FIGURA 32 - GRÁFICO DA RELAÇÃO ENTRE A ÁREA DA AMÊNDOA NA IMAGEM E DO PESO REAL........................56

FIGURA 33 - IMAGEM RESULTANTE DAS DUAS ETAPAS DE SELEÇÃO. .............................................................. 57

FIGURA 34 - ARQUITETURA INICIAL DA MLP (4 NEURÔNIOS NA CAMADA DE ENTRADA; 6 NEURÔNIOS NA CAMADA INTERMEDIÁRIA; 2 NEURÔNIOS NA CAMADA DE SAÍDA).

FIGURA 35 - IMAGENS DAS AMÊNDOAS: (A) ESTRAGADAS; (B) BOAS SEM E COM PELÍCULA; (C) BOA COM ALGUMA PELÍCULA E JÁ PERDENDO ÓLEO.

FIGURA 36 - UNIVERSOS DE DisCURSOS UTILIZAdOS: (A) INTENSIDADE DE B; (B) VALOR DE H; (C)

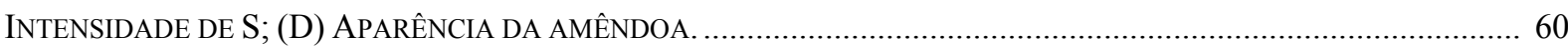

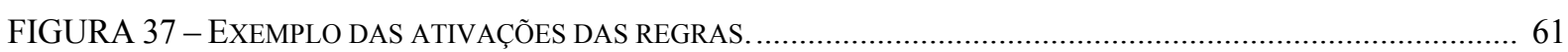

FIGURA 38 - GRÁFICO DA DIVERSIDADE DAS AMOSTRAS EM RELAÇÃO AOS VALORES DE INTENSIDADE.......... LXXI

FIGURA 39 - GRÁFICO DA DIVERSIDADE DAS AMOSTRAS EM RELAÇÃO AOS VALORES DE CONTRASTE. ........... LXXI

FIGURA 40 - GRÁFICO DA DIVERSIDADE DAS AMOSTRAS EM RELAÇÃO AOS VALORES DE SUAVIDADE........... LXXII

FIGURA 41 - GRÁFICO DA DIVERSIDADE DAS AMOSTRAS EM RELAÇÃO AOS VALORES DE TERCEIRO MOMENTO......

LXXII

FIGURA 42 - GRÁFICO DA DIVERSIDADE DAS AMOSTRAS EM RELAÇÃO AOS VALORES DE UNIFORMIDADE. .... LXXII FIGURA 43 - GRÁFICO DA DIVERSIDADE DAS AMOSTRAS EM RELAÇÃO AOS VALORES DE ENTROPIA............. LXXIII FIGURA 44 - GRÁFICO DA DIVERSIDADE DAS AMOSTRAS EM RELAÇÃO AOS VALORES DE R DO ESPAÇO RGB. LXXIII

FIGURA 45 - GRÁFICO DA DIVERSIDADE DAS AMOSTRAS EM RELAÇÃO AOS VALORES DE G DO ESPAÇO RGB......... LXXIII

FIGURA 46 - GRÁFICO DA DIVERSIDADE DAS AMOSTRAS EM RELAÇÃO AOS VALORES DE B DO ESPAÇO RGB. LXXIV

FIGURA 47 - GRÁFICO DA DIVERSIDADE DAS AMOSTRAS EM RELAÇÃO AOS VALORES DE H DO ESPAÇO HSV. LXXIV

FIGURA 48 - GRÁFICO DA DIVERSIDADE DAS AMOSTRAS EM RELAÇÃO AOS VALORES DE S DO ESPAÇO HSV. LXXIV

FIGURA 49 - GRÁFICO DA DIVERSIDADE DAS AMOSTRAS EM RELAÇÃO AOS VALORES DE V DO ESPAÇO HSV LXXV

FIGURA 50 - GRÁFICO DA DIVERSIDADE DAS AMOSTRAS EM RELAÇÃO AOS VALORES DE L DO ESPAÇO L*A*B..... LXXV

FIGURA 51 - GRÁFICO DA DIVERSIDADE DAS AMOSTRAS EM RELAÇÃO AOS VALORES DE *A DO ESPAÇO L*A*B..... LXXV

FIGURA 52 - GRÁFICO DA DIVERSIDADE DAS AMOSTRAS EM RELAÇÃO AOS VALORES DE *B DO ESPAÇO L*A*B..... LXXVI

FIGURA 53 - TELA INICIAL DO SOFTWARE. LXXVII FIGURA 54 - TELA DE CONFIGURAÇÃO DOS PESOS. LXXVII 
FIGURA 55 - TELA DE CONFIGURAÇÃO DA MLP. LXXVIII

FIGURA 56 - SELECIONANDO A MLP QUE SERÁ UTILIZADA E O ARQUIVO DE MÍNIMOS E MÁXIMOS GERADOS NO TREINAMENTO DA RNA. LXXVIII

FIGURA 57 - ABRINDO ARQUIVO DA IMAGEM DO FUNDO. LXXIX

FIGURA 58 - ABRINDO A CÂMERA PARA ANÁLISE AO VIVO. LXXIX

FIGURA 59 - TELA DO SISTEMA EM FUNCIONAMENTO. LXXX

FIGURA 60 - TELA DO ABOUT DO SISTEMA. LXXX

FIGURA 61 - FINALIZANDO O SOFTWARE LXXXI

FIGURA 62 - VISTA 1 DA MONTAGEM FEITA PARA A SELEÇÃO DAS AMÊNDOAS. LXXXIII

FIGURA 63 - VISTA 2 DA MONTAGEM FEITA PARA SELEÇÃO DAS AMÊNDOAS. LXXXIII

FIGURA 64 - FLUXOGRAMA DO FUNCIONAMENTO DO SOFTWARE DE SELEÇÃO DAS AMÊNDOAS. LXXXV 


\section{LISTA DE TABELAS}

TABELA 1 - TABELA DE ESPECIFICAÇÕES DEFINIDOS PELO MAPA PARA CLASSIFICAÇÃO DAS CASTANHAS COM CASCAS (PROJETO FLORESTA VIVA, [2009]).

TABELA 2 - TABELA DE ESPECIFICAÇÕES DEFINIDOS PELO MAPA PARA CLASSIFICAÇÃO DAS CASTANHAS PROCESSADAS (PROJETO FLORESTA VIVA, [2009]) (ADAPTADA).

TABELA 3 - QUANTIDADE DE BITS NECESSÁRIOS PARA IMAGENS COM DIFERENTES RESOLUÇÕES ESPACIAIS E DE NÍVEIS DE CINZA (GONZALEZ; WOODS, 2001)...

TABELA 4 - DESCRITORES DA ABORDAGEM ESTATÍSTICA DE TEXTURA (GONZALEZ; WOODS; EDDINS, 2004)

TABELA 5 - IDENTIFICAÇÕES CORRETAS (\%) DA ARQUITETURA INICIAL DA MLP PARA CADA FOLD. 45

TABELA 6 - IDENTIFICAÇÕES CORRETAS (\%) DA ARQUITETURA APÓS A SELEÇÃO DE VARIÁVEIS PARA CADA FOLD

TABELA 7 - MÉDIA DE IDENTIFICAÇÕES CORRETAS (\%) DOS FOLDS PARA CADA ARQUIETURA. 45

TABELA 8 - IDENTIFICAÇÕES CORRETAS (\%) DAS REGIÕES DE CADA GRUPO DE AMOSTRAS PARA CADA PESSOA

TABELA 9 - RESULTADO DO TESTE T STUDENT COMPARANDO OS TESTES DOS DOIS TREINAMENTOS DA PRIMEIRA ARQUITETURA COM A ANÁLISE VISUAL DE CADA PESSOA

TABELA 10 - TEMPO DE PROCESSAMENTO DAS METODOLOGIAS TESTADAS PARA MINIMIZAR RASTROS NA IMAGEM 54

TABELA 11 - DESCRITORES DE FORMA UTILIZADOS PARA SELEÇÃo DAS AMÊNDOAS (COSTA; CESAR JUNIOR, 2001).

TABELA 12 - IDENTIFICAÇÕES CORRETAS (\%) DA CONDIÇÃO FÍSICA DAS AMÊNDOAS. 58 


\section{LISTA DE SIGLAS}

CCD - Charge Coupled Device

CIE - Commission Internationale de L'Eclairage

DPI - Dots Per Inch

DSP - Digital Signal Processor

EQM - Erro Quadrático Médio

FPGA - Field Programmable Gate Array

HSV - Hue, Saturation and Value

LIPCo - Laboratório de Inovação em Pós Colheita

MAPA - Ministério Agricultura, Pecuária e Abastecimento

MBR- Minimum Bounding Rectangle

MLP - Multi Layer Perceptron

OpenCV - Open Computer Vision

RGB - Red, Green and Blue

RNA - Rede Neural Artificial

ROI - Region Of Interest

WEKA - Waikato Environment for Knowledge Analysis 


\section{INTRODUÇÃO}

\subsection{Motivação}

A castanha do Brasil, em algumas regiões do Brasil também conhecida como castanha do Pará (Bertholletia excelsa H.B.K.) é a semente da castanheira, uma árvore da família botânica Lecythidaceae, nativa da Floresta Amazônica. As castanheiras se estendem entre as regiões Brasileiras, Bolivianas, Equatorianas, Peruanas e Venezuelanas. Seu fruto é chamado de ouriço, um pixídio lenhoso e globoso de diversos tamanhos, que armazena as castanhas em seu interior. O valor econômico das castanhas está diretamente relacionado ao óleo extraído e principalmente pelo valor nutritivo de suas amêndoas, tornando-as conhecidas também como "carnes vegetais". Os ouriços e as castanhas são mostrados na Figura 1.

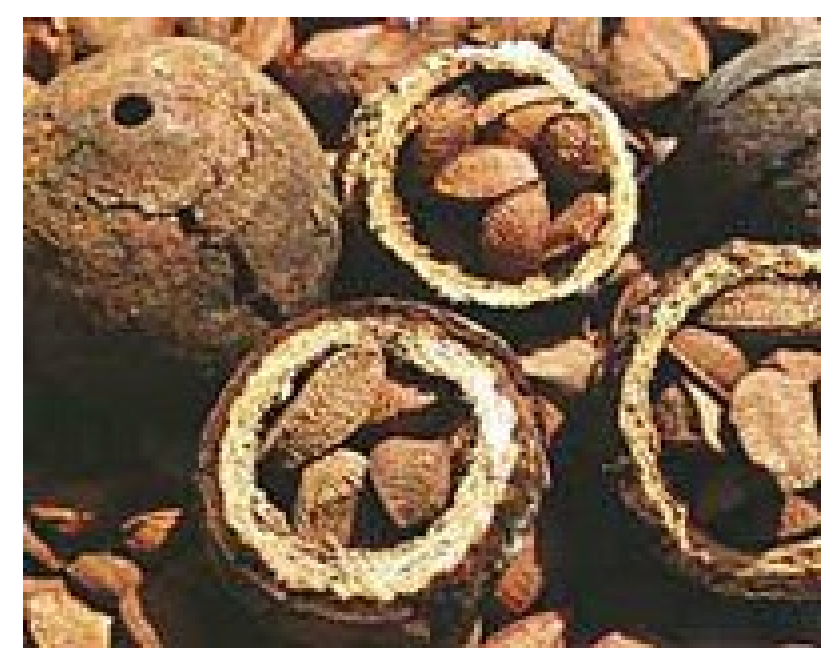

FIGURA 1 - IMAGEM DOS FRUTOS (OURIÇOS) E SEMENTES (CASTANHAS) DA CASTANHEIRA (VILELA, 2008).

Por suas características, a castanha do Brasil é uma das maiores fontes de renda da região norte do Brasil, desempenhando um papel econômico importante para o mercado extrativista dessa região. Sua produção está distribuída entre os estados do Pará, Amazonas, Acre, Mato Grosso, Rondônia, Roraima e Amapá, sendo os três primeiros responsáveis pela maior parte da produção total (PENNACCHIO, 2006a, 2006b). Sua cadeia produtiva é 
composta por várias etapas, tendo inicio na coleta, passando pela fase de beneficiamento e com fim nos mercados interno e externo. Toda a cadeia produtiva é representada pelo fluxograma na Figura 2.

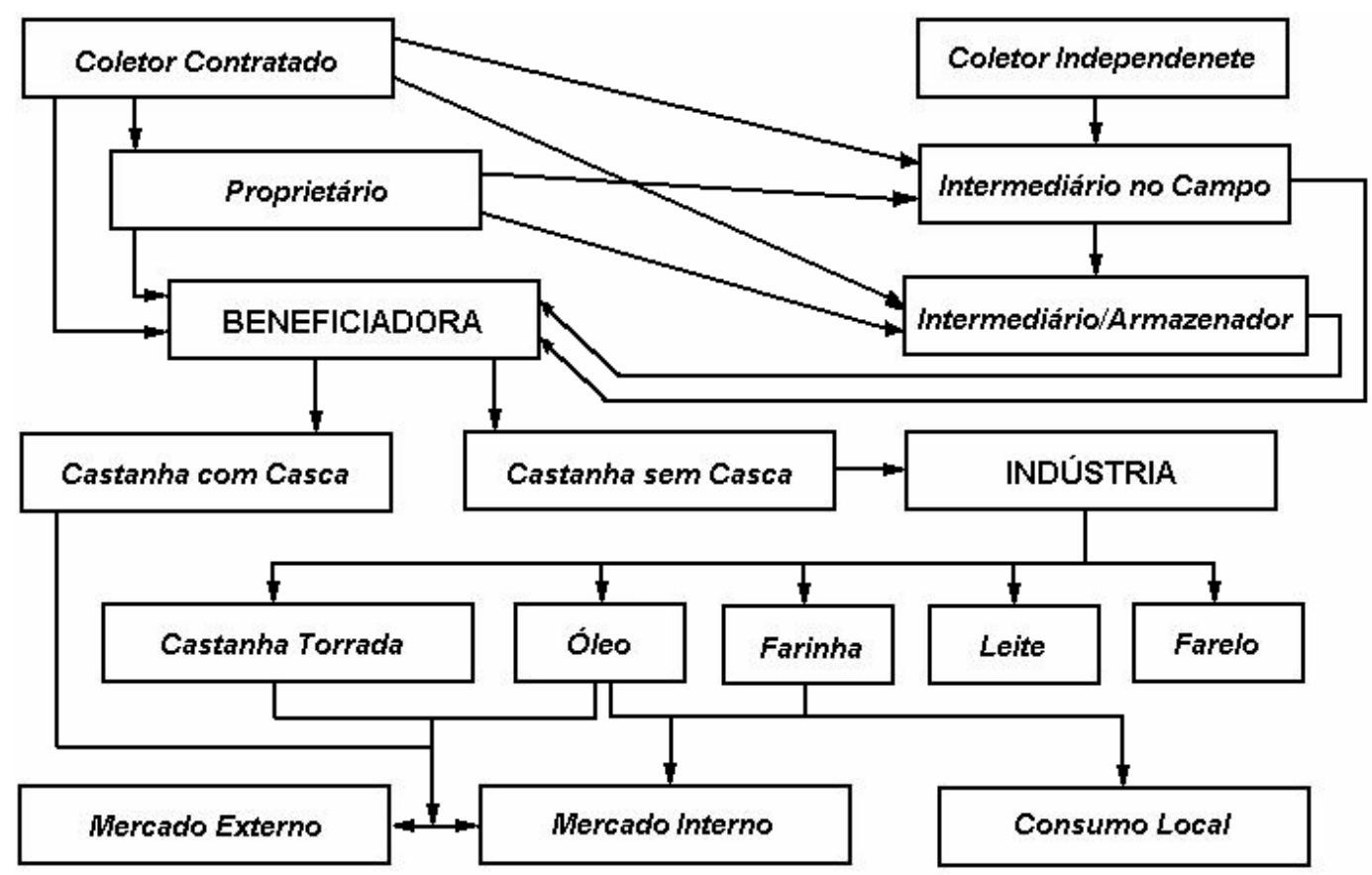

FIGURA 2 - FluXograma da CADEIA PROdUtiva dA CASTANHA do BRAsil (PROJETO FLORESTA VIVA, [2009]).

Até 2003 a produção das castanhas era distribuída em somente 40 \% para exportação e $60 \%$ para o mercado interno. Essa situação foi invertida a partir de 2004, com o direcionamento da produção para exportação (PENNACCHIO, 2006a, 2006b).

A Bolívia é a maior produtora de castanhas processadas (amêndoa com ou sem película) há mais de 10 anos, abrangendo hoje cerca de $71 \%$ do mercado mundial. O Brasil e os outros países juntos exportam para a percentagem restante desse mercado, sendo que o Brasil exporta para $18 \%$ do total. Por esse fato, no período de 2000 a 2003 o Brasil obteve um lucro médio anual de US\$7.034.815 enquanto a Bolívia obteve US\$ 27.968.224 (COSLOVSKY, 2008), pois a castanha processada valeu em média 2,5 vezes mais do que a castanha não processada. Contudo, atualmente no Brasil, apenas $60 \%$ da produção de amêndoas é de amêndoas intactas e utilizadas na forma de subprodutos (VILELA, 2008), sendo que o restante é aproveitado para a extração de óleo, fabricação de farinha, leite e farelo.

Diferente do que acontece com as castanhas processadas, o Brasil há muito tempo é líder do mercado de castanhas in natura e com sua casca desidratada. As Figuras 3 e 4 
mostram os gráficos das quantidades (Ton.) e dos valores (U\$) das castanhas com e sem casca exportadas pelo Brasil de 1999 a 2007.

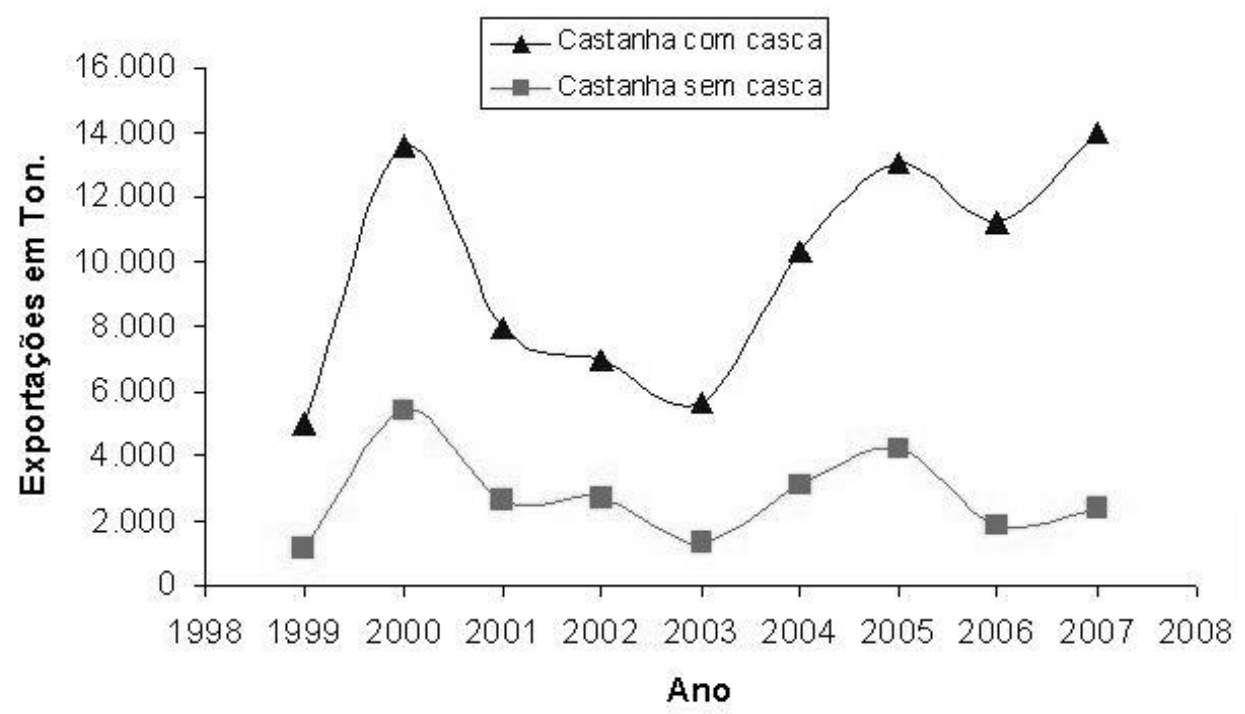

FIGURA 3 - QUANTIDADE DE CASTANHAS EXPORTADAS EM TONELADAS (SISTEMA..., [1989]).

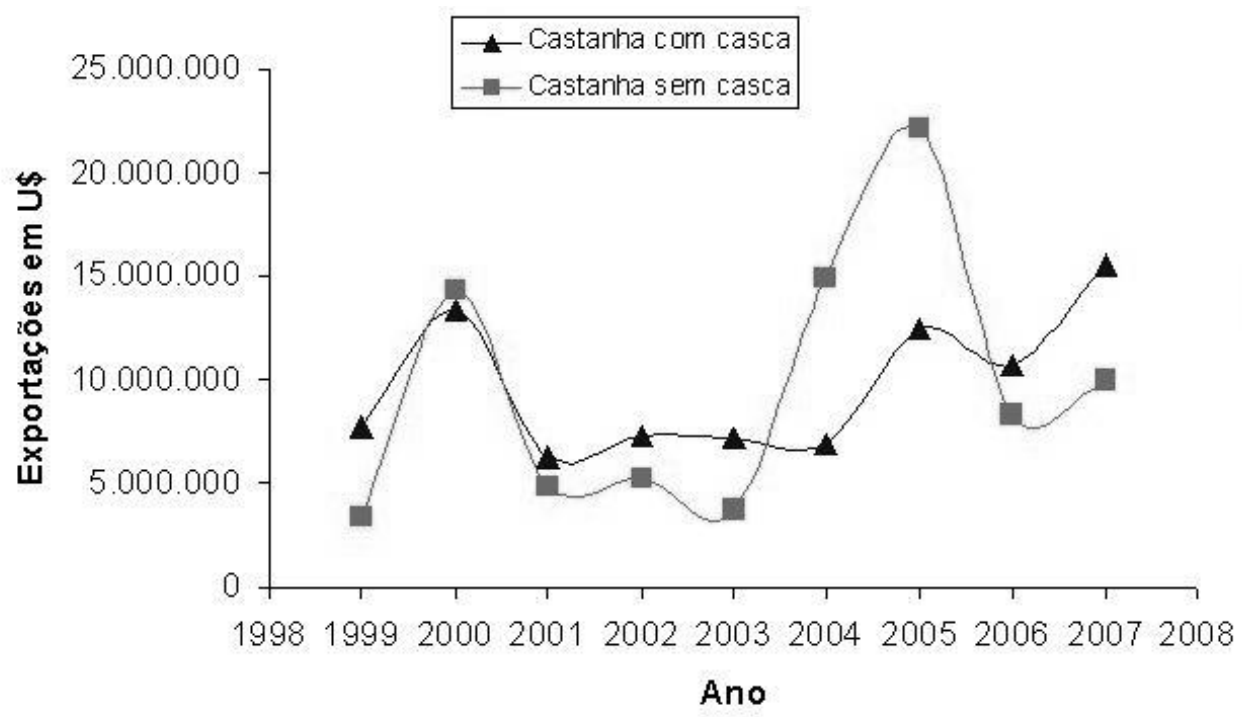

FIGURA 4 - VALOR EM U\$ POR TONELADA DAS CASTANHAS EXPORTADAS (SISTEMA..., [1989]).

Por ser um produto extrativista, a produção de castanha do Brasil é considerada orgânica e sua extração ambientalmente correta, uma vez que não são utilizados defensivos químicos para o controle de pragas, plantas daninhas ou adubação. Isso reduz os perigos químicos comuns aos produtos cultivados, pelo menos em relação a contaminação por substâncias químicas. No entanto, os baixos níveis tecnológicos característicos de sua cadeia produtiva bem como as condições inadequadas de manejo da matéria-prima, favorecem a 
constituição de pontos de contaminação com conseqüente risco a saúde dos consumidores e perdas econômicas comum em todas as etapas.

Dentre os principais problemas identificados na produção da castanha do Brasil está a elevada contaminação por bactérias do grupo coliforme, devido à prolongada exposição a fatores ambientais e as condições de manipulação na indústria, além da contaminação por fungos Aspergillus flavus, produtores das aflatoxinas. Esses problemas têm constituído um forte entrave para a comercialização do produto, principalmente no mercado externo, dado ao rigoroso controle fitossanitário imposto por Europa e Estados Unidos (SILVA, F. A. 2002). Além disso, a seleção das castanhas e amêndoas necessita de alto custo e trabalho intenso, já que essas etapas são feitas manualmente (MELLO, 2007).

A Bolívia é líder na exportação das castanhas, pois possui menor carga tributária e principalmente por utilizar tecnologia em todos os processos de suas indústrias. $\mathrm{O}$ que significa uma economia de $28 \%$ no custo de todo o processo, mantendo a alta produtividade e qualidade sanitária (COSLOVSKY, 2005).

A pós-colheita da produção de castanha do Brasil inclui a fase exploratória e a fase de beneficiamento da amêndoa nas usinas. A fase de beneficiamento, onde é encontrado o maior problema de contaminação, consiste em separação e seleção, armazenamento na unidade e beneficiamento, lavagem, tratamento térmico, quebra, seleção e classificação. Nesta última, as castanhas podem ser processadas ou apenas estar em casca desidratada, sendo classificadas de acordo com as especificações definidas pelo $\mathrm{MAPA}^{1}$. O processo ainda consiste em desidratação, polimento, pesagem, embalamento e finalmente o armazenamento do produto final na indústria (MANUAL..., 2004). A Tabela 1 e 2 abaixo, mostram as especificações de classificação do MAPA de acordo com a Portaria nº89 de 08 de Novembro de 1976.

A Tabela 2 foi adaptada para mostrar os pesos mínimos e máximos de cada amêndoa para obter-se a quantidade definida pelo MAPA a cada $453^{\circ} \mathrm{g}$.

\footnotetext{
${ }^{1}$ MAPA - Ministério da Agricultura, Pecuária e Abastecimento.
} 
TABELA 1 - TABELA DE ESPECIFICAÇÕES DEFINIDOS PELO MAPA PARA CLASSIFICAÇÃO DAS CASTANHAS COM CASCAS (PROJETO FLORESTA VIVA, [2009]).

Castanha em casca

Quantidade (un) a cada $453 \mathrm{~g}$

\begin{tabular}{ccc}
\hline Tipo & Natural & Desidratada e Desidratada Polida \\
\hline Pequena (Small) & Acima de 58 & Acima de 68 \\
\hline Média (Médium) & de 51 a 58 & de 63 a 68 \\
\hline Extra Média (Extra-Medium) & de 46 a 50 & de 56 a 62 \\
\hline Semi Grande (Weak-Large) & de 41 a 45 & de 51 a 55 \\
\hline Grande (Large) & de 36 a 40 & de 46 a 50 \\
\hline Extra Grande (Extra-Large) & Menos de 36 & Menos de 46 \\
\hline
\end{tabular}

TABELA 2 - TABELA DE ESPECIFICAÇÕES DEFINIDOS PELO MAPA PARA CLASSIFICAÇÃO DAS CASTANHAS PRocESSADAS (PROJETO FLORESTA VIVA, [2009]) (ADAPTADA).

\begin{tabular}{cccc}
\hline & Amêndoa com e sem Película (Castanha Processada) \\
\hline & Quantidade (un) & \multicolumn{2}{c}{ Peso (g) Unitário } \\
\cline { 3 - 4 } Tipo & Acada 453g & Máximo & Mínimo \\
\hline Miudinha (Tiny) & de 160 a 180 & 2,502 & 1 \\
\hline Miúda (Midget) & de 140 a 159 & 3,831 & 2,53 \\
\hline Pequena (Small) & de 115 a 139 & 3,939 & 2,849 \\
\hline Média (Medium) & de 102 a 114 & 4,441 & 3,258 \\
\hline Extra Média (Extra-Medium) & Menos de 102 & 10 & 3,973 \\
\hline Grande (Large) & & & 4,485 \\
\hline
\end{tabular}

\subsection{Objetivos do Trabalho}

Este trabalho teve como objetivos desenvolver uma metodologia de classificação de castanhas por sua origem e desenvolver um sistema de seleção de suas amêndoas. Dando assim, continuidade aos estudos feitos pelo LIPCo $^{2}$ da Embrapa Instrumentação Agropecuária na área de beneficiamento da castanha do Brasil. Para isso foram utilizadas técnicas de visão computacional e inteligência artificial, visando melhorias nos processos de seleção e classificação na produção das castanhas do Brasil. Tendo as seguintes metas:

$\mathrm{Na}$ classificação das castanhas por origem:

- Identificar a origem das castanhas através de suas características físicas.

\footnotetext{
${ }^{2}$ LIPCo - Laboratório de Inovação em Pós Colheita
} 
Para selecionar as castanhas processadas (amêndoas com ou sem película) o sistema contém as seguintes funções:

- Distinguir as amêndoas intactas das danificadas;

- Distinguir as amêndoas boas das estragadas;

- Estimar e selecionar as amêndoas por peso.

Além disso, o sistema deverá apresentar robustez às situações que poderão acontecer nas indústrias. Por fim, o sistema desenvolvido será testado visando a análise de sua eficiência.

\subsection{Organização do Trabalho}

Esta dissertação é constituída por 6 capítulos que estão organizados da seguinte maneira:

- Neste capitulo foi feita à introdução sobre o assunto, relatando as características do sistema de produção atual das castanhas do Brasil e sua importância econômica para região. Os objetivos dessa dissertação também foram citados.

- No capítulo 2, são apresentados os trabalhos encontrados na literatura que estão relacionados com seleção e classificação de sementes, frutas ou objetos.

- No capítulo 3, são mostradas em detalhes as técnicas de visão computacional e inteligência artificial que foram utilizadas no desenvolvimento da metodologia de classificação e no sistema de seleção das amêndoas das castanhas do Brasil.

- No capítulo 4, são mostrados os métodos utilizados para a classificação por origem das castanhas do Brasil e discussão dos resultados obtidos.

- Já no capítulo 5, são mostrados os métodos utilizados para a seleção das amêndoas e estimação do seu peso. Neste também são discutidos os resultados e mostrado o funcionamento do sistema desenvolvido.

- Por fim, no capítulo 6 é feita a conclusão do trabalho, demonstrando as principais contribuições e também os trabalhos futuros. 


\section{SISTEMAS DE CLASSIFICAÇÃO, SELEÇÃO OU CARACTERIZAÇÃO DE SEMENTES, FRUTOS E OBJETOS}

\subsection{Considerações Iniciais}

Grande parte das indústrias brasileiras não utiliza tecnologia para classificar as castanhas do Brasil e nem para selecionar suas amêndoas. Mesmo nas grandes indústrias a seleção é feita através de inspeção visual. Essa inspeção é feita por pessoas em torno de uma bancada com centenas de amêndoas, separando-as e classificando-as pela estimativa do peso através de seu tamanho. Mesmo com a grande capacidade do sistema visual humano, existem muitas situações que influenciam na precisão da decisão humana, o cansaço é um bom exemplo. Assim, cada vez mais são utilizadas técnicas de visão computacional e de sistemas inteligentes em sistemas de processos industriais de vários segmentos para diminuir ou eliminar a subjetividade.

Além disso, o alto valor econômico das amêndoas já citado anteriormente, está fazendo com que os empresários comecem a investir em equipamentos para suas indústrias beneficiadoras, visando aumentar a produção e melhorar a qualidade do processo. Pensando nisso, neste capítulo são descritos alguns trabalhos que podem ser encontrados na literatura para classificação, seleção ou caracterização de objetos, sementes ou frutas. Esses trabalhos utilizaram técnicas de visão computacional ou sistemas inteligentes.

\subsection{Análise de Sementes}

Assim como no caso das castanhas do Brasil, quaisquer outros tipos de sementes (milho, feijão, castanha de caju, etc.) podem sofrer danos mecânicos durante o processamento ou ter problemas fisiológicos por outros fatores. Para explicar esse problema na produção de sementes, Forti, Cícero e Pinto (2008) citam o trabalho de Andrade et al. (1999) que 
considera esta situação praticamente inevitável. De acordo com seu trabalho, isso acontece devido às várias fases de produção das quais as sementes são expostas a diferentes tipos de tensões, umidade e outros tipos de injúrias.

No entanto, Forti, Cícero e Pinto (2008) avaliaram as técnicas de análise de imagens para identificação de danos causados por percevejos na semente de feijão. Nesse trabalho foram utilizadas radiografias (imagens de raios $\mathrm{X}$ de baixa energia) que foram avaliadas conforme a severidade do dano. Com isso, seu trabalho identificou as localizações dos danos nas sementes de feijão e os relacionou com seus problemas germinativos.

Em trabalho semelhante utilizando imagens de raios $\mathrm{X}$, porém com sementes de milho, Cícero e Banzatto Junior (2003) analisaram as injúrias das sementes e as relacionaram com o seu vigor por meio de testes germinativos. Já os trabalhos de Flor et al. (2004) e Pinto, Cícero e Forti (2007) fizeram os testes utilizando radiografias de sementes de soja. A diferença entre os trabalhos foi de que Flor et al (2004) analisou os danos mecânicos e Pinto, Cícero e Forti (2007) analisaram os danos causados pela umidade. Todos esses trabalhos utilizaram imagens de raios $\mathrm{X}$ por ser um método não destrutivo à semente e ser eficiente para as análises da morfologia das mesmas.

Pensando em classificar as sementes de milho por suas características morfológicas, Teixeira et al. (2007) utilizou imagens para determinar as dimensões das sementes. Para isso, foram adquiridas imagens de grupos de sementes por um scanner. A partir das imagens foi possível obter a largura e o comprimento das sementes e classificá-las estatisticamente. Em suas referências, está a de McDonald, Evans e Bennett (2000) que concluíram ao utilizar scanners em suas análises que a captação das imagens pode padronizar os testes na avaliação de sementes e plântulas.

Ao invés de milho, o trabalho de Shahin, Symons e Poysa (2006) classificaram sementes de soja utilizando também processamento de imagens. Neste, foram calculadas a uniformidade de suas dimensões e depois classificadas utilizando RNA $^{3}$ e métodos estatísticos. Ambos os trabalhos mostraram-se eficientes com bons resultados se comparados com a inspeção visual.

Como exemplo de segmentação de sementes em imagens, o trabalho de Betancur e Prieto (2008) utilizou um algoritmo de sistema difuso (Fuzzy C-Means). Neste trabalho, o número de grupos (clusters) para representação da informação foi definido a critério do usuário. Após essa definição, o sistema registrava três medidas: a área da região, os valores de

\footnotetext{
${ }^{3}$ RNA - Redes Neurais Artificiais.
} 
cores dessas regiões e se as regiões estavam ou não conectadas (vizinhança de 8-adjacente). Os dados de cores tendiam para 0 (se cor de fundo) ou para 1 (se cor das sementes). Assim era possível detectar o contorno das sementes cujas cores variavam entre: verde, amarelo e marrom. O software foi implementado usando $\mathrm{FPGA}^{4}$ e $\mathrm{DSP}^{5}$ para aumentar a eficiência e velocidade de processamento.

\subsection{Classificação de Frutos e Objetos}

A visão computacional e a inteligência computacional podem ser utilizadas em diversas aplicações além de caracterização de sementes. Ainda voltado para agricultura e ambientes industriais, o trabalho de Louro, Mendonça e Gonzaga (2006) classificou tomates e mostrou a importância da definição das variáveis a serem inseridas numa RNA para classificação. As variáveis utilizadas como entrada da primeira RNA foram os canais de cores Vermelho e Verde. A saída dessa RNA foi utilizada como entrada de uma segunda RNA que junto com o diâmetro equatorial classificavam os tomates. Após vários testes para determinação das variáveis de entrada da arquitetura da RNA, os tomates foram classificados como verde ou maduro e grande ou pequeno.

Já os trabalhos de Simões, Costa e Andrade (2001) e Simões e Costa (2003), foram focados na inspeção visual das laranjas. Nesses trabalhos, imagens das laranjas tiveram cada pixel adicionados na camada de entrada de uma RNA para determinação da cor. Nesse caso as cores eram: verde escuro, verde claro, amarelo, laranja claro, laranja escuro, branco (fundo) e cores denominadas de mancha. Então, foi utilizado um sistema difuso para a classificação da fruta a partir dos vetores de pixels criados pela RNA. Os dois trabalhos tiveram resultados interessantes para o domínio proposto.

Outra pesquisa relacionada com laranjas, mas focada em suas plantações, foi o de Cavani et al. (2006). Este trabalho segmentou as imagens em: laranjas, árvore, solo e céu. Essa segmentação utilizou vetores de cores do espaço $\mathrm{HSV}^{6}$. Além disso, seu trabalho mostrou ser possível a utilização de uma RNA para a classificação dos segmentos.

$\mathrm{Na}$ literatura, alguns trabalhos utilizam o conceito de sistemas Neuro-Fuzzy para realizar a classificação e a detecção de defeitos em placas de madeira, a partir de segmentação de imagens. Em Gonzaga, França e Slaets (2000), foram utilizadas três classificações para as madeiras: alta, média e baixa qualidade. O sistema foi executado a partir dos histogramas em

\footnotetext{
${ }^{4}$ FPGA - Field Programmable Gate Array.

${ }^{5}$ DSP - Digital Signal Processor.

${ }^{6} \mathrm{HSV}$ - Hue, Saturation, Value.
} 
nível de cinza das imagens das madeiras colocadas como variáveis de entrada na NeuroFuzzy. Assim, eles obtiveram ótimos resultados com grande velocidade de processamento.

Ruz, Estévez e Perez (2005) detectaram defeitos nas placas de madeiras por segmentação de imagens. Esses defeitos foram detectados a partir das sementes (pixels) colocadas em alguns pontos da imagem. Essas sementes permitiram encontrar os $\mathrm{MBR}^{7}$ mais conhecidos como Bounding Box. O sistema Neuro-Fuzzy nesse caso foi utilizado para selecionar as sementes implantadas visando uma segmentação mais efetiva.

Existem muitos outros trabalhos na literatura os quais tem como objetivo identificar folhas, placas automotivas, objetos, pessoas e até mesmo movimento. Áreas como medicina, biologia, química e também indústrias automotivas, estão desenvolvendo cada vez mais trabalhos utilizando técnicas de visão computacional ou inteligência artificial.

\subsection{Considerações Finais}

A maior parte dos trabalhos ligados às sementes utilizou imagens radiológicas para análise. Isso porque esse método não é destrutivo para as sementes, deste modo puderam ser feitas outras análises. Essa é uma solução interessante, porém com custo elevado e também não muito robusto em ambientes industriais.

Apesar disso, os trabalhos apresentaram técnicas importantes para segmentação dos objetos a serem analisados na imagem. Também foram apresentadas arquiteturas de classificadores utilizando principalmente RNA e sistemas difusos e que podem ser testados com as castanhas e amêndoas.

Analisando os trabalhos apresentados nesse capítulo, pode-se perceber que sistemas de visão computacional e de inteligência artificial estão resolvendo problemas de maiores dificuldades em diversas áreas do conhecimento. Assim, já visando à melhoria do processo de beneficiamento da castanha do Brasil, os próximos capítulos apresentarão os métodos que foram utilizados para execução do presente trabalho.

\footnotetext{
${ }^{7}$ MBR - Minimum Bounding Rectangle.
} 


\section{FUNDAMENTOS DE VISÃO COMPUTACIONAL E SISTEMAS INTELIGENTES}

\subsection{Considerações Iniciais}

Neste capítulo são apresentados os conceitos de visão computacional e sistemas inteligentes que são relevantes para o entendimento dos métodos utilizados pela metodologia de classificação e pelo sistema de seleção desenvolvido. Os dois serão apresentados em detalhes nos próximos capítulos.

\subsection{Visão Computacional}

Visão computacional, segundo Jähne, Haubecker e Geibler (1999), é uma técnica para adquirir, processar, analisar e compreender dados de maior dimensão de complexidade do nosso meio ambiente para exploração científica e técnica. Pode-se dizer também que visão computacional é a visão por meio de máquinas que automatizam e complementam (cobrindo um maior espectro eletromagnético) os processos da percepção visual humana. Basicamente esses processos podem ser divididos em três partes: pré-processamento das imagens, extração das características e análise dos dados.

\subsubsection{Imagens Digitais}

Uma imagem pode ser definida por uma função bidimensional $\mathrm{f}(\mathrm{x}, \mathrm{y})$, sendo o par $(\mathrm{x}, \mathrm{y})$ conhecido como pixel e f para cada par $(\mathrm{x}, \mathrm{y})$ a intensidade luminosa. Por representar uma forma de energia, $\mathrm{f}(\mathrm{x}, \mathrm{y})$ é um valor inteiro não negativo e finito (W), como representado a seguir pela expressão (1). 


$$
0 \leq f(x, y) \leq W
$$

As imagens são caracterizadas por dois componentes: iluminância e reflectância. A iluminância é a quantidade de luz incidente e a reflectância é a luz refletida nos objetos. Considerando a iluminância i $(x, y)$ e a reflectância $r(x, y)$, quando feito o produto entre eles têm-se $\mathrm{f}(\mathrm{x}, \mathrm{y})$, como mostra a expressão (2):

$$
\begin{gathered}
f(x, y)=i(x, y) * r(x, y) \\
0<i(x, y)<W \\
0<r(x, y)<1
\end{gathered}
$$

A expressão (4) mostra que a reflectância é limitada entre 0 (total absorção) e 1 (total reflexão). A representação da imagem $\mathrm{f}(\mathrm{x}, \mathrm{y})$ arranjada de maneira matricial $\mathrm{P} x \mathrm{Q}$ é chamada de imagem digital. Essa representação é mostrada em (5).

$$
f(x, y)=\left(\begin{array}{cccc}
f(0,0) & f(0,1) & \ldots & f(0, Q-1) \\
f(1,0) & f(1,1) & \ldots & f(1, Q-1) \\
\vdots & \vdots & \ddots & \vdots \\
f(P-1,0) & f(P-1,1) & \ldots & f(P-1, Q-1)
\end{array}\right)
$$

Cada elemento dessa matriz representa um pixel. A quantidade de pixels de uma imagem determina a resolução espacial. A resolução espacial é determinada pela Equação 6 e o seu efeito na imagem pode ser observado na Figura 5.

$$
R=\frac{n P}{a}
$$

Sendo:

$\mathrm{R}=$ resolução espacial;

$\mathrm{nP}=$ número de pixels;

$\mathrm{a}=$ unidade de área. 

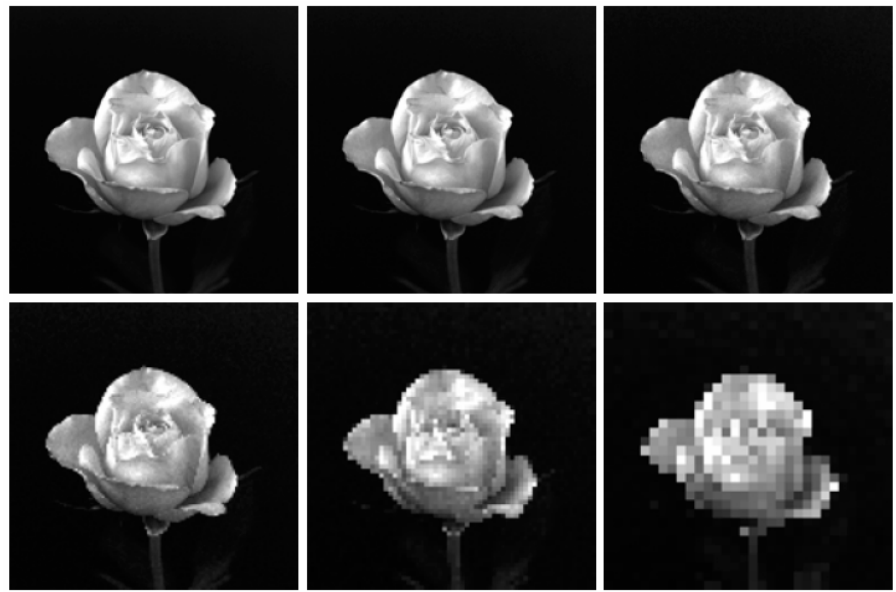

FIGURA 5 - SEQÜÊNCIA DE IMAGENS DIGITAIS, COM RESOLUÇÃO ESPACIAL CADA VEZ MENOR, MOSTRANDO O EFEITO DA RESOLUÇÃO ESPACIAL SOBRE ELAS (GONZALEZ; WOODS, 2001).

A Figura 5 contém imagens com 8 bits de nível de cinza que estão variando sua resolução espacial de 1024 x 1024 pixels até 32 x 32 pixels. Como pode ser observado, conforme se reduz a resolução se reduz também a representação dos detalhes da imagem.

Já na resolução de níveis de cinza, quanto menor a resolução, menor é a variação de intensidade do pixel, o que pode criar uma representação infiel da imagem com bordas falsas. A Figura 6 contém imagens variando entre 256 a 2 níveis de cinza mostrando o efeito da resolução de níveis de cinza nas imagens.

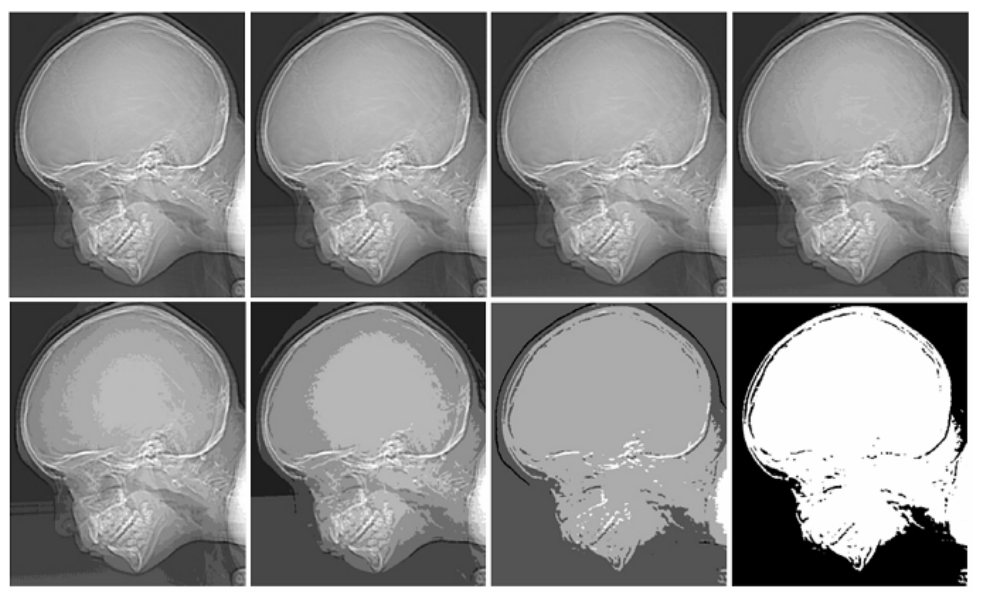

FIGURA 6 - SEQÜÊNCIA DE IMAGENS DIGITAIS, COM RESOLUÇÃO DE NÍVEL DE CINZA CADA VEZ MENOR, MOSTRANDO O EFEITO DA RESOLUÇÃO DE NÍVEL DE CINZA SOBRE ELAS (GONZALEZ; WOODS, 2001).

As imagens com níveis de cinza iguais a dois, são chamadas de imagens binárias, com valores de 0 (preto) ou 1 (branco). A Tabela 3 nos mostra a quantidade de bits de uma imagem variando sua resolução espacial e sua resolução de níveis de cinza. Sendo Q a dimensão da matriz quadrada e L a quantidade de níveis de cinza. 
TABELA 3 - QUANTIDADE DE BITS NECESSÁRIOS PARA IMAGENS COM DIFERENTES RESOLUÇÕES ESPACIAIS E DE NÍVEIS DE CINZA (GONZALEZ; WOODS, 2001).

\begin{tabular}{ccccccccc}
\hline $\mathbf{Q}$ & $\mathbf{L}=\mathbf{2}$ & $\mathbf{L}=\mathbf{4}$ & $\mathbf{L}=\mathbf{8}$ & $\mathbf{L}=\mathbf{1 6}$ & $\mathbf{L}=\mathbf{3 2}$ & $\mathbf{L}=\mathbf{6 4}$ & $\mathbf{L}=\mathbf{1 2 8}$ & $\mathbf{L}=\mathbf{2 5 6}$ \\
\hline $\mathbf{3 2}$ & 1.024 & 2.048 & 3.072 & 4.096 & 5.120 & 6.144 & 7.168 & 8.192 \\
\hline $\mathbf{6 4}$ & 4.096 & 8.192 & 12.288 & 16.384 & 20.480 & 24.576 & 28.672 & 32.768 \\
\hline $\mathbf{1 2 8}$ & 16.384 & 32.768 & 49.152 & 65.536 & 81.920 & 98.304 & 114.688 & 131.072 \\
\hline $\mathbf{2 5 6}$ & 65.536 & 131.072 & 196.608 & 262.144 & 327.680 & 393.216 & 458.752 & 524.288 \\
\hline $\mathbf{5 1 2}$ & 262.144 & 524.288 & 786.432 & 1.048 .576 & 1.310 .720 & 1.572 .864 & 1.835 .008 & 2.097 .152 \\
\hline $\mathbf{1 0 2 4}$ & 1.048 .576 & 2.097 .152 & 3.145 .728 & 4.194 .304 & 5.242 .880 & 6.291 .456 & 7.340 .032 & 8.388 .608 \\
\hline
\end{tabular}

\subsubsection{Vizinhança de um Pixel}

Cada pixel da imagem, aqui representado pela letra p, é compartilhado por bordas com outros pixels, conhecida como vizinhança de 4 - adjacentes ou 8 - adjacentes. A vizinhança de 4 -adjacentes é aquela em que sendo $\mathrm{p}$ de coordenada ( $\mathrm{x}, \mathrm{y})$ possui 4 vizinhos com coordenadas em (7). Já a vizinhança de 8 - adjacente é igual à vizinhança de 4 - adjacentes acrescida das coordenadas diagonais em (8). A Figura 7 mostra os dois exemplos.

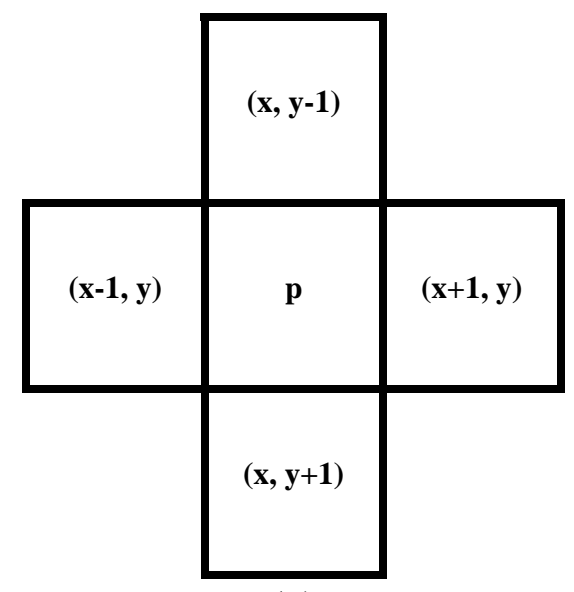

(a)

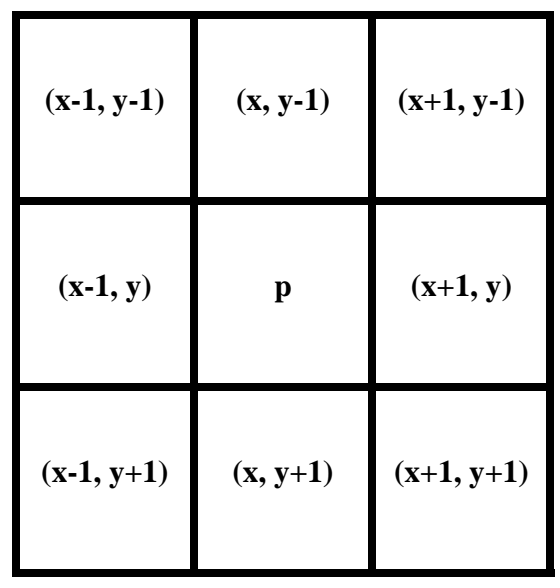

(b)

FIGURA 7 - (A) VIZINHANÇA 4-ADJACENTES DE P; (B) VIZINHANÇA 8-ADJACENTES DE P.

$$
\begin{gathered}
(x+1, y),(x-1, y),(x, y+1),(x, y-1) \\
(x+1, y+1),(x-1, y-1),(x-1, y+1),(x+1, y-1)
\end{gathered}
$$

Para se medir uma distância entre dois pixels pode ser utilizada métricas como: distância Euclidiana, distância City Block e distância de ChessBoard. Neste trabalho será utilizada a métrica de distância Euclidiana, que é a mais precisa por ser baseada no teorema de 
Pitágoras, para os cálculos necessários na segmentação e obtenção de dados (por exemplo, o tamanho da amêndoa). Então, a distância Euclidiana entre os pixels p e q é dada pela equação (9) a seguir:

$$
D(p, q)=\sqrt{\left(x_{p}-x_{q}\right)^{2}+\left(y_{p}-y_{q}\right)^{2}}
$$

\subsubsection{Morfologia Matemática}

Morfologia matemática pode ser utilizada para ajuste ou filtragem da imagem através de um elemento estruturante. As operações de morfologia matemática são basicamente duas: Dilatação e erosão. No caso das imagens binárias, a dilatação pode ser definida como a transformação morfológica que combina dois conjuntos utilizando adição vetorial (expande uma imagem). Já a erosão, pode ser definida como a transformação morfológica que combina dois conjuntos utilizando subtração vetorial (reduz uma imagem).Apesar disso, essas são operações duais, ou seja, o complemento de uma erosão é o mesmo que uma dilatação do complemento da imagem pelo elemento estruturante refletido.

As expressões (18), (19) e (20) exemplificam as operações morfológicas de dilatação e erosão nas imagens binárias e também sua dualidade.

$$
A \oplus B=\{c \mid c=a+b, a \in A, b \in B\}
$$

$$
A \theta B=\{c \mid c+b \in A \text {, para todo } \mathrm{b} \in \mathrm{B}\}
$$

$$
(A \theta B)^{c}=A^{c} \oplus \hat{B}
$$

Sendo:

$$
\begin{aligned}
& \mathrm{A}=\text { Imagem } ; \\
& \mathrm{B}=\text { Elemento estruturante. }
\end{aligned}
$$

\subsubsection{Características de Textura}

Não há uma única definição para textura, mas uma delas diz que a textura é a organização ou disposição das partes num todo. Termos como: granular, suave, regular, irregular, áspero, ondulado entre várias outras são características de textura. Existem três 
tipos de caracterização de texturas (JAIN, 1989) (GONZALEZ; WOODS; EDDINS, 2004), que são:

\section{- Estatística}

A abordagem estatística baseia-se no histograma (indicador da quantidade de pixels em cada nível de cinza) da região a ser analisada. Funciona muito bem para texturas da natureza. Essas características são mostradas na Tabela 4

\section{- Estruturada}

Descreve-se através de arranjos primitivos que se repetem por meio de algumas regras determinísticas ou aleatórias.

\section{- Espectral}

Baseia-se nas propriedades do espectro de Fourier.

TABELA 4 - DESCRITORES DA ABORDAGEM ESTATÍSTICA DE TEXTURA (GONZALEZ; WOODS; EDDINS, 2004).

\begin{tabular}{|c|c|c|}
\hline Momento & Expressão & Medida de Textura \\
\hline Média & $m=\sum_{i=0}^{L-1} z_{i} p\left(z_{i}\right)$ & Medida da intensidade média. \\
\hline $\begin{array}{l}\text { Desvio } \\
\text { Padrão }\end{array}$ & $\sigma=\sqrt{\mu_{2}(z)}=\sqrt{\sigma^{2}}$ & Medida do contraste médio. \\
\hline Suavidade & $R=1-1 /\left(1+\sigma^{2}\right)$ & $\begin{array}{l}\text { Medida relativa a suavidade da intensidade da região. } \\
\mathrm{R} \text { é } 0 \text { para regiões com intensidade constante e se } \\
\text { aproxima de } 1 \text { para regiões com grandes variações } \\
\text { dos valores de nível de intensidade. Na prática a } \\
\text { variância usada nesta medida é normalizada para } \\
{[0,1] \text { dividindo por }(\mathrm{L}-1)^{2} \text {. }}\end{array}$ \\
\hline $\begin{array}{c}\text { Terceiro } \\
\text { Momento }\end{array}$ & $\mu_{3}=\sum_{i=0}^{L-1}\left(z_{i}-m\right)^{3} p\left(z_{i}\right)$ & $\begin{array}{l}\text { Medida de assimetria do histograma. Esta medida é } 0 \\
\text { para histogramas simétricos, positivo para } \\
\text { histogramas mais para a direita (na média) e negativo } \\
\text { para histogramas mais para a esquerda. Valores desta } \\
\text { medida são apresentados em uma escala de valores } \\
\text { comparáveis com as outras cinco medidas dividindo } \\
\left.\mu_{3} \text { por (L-1) }\right)^{2} \text { também, que é o mesmo divisor } \\
\text { utilizado para normalizar a variância. }\end{array}$ \\
\hline Uniformidade & $U=\sum_{i=0}^{L-1} p^{2}\left(z_{i}\right)$ & $\begin{array}{l}\text { Medida de uniformidade. Esta medida é máxima } \\
\text { quando todos os níveis de cinza são iguais (ao } \\
\text { máximo uniforme) e diminui a partir daí. }\end{array}$ \\
\hline Entropia & $e=-\sum_{i=0}^{L-1} p\left(z_{i}\right) \log _{2} p\left(z_{i}\right)$ & Medida de aleatoriedade. \\
\hline
\end{tabular}


Sendo:

$\mathrm{Z}_{\mathrm{i}}=$ Intensidade dos pixels;

$\mathrm{p}\left(\mathrm{z}_{\mathrm{i}}\right)=$ Histograma das intensidades;

$\mathrm{L}=$ Número dos possíveis níveis de cinza;

$\mu_{2}=$ Segundo momento ou variância de $\mathrm{z}$.

\subsubsection{Imagens Digitais Coloridas}

A distinção das cores da luz está relacionada com o seu comprimento de onda, sendo que essas cores podem ser representadas por espaços de cores, por exemplo, $\mathrm{RGB}^{8}, \mathrm{HSV}$, L*a*b, XYZ e outros (PASCALE, 2006). Os espaços de cores RGB e HSV são representados conforme mostram as Figuras 8 e 9 e foram definidos pelo CIE $^{9}$. O CIE é uma comissão internacional responsável pela padronização e coordenação de cores e iluminação.

Os dois espaços de cores têm as seguintes definições para seus canais de cores:

- $\quad \boldsymbol{R}$ - Valor de Vermelho.

- $\boldsymbol{G}$ - Valor de Verde.

- $\quad \boldsymbol{B}$ - Valor de Azul.

- $\boldsymbol{H}$ - É a cor pura (Matiz) e é representada em graus.

- $\boldsymbol{S}$ - É a pureza da cor (Saturação), variando de 0 até 1 .

- $\quad \boldsymbol{V}$ - É a variação entre preto (0) e branco (1) (Valor).

Também é possível se converter dados de um espaço de cores para outro utilizando os algoritmos de conversão. Os pseudocódigos para conversões entre os espaços de cores RGB e o HSV são mostrados no Anexo A e outras conversões podem ser encontradas em EASYRGBCOLOR, [2008].

Sabendo disso, pode-se dizer que uma imagem digital colorida é representada pelo arranjo matricial P x Q de funções f (x, y) para cada canal de cor do mesmo espaço de cores, ou seja, P x Q x 3.

\footnotetext{
${ }^{8}$ RGB - Red, Green, Blue.

${ }^{9} \mathrm{CIE}$ - Commission Internationale de L'Eclairage.
} 


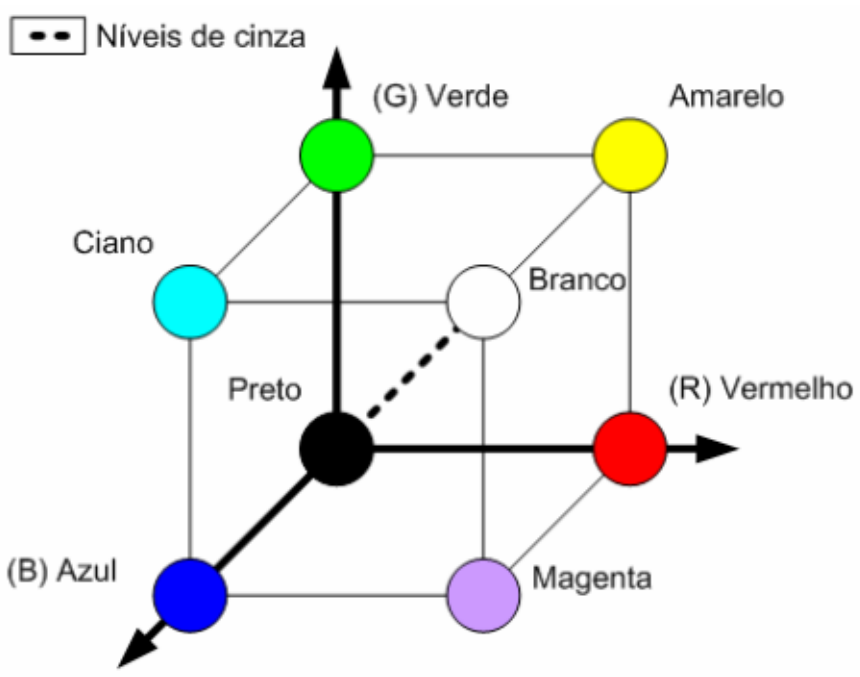

FIGURA 8 - REPRESENTAÇÃO ESPAÇO DE COR RGB.

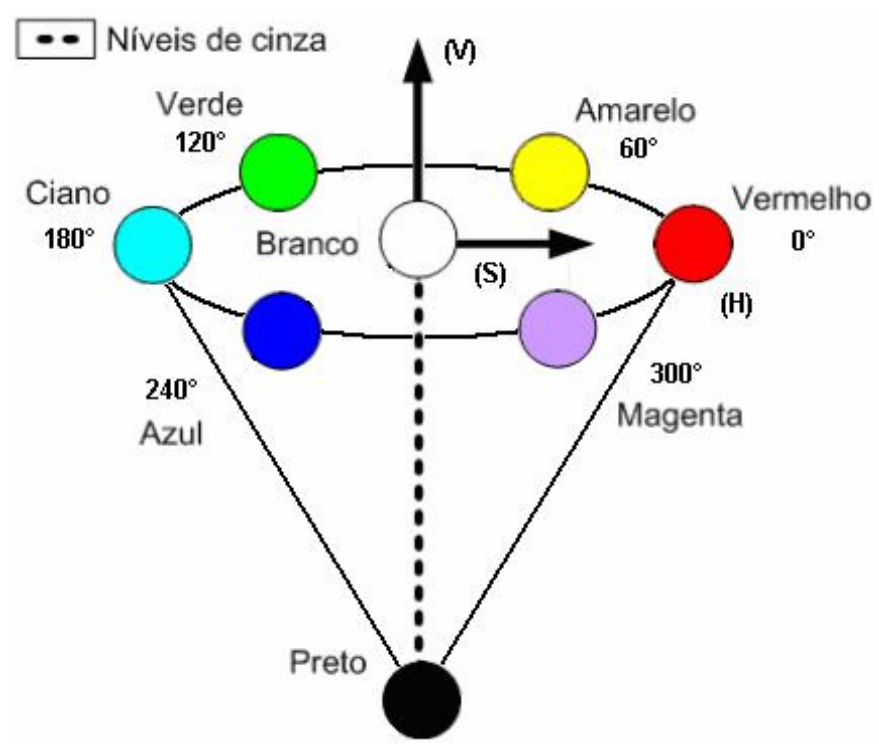

FIGURA 9 - REPRESENTAÇÃO ESPAÇO DE COR HSV.

\subsubsection{Processamento de Imagens Digitais}

O processamento de imagens digitais é feito após a definição do que se almeja de uma imagem. Esse processamento pode ser dividido em 5 etapas típicas na manipulação das imagens para retirada das características e dos dados relevantes. Todas elas estão ligadas a uma base de conhecimento que contém informações capazes de auxiliar nas decisões de cada etapa aplicada. Como exemplo, tem-se características comuns de um determinado objeto na imagem.

A Figura 10 mostra um fluxograma baseado na estrutura utilizada por Ribeiro (2006) e por Koenigkan (2005) em suas dissertações. Cada item é detalhado em seguida. 


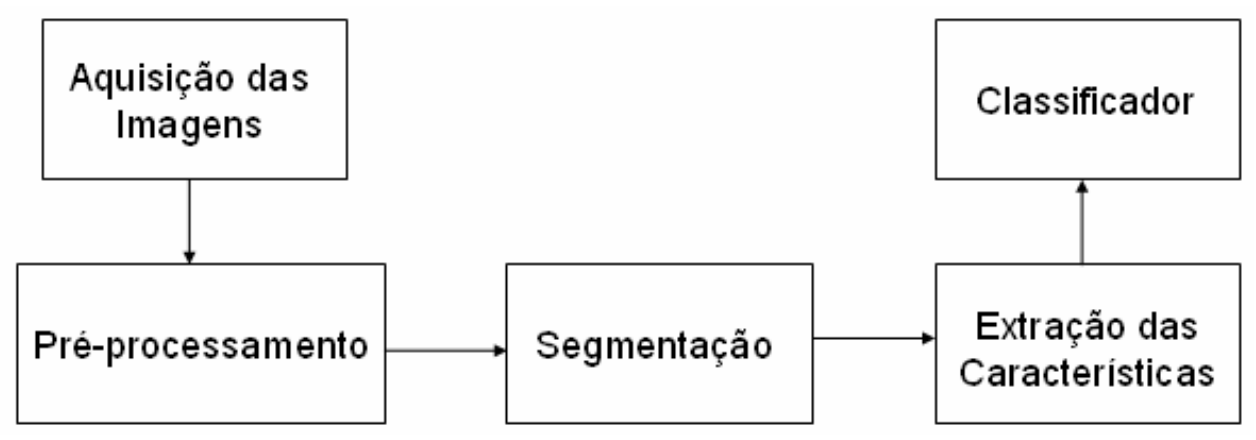

FIGURA 10 - ETAPAS BÁSICAS PARA O PROCESSAMENTO DE IMAGENS.

- Aquisição de Imagens:

É a etapa na qual se adquire a informação do mundo físico (cena) por mecanismos de captura como câmera fotográfica, câmera de vídeo ou scanner. A cena capturada é representada por meio da imagem. A iluminação, a estrutura, o posicionamento da câmera e do objeto são fatores importantes e que influenciam na qualidade da imagem adquirida.

- Pré-processamento:

O pré-processamento visa a correção ou adequação das imagens adquiridas para os próximos passos. Isso é feito com a utilização de técnicas como a limiarização, a equalização das imagens a partir de histogramas, filtros e outros mecanismos de pré-processamento.

\section{- Segmentação:}

É a complementação da etapa de pré-processamento. Basicamente, a segmentação consiste na divisão da imagem em partes com significado (fronteiras e regiões). Se nos basearmos no nível de cinza temos: descontinuidade e similaridade. São utilizadas técnicas como a própria limiarização, descontinuidade, detectores de bordas e outros para a segmentação da imagem de acordo com o que se busca.

\section{- Extração das Características:}

Após a segmentação é necessário extrair as características relevantes da imagem (descritores) no formato apropriado para análise. As regiões de uma imagem podem ser caracterizadas por sua área, textura e outros. Já as fronteiras podem ser caracterizadas por suas assinaturas, seus tamanhos e outros.

\section{- Classificador:}

É a última etapa e tem por objetivo dar sentido aos dados extraídos da imagem. Existem vários métodos para classificação de imagens, por exemplo, classificadores estatísticos e RNA. 


\subsection{Redes Neurais Artificiais (RNA)}

Uma definição válida para RNA é que são modelos matemáticos baseados no funcionamento dos neurônios biológicos (KOVÁCS, 1996). A semelhança entre a rede neural artificial e a biológica pode ser observada na capacidade de aprender através de exemplos e de generalizar a informação aprendida. A generalização está relacionada com a capacidade da RNA aprender a partir de um conjunto reduzido de amostras e dar respostas coerentes para dados não conhecidos.

\subsubsection{Neurônio Biológico x Neurônio Artificial}

Como qualquer célula biológica, o neurônio é delimitado por uma fina membrana celular que além de sua função biológica normal, possui determinadas propriedades que são essenciais para o funcionamento elétrico da célula nervosa (KOVÁCS, 1996). O neurônio pode ser dividido em três componentes como mostra a Figura 11.

Os dendritos são responsáveis por receber as informações (impulsos nervosos) e conduzi-los até o corpo celular. Esse processa os sinais recebidos e envia novos impulsos através dos axônios, também conhecidos como dispositivos de saídas.

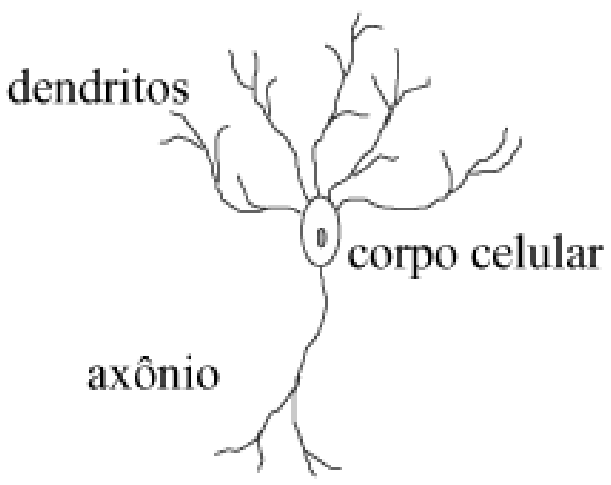

FIGURA 11 - REPRESENTAÇÃO DE UM NEURÔNIO BIOLÓGICO.

A saída só é produzida se um impulso elétrico for maior ou igual a função de limiar. As sinapses são pontos de conexão entre os axônios e os dendritos de outros neurônios que propagam os impulsos. Assim, com a união desses nodos se tem uma rede neural.

O neurônio artificial de McCulloch e Pitts, apresentada na Figura 12, se baseia em n entradas $\left(\mathrm{x}_{1}, \mathrm{x}_{2}, \ldots, \mathrm{x}_{\mathrm{n}}\right)$ para apresentação dos padrões. Para emular o comportamento das sinapses, esses terminais tem os pesos $\left(\mathrm{w}_{1}, \mathrm{w}_{2}, \ldots, \mathrm{w}_{\mathrm{n}}\right)$ com valores positivos ou negativos (excitatórios ou inibitórios) que permitem ou não a passagem das informações. $O$ cálculo entre as entradas e os pesos, é feito com a equação (10). 


$$
\sum_{i=0}^{n} x_{i} w_{i} \geq \theta
$$

Sendo:

$\mathrm{n}=$ Número de neurônios;

$\mathrm{x}_{\mathrm{i}}=$ Entrada da rede;

$\mathrm{W}_{\mathrm{i}}=$ Peso associado à entrada $\mathrm{x}_{\mathrm{i}}$;

$\theta=$ Limiar de excitação (threshold) do neurônio.

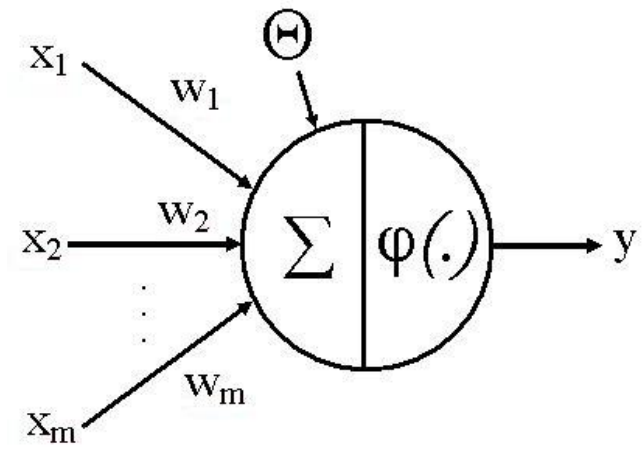

FIGURA 12 - REPRESENTAÇ̃̃O DO NEURÔNIO ARTIFICIAL.

O modelo de neurônio artificial apresentado por McCulloch e Pitts (1943), mostra apenas um terminal de saída (y) que apresenta o resultado final do processamento neural. Este é um modelo simplificado, pois os neurônios disparam sincronamente, fazendo com que sejam avaliados ao mesmo tempo. Esse sincronismo não ocorre no sistema biológico, assim como não existe a restrição em relação à ativação da saída em tempos discretos como neste modelo (BRAGA; CARVALHO; LUDERMIR, 2000).

O resultado do cálculo utilizando as entradas e os pesos passam pela função de ativação, ativando ou não a saída do neurônio dependendo do valor da soma ponderada das entradas. A saída do neurônio poderá ser linear ou não-linear de acordo com a função de ativação utilizada, como mostra a Figura 13. 


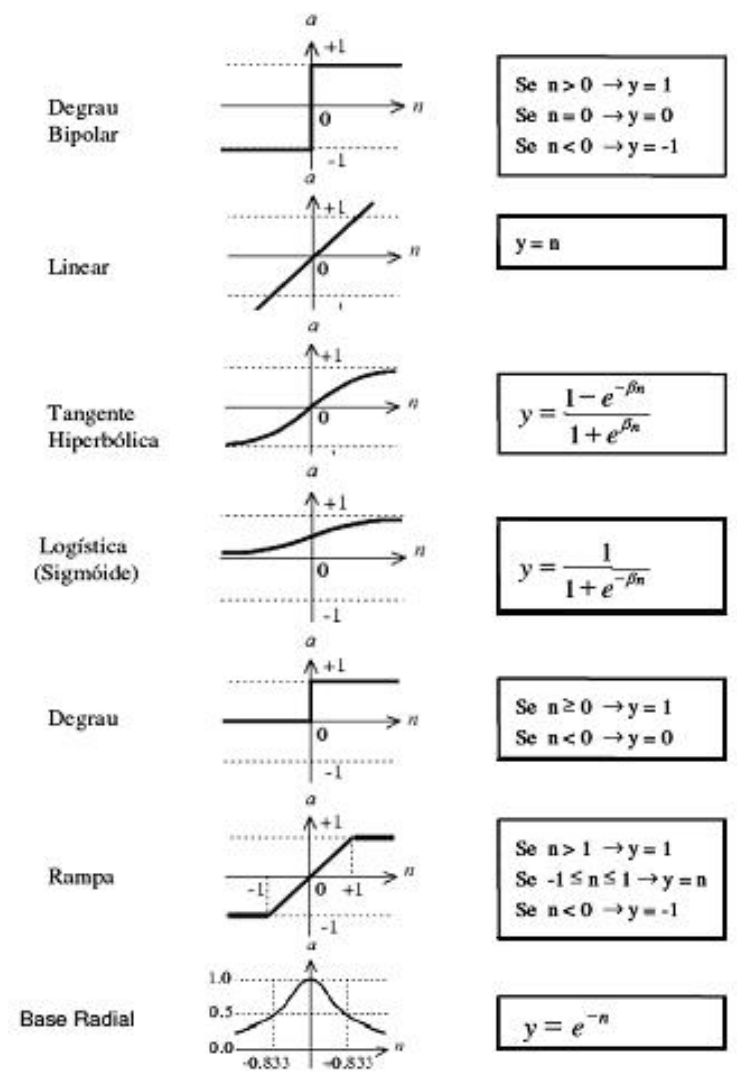

FIGURA 13 - FunÇÕES DE ATIVAÇÃO COMUMENTE USADAS E SUAS EQUAÇÕES (SILVA, C. B. S, 2007).

\subsubsection{Rede neural artificial Perceptron Multicamadas}

A RNA Perceptron Multicamadas (Multilayer Perceptron - MLP) é uma arquitetura chamada de alimentação para frente (feedforward) que contêm pelo menos uma camada intermediária e uma de saída. O treinamento da MLP é feito com o algoritmo Backpropagation ou conhecida também como Regra Delta Generalizada. O treinamento consiste em ajustar os pesos e limiares de maneira que uma aplicação com um conjunto de entradas consiga produzir a saída desejada e minimizar o erro quadrático médio $\left(\mathrm{EQM}^{10}\right)$. $\mathrm{O}$ EQM é a diferença entre o valor estimado e o valor real elevado ao quadrado.

O número de repetições do treinamento é denominado de época. No caso da MLP o treinamento é supervisionado, ou seja, necessita de um conjunto de treinamento composto por entradas e saídas. O número de camadas intermediárias determina a resolução de problemas de classificação lineares ou não lineares. Já o número de neurônios, influencia no treinamento da RNA, pois o número excessivo pode sobre ajustar a rede na presença de ruídos, memorizando os padrões de treinamento (overfitting). $\mathrm{O}$ inverso também ocorre, caso a quantidade de neurônios seja pequena, a rede pode não convergir (underfitting).

${ }^{10} \mathrm{EQM}$ - Erro Quadrático Médio 
A taxa de aprendizagem é o termo que interfere na convergência da solução para um mínimo local ou global e com isso aumentando o tempo de aprendizado. Outro termo que pode ser utilizado nesse algoritmo é a constante de momentum. Esse determina o efeito das mudanças passadas dos pesos na direção atual do treinamento, permitindo o aumento na velocidade de convergência (SILVA, C. B. S, 2007).

As duas fases do algoritmo são descritas a seguir e ilustradas na Figura 14.

\section{- Forward}

Um padrão de entradas é apresentado e propagado até a camada de saída sem qualquer alteração dos pesos sinápticos.

\section{- Backward}

Enquanto o valor da saída for diferente da saída desejada, o erro é calculado e retropropagado, ajustando os pesos para cada padrão.

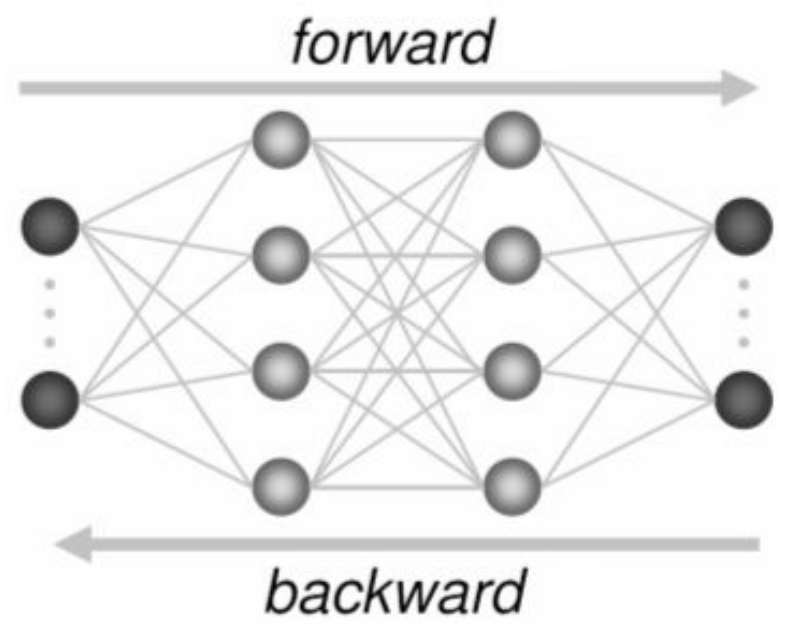

FIGURA 14 - SENTIDOS DE PROCESSAMENTO DO ALGORITMO BACKPROPAGATION.

O erro quadrático é dado conforme a equação (11).

$$
E(k)=\sum_{j \in C}\left(d_{n}(k)-y_{n}(k)\right)^{2}
$$

Sendo:

$\mathrm{d}_{\mathrm{n}}=$ Resposta desejada na saída do neurônio $\mathrm{n}$;

$\mathrm{y}_{\mathrm{n}}=$ Resposta produzida na saída do neurônio $\mathrm{n}$;

$\mathrm{E}(\mathrm{k})$ = Soma instantânea do erro quadrático na interação k;

$\mathrm{C}=$ Refere-se a todos os neurônios da camada de saída da rede. 
O sinal de erro na saída do neurônio a cada interação é exatamente a saída desejada subtraída da saída produzida. Já o erro quadrático médio é obtido pela somatória do erro quadrático, demonstrado na equação (11), ou seja:

$$
E Q M=\frac{1}{P} \sum_{n=1}^{P} E(k)
$$

Sendo:

$\mathrm{EQM}=$ Erro quadrático médio;

$\mathrm{P}=$ Número total de padrões.

\subsubsection{Seleção de Variáveis (Wrapper)}

A seleção de variáveis consiste em encontrar o menor subconjunto de características, eliminando os atributos redundantes ou irrelevantes para a tomada de decisão do sistema inteligente. O sistema inteligente utilizado neste trabalho é uma RNA com algoritmo de MLP. A seleção de variáveis é tão importante quanto à configuração da RNA. Existem métodos que dependem somente das propriedades dos dados (Filtros) e os que dependem do modelo de aprendizagem (Wrapper) (CASTRO JORGE et al., 2007).

Apesar do seu alto custo computacional, o algoritmo Wrapper é muito utilizado na seleção de atributos para problemas de aprendizado supervisionado e no geral fornece melhores resultados (FERNANDES; SILVA; OLESKOVICZ, 2008). Esse algoritmo funciona como uma caixa preta em conjunto com o modelo de aprendizagem. Sua metodologia é mostrada na Figura 15 que foi apresentada no trabalho de Kohavi e John (1997) citado nos trabalhos de Castro Jorge et al. (2007) e HALL et al. (2009).

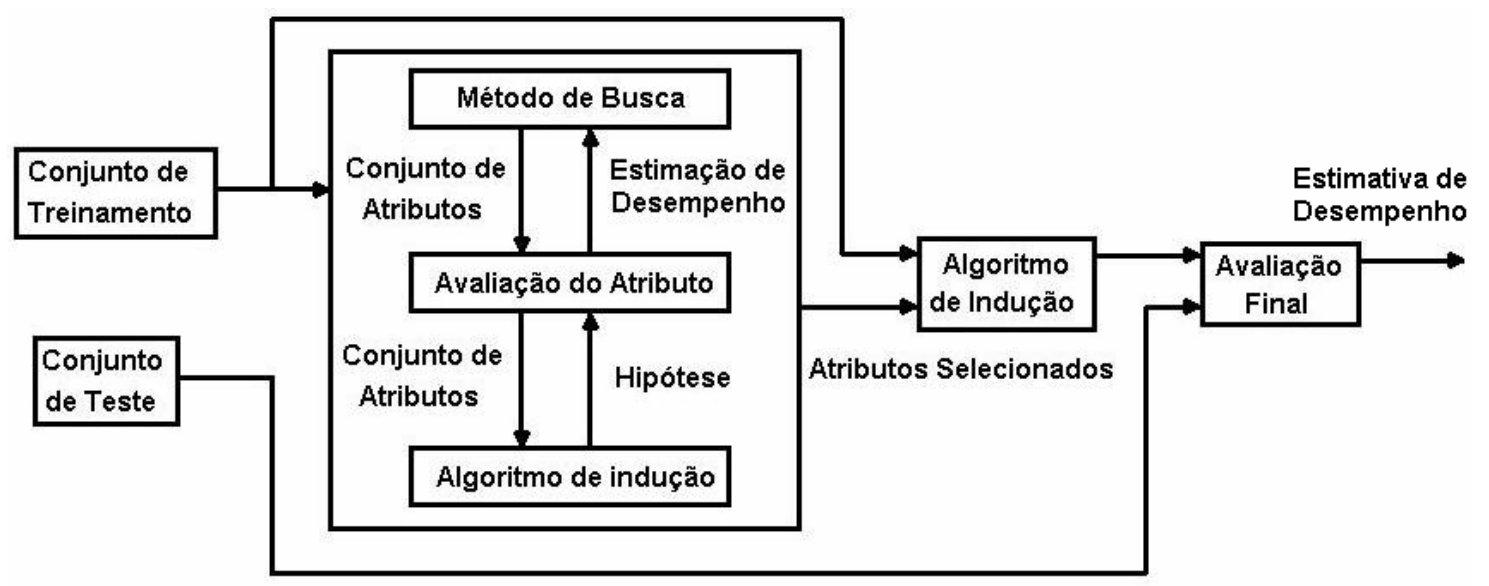

FIGURA 15 - ABORDAGEM WRAPPER (KOHAVI; JOHN, 1997). 
A entrada é o conjunto de treinamento, sendo que suas características passam por um método de busca. Hill-Climbing ou Best-First são exemplos, porém o método de busca exaustiva é um dos mais utilizados. A busca exaustiva percorre por todas as possibilidades, mas em contra partida acaba aumentando o custo computacional.

Os subconjuntos de características resultantes dessa busca recebem um custo em uma avaliação. Já o algoritmo de indução classifica todos esses subconjuntos com a precisão do classificador, obtendo assim uma estimativa de desempenho. Com os critérios de busca pelos subconjuntos já satisfeitos, os subconjuntos selecionados passam novamente por outro algoritmo de indução. Nessa segunda passagem, eles são avaliados juntamente com o conjunto de treinamento.

\subsection{Sistemas Nebulosos (Fuzzy)}

Sistemas nebulosos podem ser definidos como sistemas que se aproximam das decisões humanas, sendo os dados tratados por meio de incertezas e imprecisões. Como exemplo, pode-se utilizar um universo de discurso da variável lingüística Intensidade, com duas classes (claro e escuro), sendo seus valores numéricos representados por “i” pertencentes a I. Assim temos:

$$
I(\text { Intensidade })=\{\text { claro, escuro }\}, \text { com } i \in=[0,255]
$$

A representação gráfica é apresentada na Figura 16.

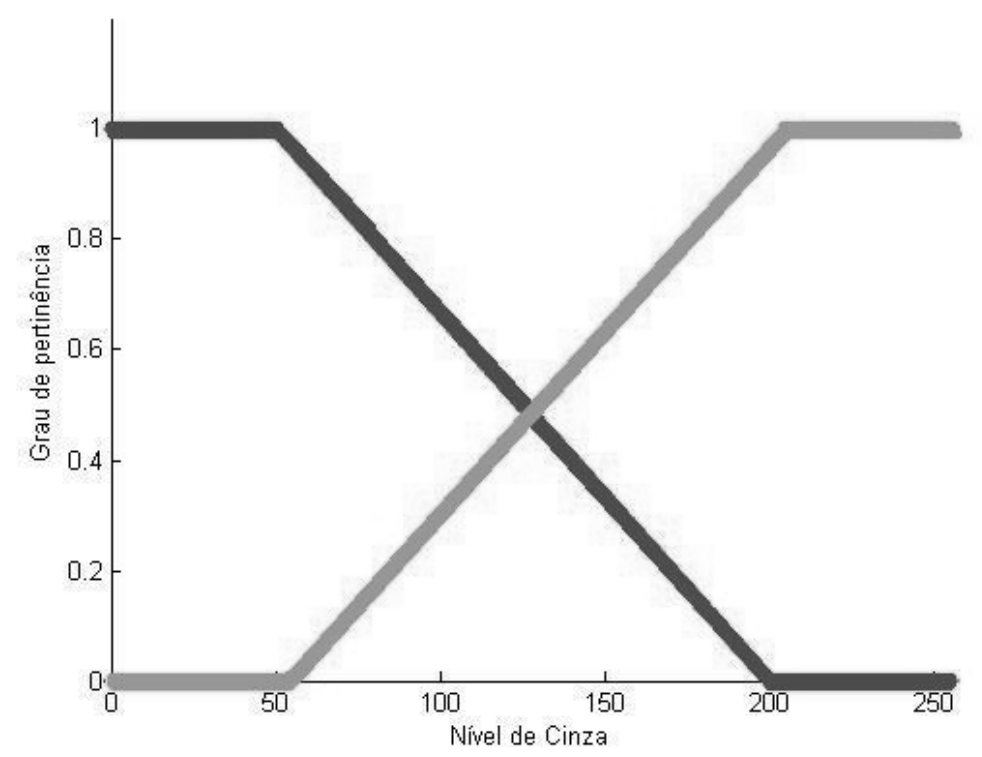

FIGURA 16 - REPRESENTAÇÃo GRÁFICA DAS CLASSES ClARO (CINZA CLARO) E ESCURO (CINZA ESCURO) DA VARIÁVEL LINGUISTICA INTENSIDADE. 
Neste gráfico, pode-se observar que a linha escura tende ao grau de pertinência 0 e a linha clara a 1 quanto maior é o nível de cinza, sendo o inverso também verdadeiro. Assim é possível dizer que um determinado nível de cinza tende mais para o escuro ou para o claro. A lógica nebulosa pode ser dividida em três etapas que são mostradas na Figura 17. Essas etapas são descritas nos próximos sub-itens.

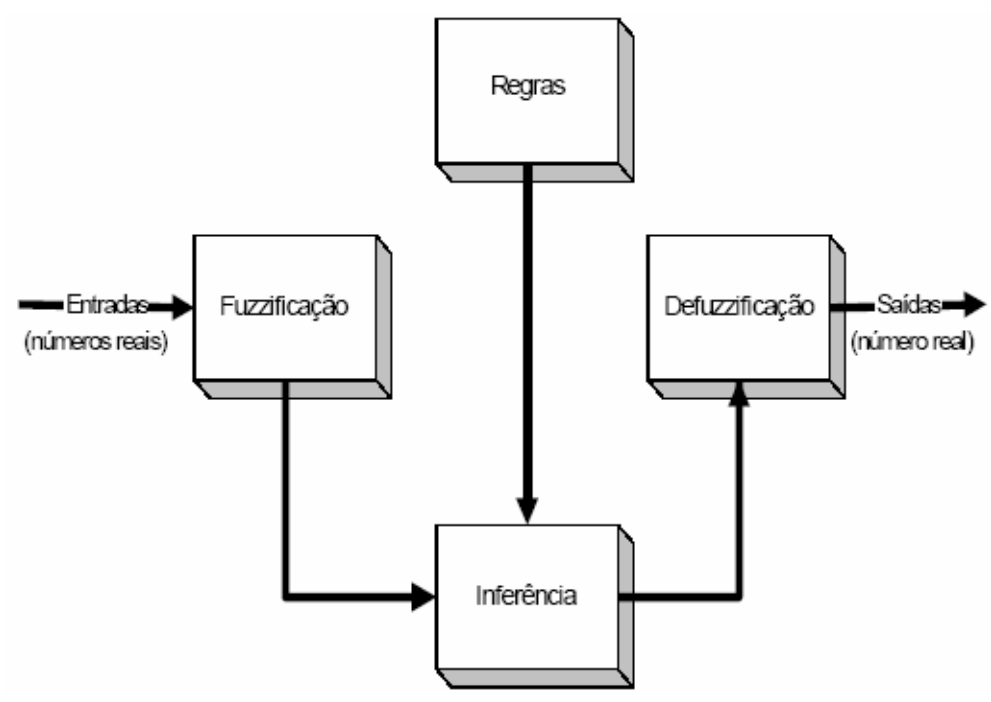

FIGURA 17 - ETAPAS DE FUNCIONAMENTO DE UM SISTEMA FUZZY (HENRIQUES, 2004).

\subsubsection{Fuzzificação}

Por ser um sistema impreciso, o conjunto Fuzzy contém graus de inclusão ou pertinência. A etapa de fuzzificação consiste em atribuir esses graus de pertinência a valores lógicos (crisp). Para isso são utilizadas funções de pertinência como: gaussianas, triangulares e trapezoidais. Suas equações são mostradas em (14) e a representação gráfica dessas podem ser vistas na Figura 18.

$$
u(x)=e^{-k^{*}(x-c)} \quad \operatorname{com} k \geq 1 \text { e } a \in X \quad u(x)=\left\{\begin{array}{c}
0, \text { se } x<a \\
\frac{\mathrm{x}-\mathrm{a}}{\mathrm{b}-\mathrm{a}}, \text { se } x \in[a, b] \\
\frac{\mathrm{c}-\mathrm{x}}{\mathrm{c}-\mathrm{b}}, \text { se } x \in[b, c] \\
0, \text { se } x>c
\end{array} \quad u(x)=\left\{\begin{array}{c}
0, \text { se } x<a \\
\frac{\mathrm{x}-\mathrm{a}}{\mathrm{b}-\mathrm{a}}, \text { se } x \in[a, b] \\
1, \text { se } x \in[b, c] \\
\frac{\mathrm{d}-\mathrm{x}}{\mathrm{d}-\mathrm{c} \text {, se } x \in[c, d]} \\
0, \text { se } x>d
\end{array}\right.\right.
$$

(a)

(b)

(c)

Sendo:

$\mathrm{u}(\mathrm{x})=$ Grau de pertinência de $\mathrm{x}$;

$\mathrm{k}=$ É o termo de variância da gaussiana. 


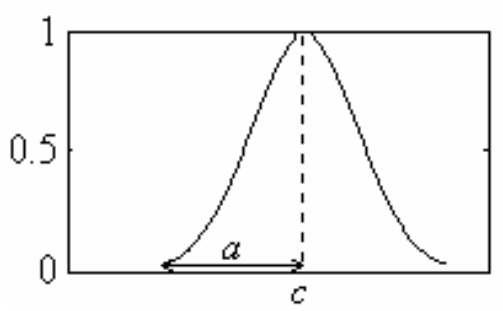

(a)

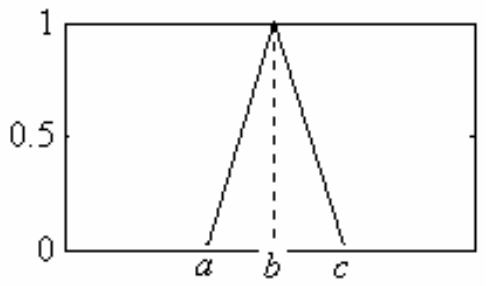

(b)

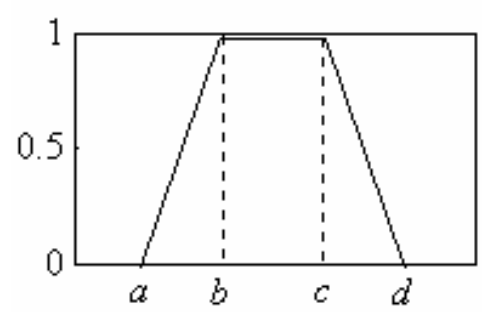

(c)

FIGURA 18 - (A) FUnÇão GaUSSIANA; (B) FUnÇão tRIANGUlar; (C) FunÇÃo TRAPEZOIDAL.

Na Figura 18, os eixos das ordenadas representam os graus de pertinência, ou seja, o quanto um ponto está mais incluído em uma classe do que em outra. Já os eixos das abscissas representam valores que variam de acordo com os problemas a serem solucionados. Esses valores podem ser referentes a temperatura, a pressão, a cor ou outras grandezas.

\subsubsection{Inferência Fuzzy}

A etapa de inferência é a etapa na qual é feita a análise das regras que são do tipo "SE" e "ENTÃO". Por exemplo:

Fato: $\mathrm{x}$ é A e y é B

Regra 1: Se x é A1 e y é B1 então z é C1

Regra 2: Se x é A2 e y é B1 então z é C2

Conseqüência: $\mathrm{z}$ é $\mathrm{C}$

Com as funções de pertinência já definidas é necessário fazer a composição das relações. Isso acontece para associar duas relações diretamente, sendo de grande importância, pois calcula a influência de cada regra na variável de saída. As principais composições são: MAX-MIN, MAX-PROD e MAX-MÉDIA sendo a primeira mais usual. Sejam duas relações $\mathrm{A}(\mathrm{x}, \mathrm{y})$ e $\mathrm{B}(\mathrm{y}, \mathrm{z})$ e utilizando a composição de MAX-MIN tem-se:

$$
A^{\circ} B(X, Z)=\operatorname{MAX}\left\{\operatorname{MIN}\left[u_{a}\left(x_{i}, y_{j}\right), u_{b}\left(y_{j}, z_{k}\right)\right]\right\}
$$

Sendo:

$\mathrm{i}, \mathrm{j}, \mathrm{k}=$ Número de pontos variando de 1 até $\mathrm{n}$;

$\mathrm{x}, \mathrm{y}, \mathrm{z}$ com valores pertencentes ao universo de discurso $\mathrm{X}, \mathrm{Y}, \mathrm{Z}$. 
Logo após, são computados os graus de pertinência que estão associados em $\mathrm{X}$ implicado em Z. O operador de implicação mais utilizado é o operador de Mandani e é dado pela equação (16).

$$
u_{R a->b}(x, y)=\operatorname{MIN}\left(u_{a}(x), u_{b}(y)\right)
$$

\subsubsection{Defuzzyficação}

Com as implicações já calculadas, são feitas as agregações das saídas que tiveram suas regras ativadas. Isso é feito para produzir uma saída única, da qual é feita a defuzzyficação. A defuzzyficação pode ser feita utilizando o método conhecido como centro de área ou centróide.

$$
C D A=\frac{\sum_{k=1}^{N} u_{c}^{\prime}(v k)^{*} v k}{\sum_{k=1}^{N} u_{c}^{\prime}(v k)}
$$

Sendo:

$$
\begin{aligned}
& \mathrm{u}_{\mathrm{c}}(\mathrm{k})=\text { Grau de pertinência; } \\
& \mathrm{N}=\text { É o número de discretizações; } \\
& \mathrm{vk}=\text { Valor de } \mathrm{C} \text { do universo de discurso. }
\end{aligned}
$$

\subsection{Considerações Finais}

Neste capítulo foram apresentados alguns conceitos na área de visão computacional e de sistemas inteligentes. Na literatura é possível aprofundar-se mais sobre os assuntos aqui abordados.

Os conceitos citados neste capítulo são importantes para o entendimento das técnicas que foram utilizadas tanto na classificação das castanhas por origem quanto na seleção das amêndoas. 


\section{CLASSIFICAÇÃO DAS CASTANHAS DO BRASIL POR ORIGEM}

\subsection{Considerações Iniciais}

Com o objetivo de classificar as castanhas por sua região de origem, foram feitos testes utilizando castanhas de cinco estados brasileiros. Essas castanhas foram disponibilizadas pela Dra. Lúcia Helena de Oliveira Wadt (Embrapa Acre) coordenadora do projeto Kamukaia $^{11}$ (PROJETO KAMUKAIA, 2009). As castanhas da região do Acre foram colhidas no Seringal Filipinas (Reserva Extrativista Chico Mendes na cidade de Epitaciolândia), as do Amapá na Reserva Extrativista do rio Cajarí (município de Laranjal do Jari), as do Mato Grosso na Reserva Extrativista Guariba Roosevelt (município de Colniza), as do Pará nas plantações pertencentes a Embrapa Amazônia Oriental e as de Rondônia foram compradas na região de Machadinho do Oeste.

Assim, este capítulo apresenta os testes e os resultados obtidos na classificação dessas castanhas.

\subsection{Aquisição dos Dados e Análise}

Utilizando um scanner HP Scanjet 8250, foram adquiridas 50 imagens $\left(72 \mathrm{dpi}^{12}\right.$ ) das castanhas do Brasil de cada região já citadas anteriormente. Dessas imagens foram retiradas imagens de tamanho 100 x 100 pixels para serem utilizadas na aquisição dos dados. Assim, foi possível adquirir os dados de textura e dados de cores de três espaços diferentes (RGB, HSV, $\left.L^{*} a * b\right)$. As imagens iniciais e as que foram utilizadas nas análises são mostradas nas Figuras 19 e 20.

\footnotetext{
${ }^{11}$ Kamukaia - Projeto de manejo de produtos florestais não madeireiros na Amazônia.

${ }^{12}$ DPI - Dots Per Inch
} 


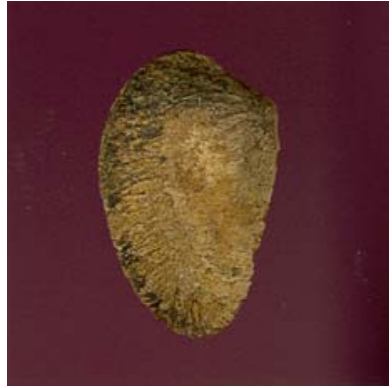

(a)

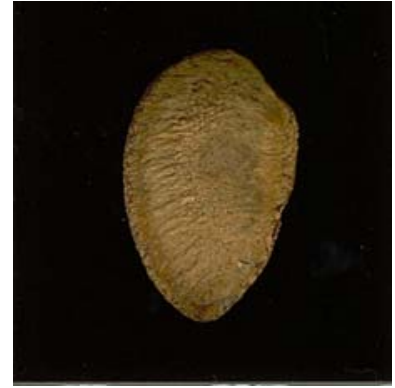

(b)

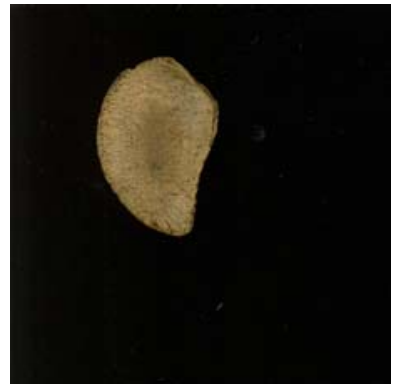

(c)

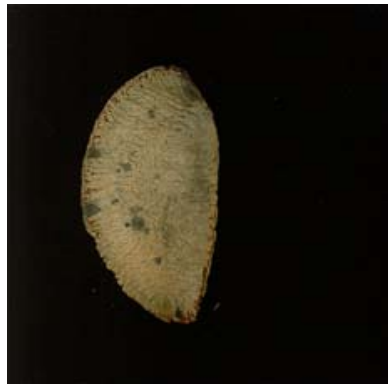

(d)

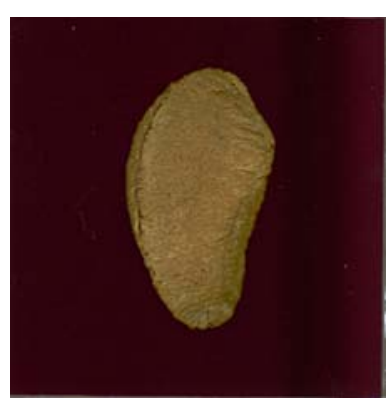

(e)

FIGURA 19 - IMAGENS DAS CASTANHAS DO BRASIL COM ORIGEM EM: (A) ACRE; (B) AMAPÁ; (C) MATO GROSSO; (D) PARÁ; (E) RONDÔNIA.

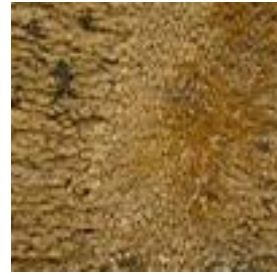

(a)

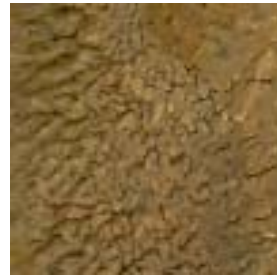

(b)

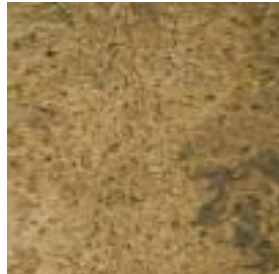

(c)

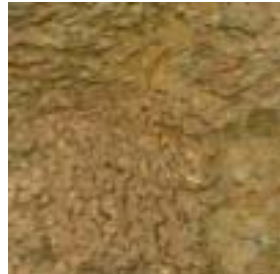

(d)

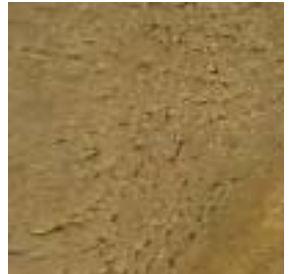

(e)

FIGURA 20 - IMAGENS DAS CASTANHAS DO BRASIL COM DIMENSÃO DE 100X100 PIXELS COM ORIGEM EM: (A) Acre; (B) AmapÁ; (C) Mato Grosso; (D) PARÁ; (E) RondÔNiA.

No caso da classificação das castanhas do Brasil por origem, foi utilizado a abordagem estatística, e seus descritores são apresentados e comentados na Tabela 4 no capítulo anterior.

O algoritmo utilizado para a aquisição dos dados de textura (intensidade, contraste, suavidade, terceiro momento, uniformidade e entropia) é encontrado em Gonzáles, Woods e Eddins (2004). Este algoritmo e o de média de cor no espaço RGB, foram programados utilizando Matlab 2006a. A média das cores foi convertida para os espaços HSV e L*a*b. O espaço de cor $\mathrm{L}^{*} \mathrm{a}^{*} \mathrm{~b}$ também foi utilizado por já ter mostrado bons resultados na classificação das castanhas no trabalho de Andrade, Roda e Pessoa (2009b). As imagens dos gráficos contendo a diversidade das variáveis para cada região podem ser vistas no Apêndice A. 
Esses dados foram utilizados como entrada da MLP, totalizando 15 entradas. A MLP foi arquitetada utilizando o software WEKA ${ }^{13}$ 3.6.0 (HALL et al., 2009). Com WEKA, foram feitos vários testes utilizando K-fold Cross Validation (validação cruzada) visando a melhor arquitetura da MLP. A validação cruzada é uma técnica utilizada na mineração de dados para avaliar a exatidão, neste caso da RNA. Os testes de validação cruzada utilizaram 10 folds (número de subconjuntos).

A arquitetura definida foi utilizada com as configurações de taxa de aprendizagem de 0.15, fator de momentum de 0.9 e 80 épocas. Então, o algoritmo de seleção de variáveis Wrapper com o modo de busca exaustiva, apresentado no capítulo 3 , foi utilizado visando melhorar a percentagem de identificações corretas. Esse algoritmo também está disponível no software WEKA 3.6.0. Assim, as variáveis selecionadas para essa configuração de MLP foram: contraste, entropia, G, B, H, S, *a.

O teste de validação cruzada feito com a primeira arquitetura (utilizando todas as características) apresentou 76,3\% de identificações corretas. $\mathrm{Na}$ segunda arquitetura (utilizando as características selecionadas) a percentagem de identificações corretas foi de $73,1 \%$. A primeira e a segunda arquitetura podem ser vistas nas Figuras 21 e 22.

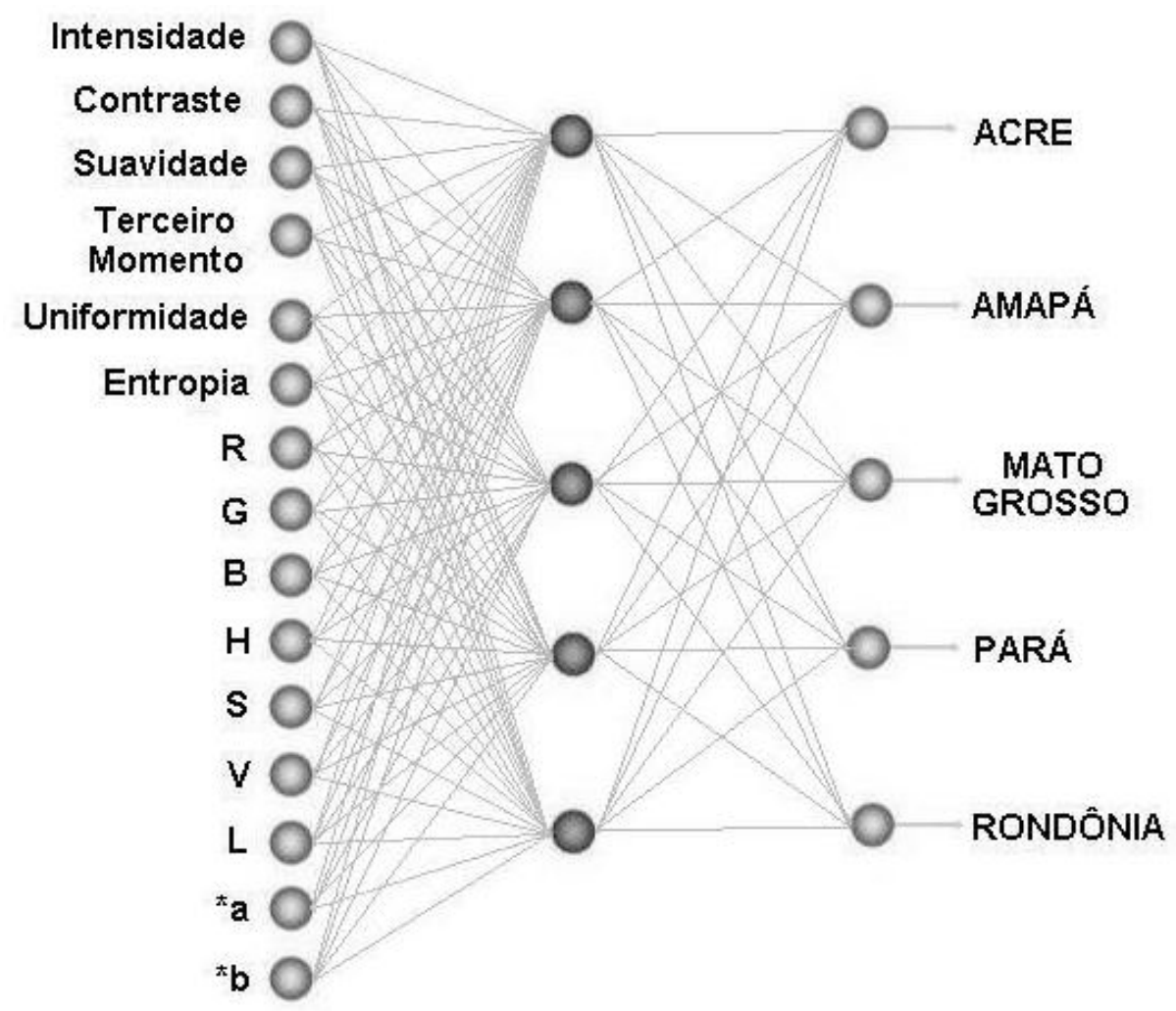

FIGURA 21 - ARQUITETURA 1 DA MLP - TODAS AS VARIÁVEIS (15 NEURÔNIOS NA CAMADA DE ENTRADA; 5 NEURÔNIOS NA CAMADA INTERMEDIÁRIA; 5 NEURÔNIOS NA CAMADA DE SAÍDA).

${ }^{13}$ WEKA - Waikato Environment for Knowledge Analysis 


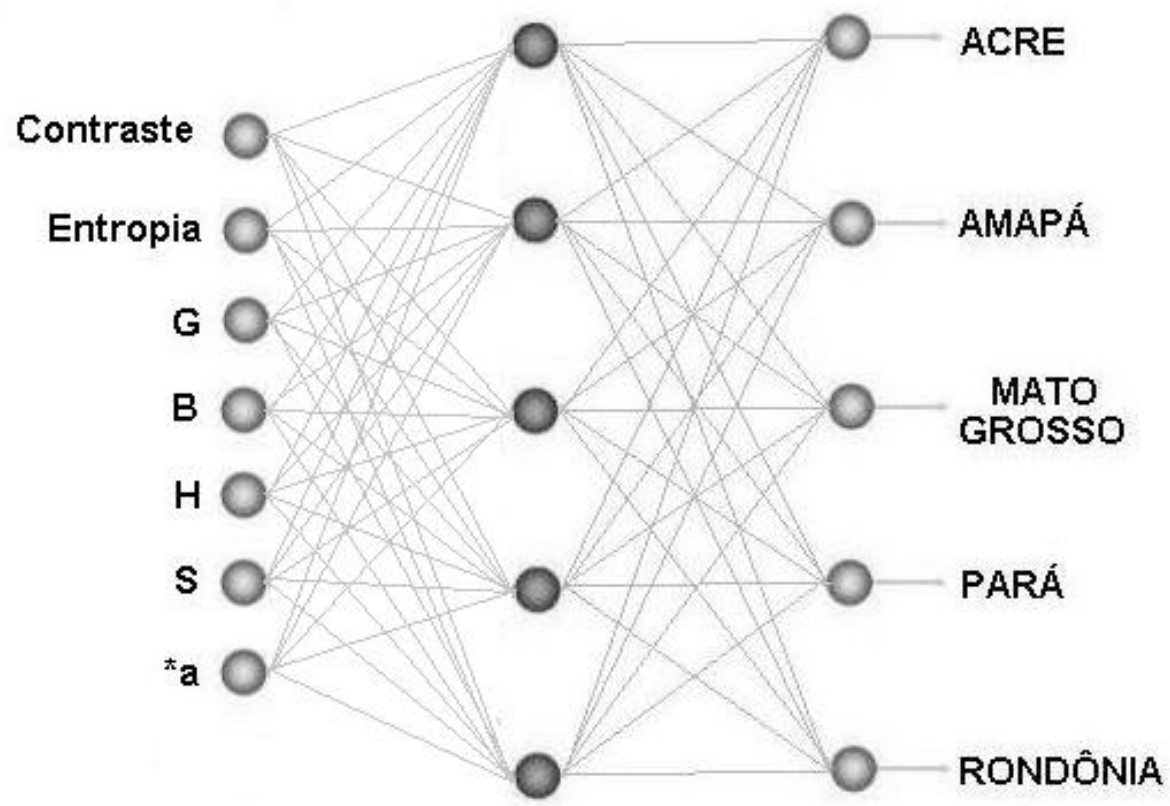

FIGURA 22 - ARQUITETURA 2 DA MLP - APÓS SELEÇÃO DAS VARIÁVEIS (7 NEURÔNIOS NA CAMADA DE ENTRADA; 5 NEURÔNIOS NA CAMADA INTERMEDIÁRIA; 5 NEURÔNIOS NA CAMADA DE SAÍDA).

\subsection{Avaliação da Metodologia}

Com as duas arquiteturas propostas, foram feitos dois tipos de análises. A análise 1 utilizou 100 amostras e a análise 2 utilizou todas as 250 amostras. Baseados no teste de validação cruzada, para cada análise foram criados 10 arquivos de treinamento sendo que na análise 1 este arquivo era composto por 90 amostras e na análise 2 por 240 amostras. Assim, o arquivo de teste sempre conteve 10 amostras, ou seja, 10 folds com 10 amostras iguais para as duas análises. As Tabelas 5 e 6 mostram a percentagem de identificação correta das análises para cada arquivo de treinamento e de teste nas duas arquiteturas. A Tabela 7 mostra as médias gerais desses arquivos. 
TABELA 5 - IDENTIFICAÇÕES CORRETAS (\%) DA ARQUITETURA INICIAL DA MLP PARA CADA FOLD.

\begin{tabular}{lccc}
\hline \multicolumn{4}{c}{ Identificações Corretas (\%) } \\
\hline Treinamento 1 & $\begin{array}{c}\text { Teste no } \\
\text { Treinamento 1 }\end{array}$ & Treinamento 2 & $\begin{array}{c}\text { Teste no } \\
\text { Treinamento 2 }\end{array}$ \\
\hline
\end{tabular}

\begin{tabular}{lcccc}
\hline Fold 1 & 90 & 70 & 81,6 & 70 \\
\hline Fold 2 & 92,2 & 50 & 82,0 & 90 \\
\hline Fold 3 & 93,3 & 80 & 79,9 & 70 \\
\hline Fold 4 & 91,1 & 80 & 80,3 & 60 \\
\hline Fold 5 & 91,1 & 90 & 80,8 & 80 \\
\hline Fold 6 & 92,2 & 80 & 79,5 & 90 \\
\hline Fold 7 & 92,2 & 50 & 80,8 & 50 \\
\hline Fold 8 & 93,3 & 70 & 79,5 & 70 \\
\hline Fold 9 & 92,2 & 70 & 81,2 & 90 \\
\hline Fold 10 & 90 & 60 & 80,8 & 60 \\
\hline
\end{tabular}

TABELA 6 - IDENTIFICAÇÕES CORRETAS (\%) DA ARQUITETURA APÓS A SELEÇÃO DE VARIÁVEIS PARA CADA FOLD.

\begin{tabular}{lccc}
\hline \multicolumn{4}{c}{ Identificações Corretas (\%) } \\
\hline Treinamento 1 & $\begin{array}{c}\text { Teste no } \\
\text { Treinamento 1 }\end{array}$ & Treinamento 2 & $\begin{array}{c}\text { Teste no } \\
\text { Treinamento 2 }\end{array}$ \\
\hline
\end{tabular}

\begin{tabular}{lcccc}
\hline Fold 1 & 91,1 & 70 & 81,6 & 70 \\
\hline Fold 2 & 88,9 & 80 & 79,9 & 90 \\
\hline Fold 3 & 92,2 & 50 & 77,8 & 90 \\
\hline Fold 4 & 92,2 & 70 & 78,2 & 80 \\
\hline Fold 5 & 91,1 & 90 & 80,8 & 100 \\
\hline Fold 6 & 91,1 & 80 & 79,5 & 90 \\
\hline Fold 7 & 88,9 & 40 & 82,0 & 50 \\
\hline Fold 8 & 88,9 & 80 & 78,7 & 90 \\
\hline Fold 9 & 85,6 & 80 & 78,7 & 100 \\
\hline Fold 10 & 90 & 80 & 82,0 & 80 \\
\hline
\end{tabular}

TABELA 7 - MÉDIA DE IDENTIFICAÇÕES CORRETAS (\%) DOS FOLDS PARA CADA ARQUIETURA.

\begin{tabular}{lccc}
\hline \multicolumn{4}{c}{ Identificações Corretas (\%) } \\
\hline Treinamento 1 & $\begin{array}{c}\text { Teste no } \\
\text { Treinamento 1 }\end{array}$ & Treinamento 2 & $\begin{array}{c}\text { Teste no } \\
\text { Treinamento 2 }\end{array}$ \\
\hline
\end{tabular}

\begin{tabular}{lcccc}
\hline Arquitetura 1 & 91,8 & 70 & 80,6 & 73 \\
\hline Arquitetura 2 & 90 & 72 & 79,9 & 84 \\
\hline
\end{tabular}

Com as Tabelas 5 e 6 é possível observar que a percentagem de identificação correta nos treinamentos da arquitetura 2 foi mais baixo na maioria dos subconjuntos em relação a arquitetura 1, sendo confirmado na média geral. Mesmo assim, houve aumento na média geral dos testes feitos com a arquitetura 2, havendo subconjuntos em que a percentagem de 
identificação correta foi de $100 \%$. O EQM variou de 0.42 no pior caso $(40 \%$ de identificações corretas) e 0.09 no melhor caso (100\% de identificações corretas)

Porém, para avaliar a eficiência da classificação feita utilizando as MLPs arquitetadas, foram feitos testes de análise visual para comparação. A análise visual foi feita por quatro mulheres, biólogas e de mesma faixa etária, que identificaram as regiões de todas as 10 amostras dos 10 subconjuntos de imagens. O grupo de pessoas não foi selecionado de maneira aleatória e também foi feito o treinamento dessas pessoas, por isso o número reduzido para comparação.

$\mathrm{O}$ treinamento das quatro pessoas constituiu em apresentar um conjunto de imagens devidamente identificado por sua região de origem. As imagens apresentadas são as mesmas que foram utilizadas para extração das características e que puderam ser vistas na Figura 20. Isso foi feito para que as pessoas identificassem as regiões das castanhas apenas pelas cores e pela textura. $\mathrm{O}$ resultado dessa identificação é mostrado na Tabela 8.

TABELA 8 - IDENTIFICAÇÕES CORRETAS (\%) DAS REGIÕES DE CADA GRUPO DE AMOSTRAS PARA CADA PESSOA.

\begin{tabular}{ccccc} 
& \multicolumn{4}{c}{ Identificações Corretas (\%) } \\
\cline { 2 - 5 } & Pessoa 1 & Pessoa 2 & Pessoa 3 & Pessoa 4 \\
\hline Fold 1 & 50 & 60 & 40 & 70 \\
\hline Fold 2 & 30 & 20 & 20 & 70 \\
\hline Fold 3 & 60 & 20 & 30 & 50 \\
\hline Fold 4 & 70 & 70 & 40 & 70 \\
\hline Fold 5 & 50 & 20 & 20 & 10 \\
\hline Fold 6 & 20 & 0 & 30 & 30 \\
\hline Fold 7 & 50 & 30 & 30 & 30 \\
\hline Fold 8 & 20 & 30 & 20 & 30 \\
\hline Fold 9 & 30 & 30 & 40 & 10 \\
\hline Fold 10 & 50 & 50 & 30 & 40 \\
\hline
\end{tabular}

Feito isso, foi utilizado o software BioEstat 5.0 para análise do Teste T ou T Student, para fazer a comparação entre duas médias, que neste caso são a da metodologia e a da análise visual. O Teste T está dividido em duas categorias: Pareados e não pareados (Pinheiro et al., 2009). Para essa validação foi utilizado o Teste T pareado por se tratar de amostras não distintas em suas características. Nesse teste existem sempre duas hipóteses: Nula (H0) e a alternativa (H1), sendo que H0 pode ser aceita ou rejeitada pelo teste. Mais detalhes do Teste T e sua utilização são encontradas nas referências de Pinheiro et al. (2009) e Reis (2009). Considerando a metodologia, foi adotado para essa análise H0 sendo igual ou pior (menor ou igual) e H1 sendo melhor (maior) do que análise visual. 
O resultado da comparação de cada pessoa com os testes relativos aos treinamentos 1 e 2 da primeira arquitetura da MLP é mostrado a seguir na Tabela 9.

TABELA 9 - RESUlTADO DO TESTE T STUDENT COMPARANDO OS TESTES DOS DOIS TREINAMENTOS DA PRIMEIRA ARQUITETURA COM A ANÁLISE VISUAL DE CADA PESSOA.

\begin{tabular}{|c|c|c|c|c|c|c|c|c|}
\hline & \multicolumn{4}{|c|}{ Treinamento 1} & \multicolumn{4}{|c|}{ Treinamento 2} \\
\hline & $\begin{array}{c}\text { Pessoa } \\
1\end{array}$ & $\begin{array}{c}\text { Pessoa } \\
2\end{array}$ & $\begin{array}{c}\text { Pessoa } \\
3\end{array}$ & $\begin{array}{c}\text { Pessoa } \\
4\end{array}$ & $\begin{array}{c}\text { Pessoa } \\
1\end{array}$ & $\begin{array}{l}\text { Pessoa } \\
2\end{array}$ & $\begin{array}{c}\text { Pessoa } \\
3\end{array}$ & $\begin{array}{c}\text { Pessoa } \\
4\end{array}$ \\
\hline Valor T & 4,3864 & 4,5278 & 8,4853 & 3,0973 & 3,3541 & 4 & 7,6955 & 3,4026 \\
\hline $\begin{array}{c}\text { Nível de } \\
\text { Significância (p) }\end{array}$ & 0,0009 & 0,0007 & $\begin{array}{c}< \\
0,0001\end{array}$ & 0,0064 & 0,0042 & 0,0015 & $\begin{array}{c}< \\
0,0001\end{array}$ & 0,0039 \\
\hline
\end{tabular}

Adotando aos testes o nível de significância de $0.005(99,5 \%)$ para descartar a hipótese H0, somente na coluna da Pessoa 4 do Treinamento 1 não se pode fazer o descarte de H0 pois o valor de p é maior. Mas, se for adotado o nível de significância de 0,01 (99\%), todos os valores de p são menores, podendo descartar a hipótese nula (H0). Isso mostra que os resultados da MLP são melhores nos dois treinamentos quando comparados com a análise visual.

Deve-se lembrar que os resultados da segunda arquitetura da MLP são melhores do que os da primeira nos dois treinamentos, logo também são melhores comparados com a análise visual.

\subsection{Considerações Finais}

Este capítulo apresentou o método utilizado para identificação das castanhas por sua região de origem utilizando imagens. Estas imagens tiveram características de textura e de espaços de cores que serviram como entrada da MLP. Também foi feita a seleção de variáveis visando maior percentagem de identificações corretas e aumento da velocidade de processamento, já que a RNA trabalha de forma mais efetiva com menores quantidades de variáveis

Neste capítulo também foi apresentado o teste T Student, que avaliou e comprovou o melhor aproveitamento da MLP em relação aos testes de análise visual. 
- 48 - 


\section{SELEÇÃO DAS AMÊNDOAS}

\subsection{Considerações Iniciais}

Visando melhorar o processo de inspeção para a seleção das amêndoas, foram utilizadas as técnicas de visão computacional e de sistemas inteligentes comentadas anteriormente. $\mathrm{O}$ software de seleção foi desenvolvido utilizando $\mathrm{C}++$ Builder 6.0 e a biblioteca de visão computacional OpenCV ${ }^{14}$, desenvolvida pela Intel. Assim, este capítulo mostrará os testes realizados, os resultados e o funcionamento do sistema desenvolvido. Os sub-itens subseqüentes são seguidos conforme o fluxograma apresentado no capítulo 3. Já as imagens contendo as telas do software desenvolvido estão no Apêndice B

\subsection{Aquisição das Imagens}

O mecanismo de aquisição das imagens no sistema de seleção das amêndoas é composto por uma câmera de vídeo $\mathrm{CCD}^{15}$ colorida marca Samsung modelo SCC-131. Essa câmera possui um sistema de lentes com auto íris Canon com distância focal de 3,5 mm $8 \mathrm{~mm}$. As lentes auto íris se ajustam automaticamente a pouca ou a muita luminosidade e foram utilizadas pelo fato do sistema não possuir uma iluminação ideal (controlada e contínua) e também não possuir um sistema de blindagem, minimizando assim os efeitos da iluminação. Foi utilizada a iluminação ambiente do laboratório (lâmpadas fluorescentes de $32 \mathrm{~W})$.

Esta câmera foi conectada a uma placa de vídeo PixelView - Play TV USB (30 frames por segundo) que por sua vez estava conectada a um computador pessoal Intel Core 2 Duo $2 \mathrm{GHz}$ e $2 \mathrm{~GB}$ de memória DDR2. A ilustração da montagem pode ser vista na Figura 23 e as imagens do mesmo encontram-se nas Figuras do Apêndice C.

\footnotetext{
${ }^{14}$ OpenCV - Open Computer Vision

${ }^{15}$ CCD - Charge Coupled Device.
} 
As imagens foram captadas com as amêndoas em movimento e são de tamanho 640 x 480 pixels, porém, para aumentar a velocidade de processamento foi definida uma região de interesse $\left(\mathrm{ROI}^{16}\right)$ com 640 x 320. A velocidade média da simulação da esteira foi de $7,5 \mathrm{~cm} / \mathrm{s}$. Em um espaço de $30 \mathrm{~cm}$ para o enquadramento da câmera, foram analisadas de $15 \mathrm{a}$ 20 amêndoas Exemplos das imagens captadas por esse mecanismo e utilizadas no sistema desenvolvido são mostrados nas Figuras 24 e 25.

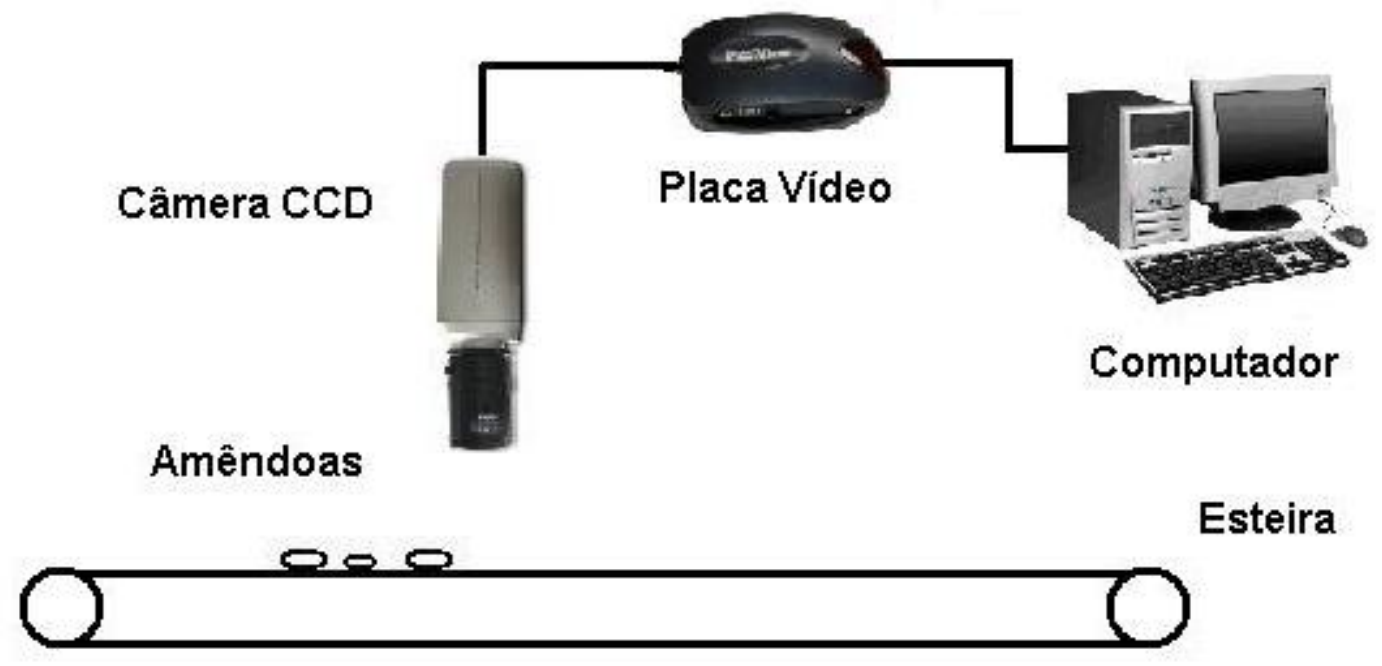

FIGURA 23 - ILUSTRAÇÃO DO SISTEMA UTILIZADO PARA SELECIONAR AS AMÊNDOAS.

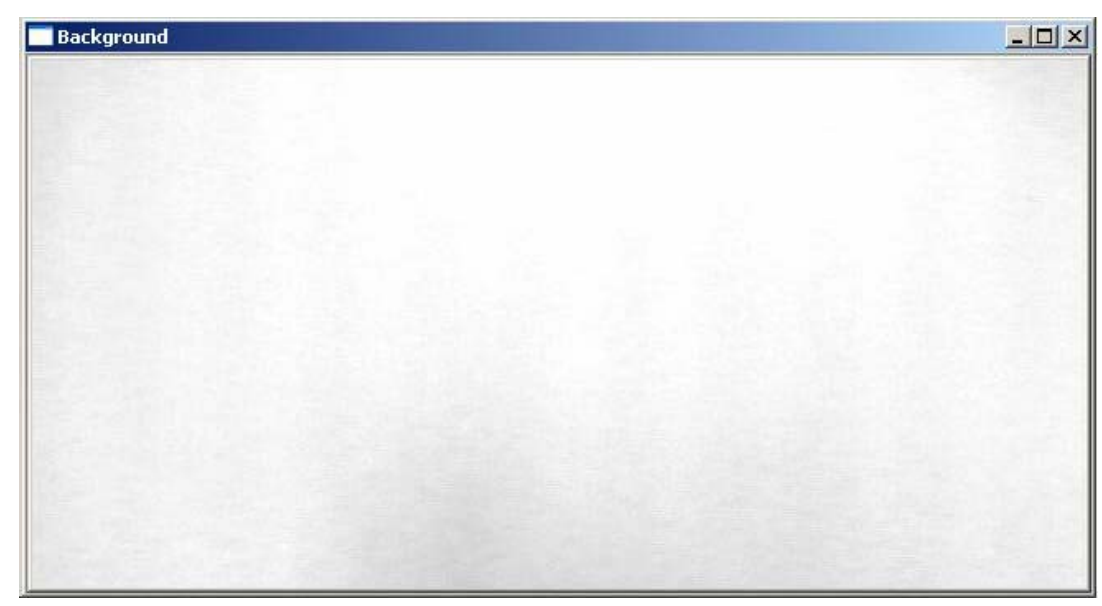

FIGURA 24 - EXEMPLO DE IMAGEM RGB CAPTURADA E UTILIZADA PELO SISTEMA (IMAGEM DE FUNDO).

${ }^{16} \mathrm{ROI}-$ Region Of Interest. 


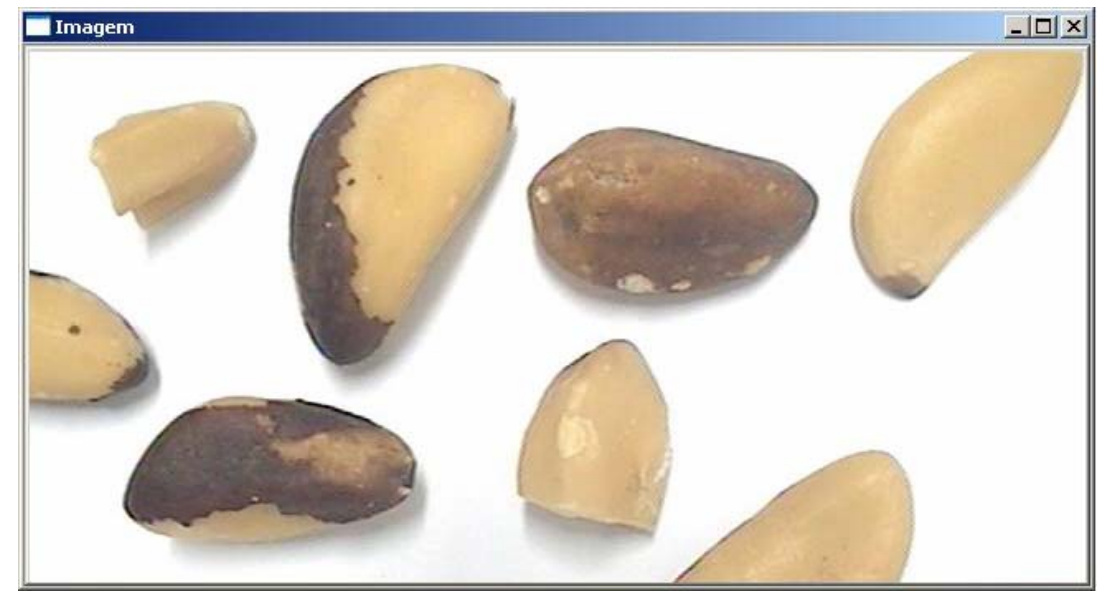

FIGURA 25 - EXEMPLO DE IMAGEM RGB CAPTURADA E UTILIZADA PELO SISTEMA (IMAGEM COM AMÊNDOAS).

O fluxograma contendo as etapas de processamento utilizadas para essas imagens é apresentado no Apêndice D. Essas etapas são descritas nos próximos sub-itens.

\subsection{Pré-processamento e Segmentação das Imagens}

Visando a segmentação adequada das amêndoas, foi utilizado o método de subtração de imagens. Essa subtração utilizou o canal B (espaço de cores RGB) da imagem de fundo e dos frames da análise. $\mathrm{O}$ canal $\mathrm{B}$ contrastou melhor do fundo as amêndoas independentemente se elas estiverem ou não com película. As imagens das Figuras 26, 27 e 28 são referentes a cada canal de cor do espaço RGB e a Figura 29 mostra o resultado da subtração.

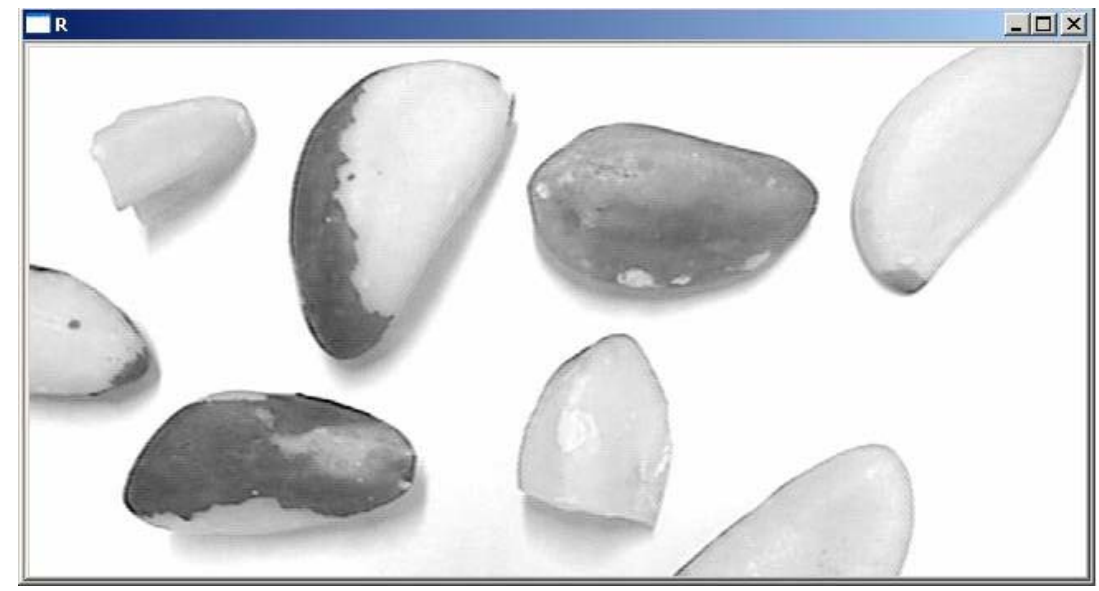

FIGURA 26 - IMAGEM REFERENTE AO CANAL R DO ESPAÇO DE COR RGB. 


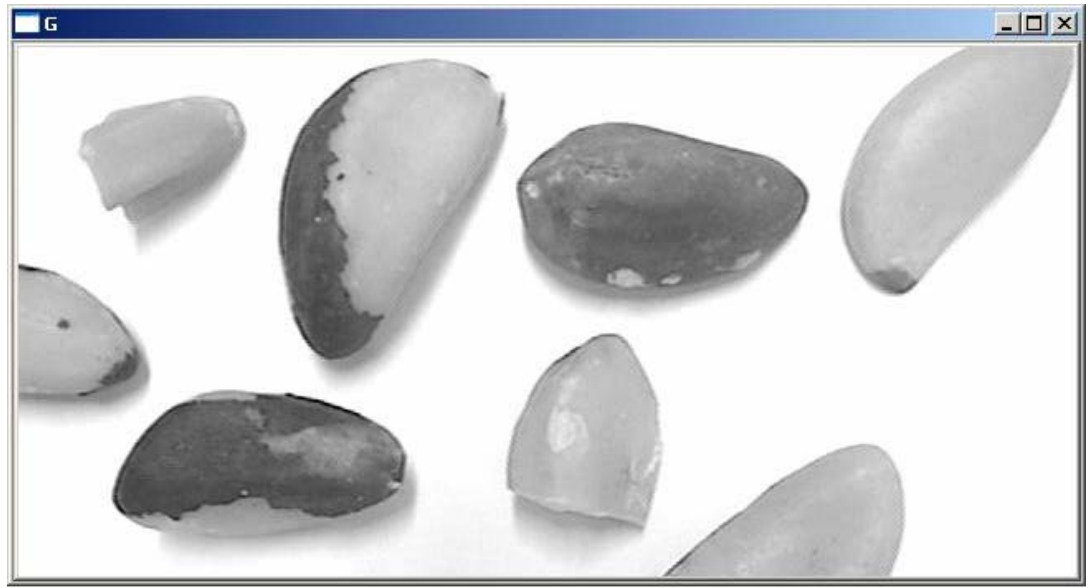

FIGURA 27 - IMAGEM REFERENTE AO CANAL G DO ESPAÇO DE COR RGB.

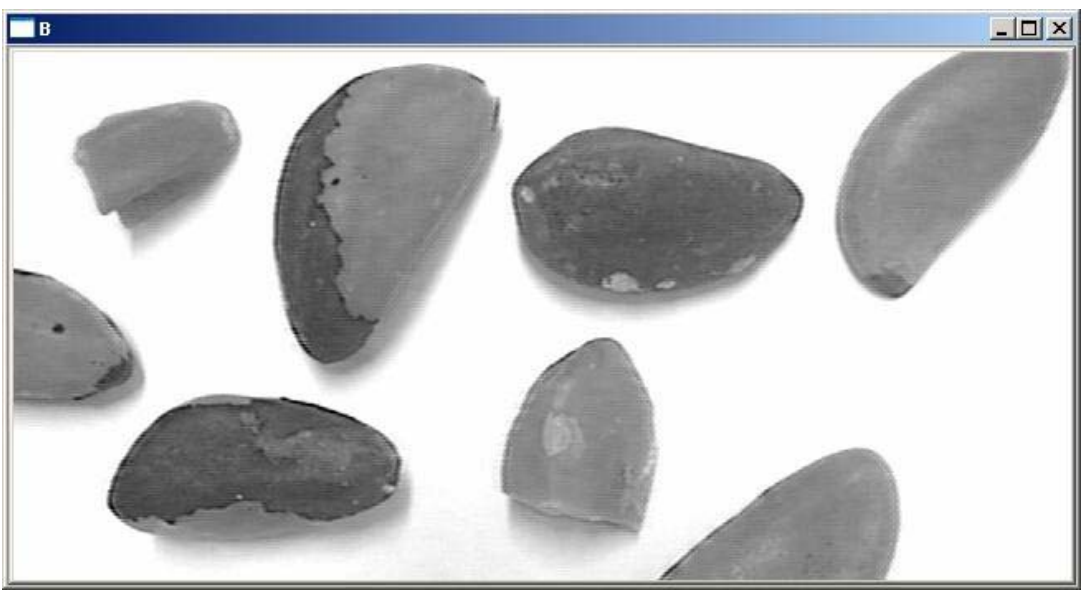

FIGURA 28 - IMAGEM REFERENTE AO CANAL B DO ESPAÇO DE COR RGB.

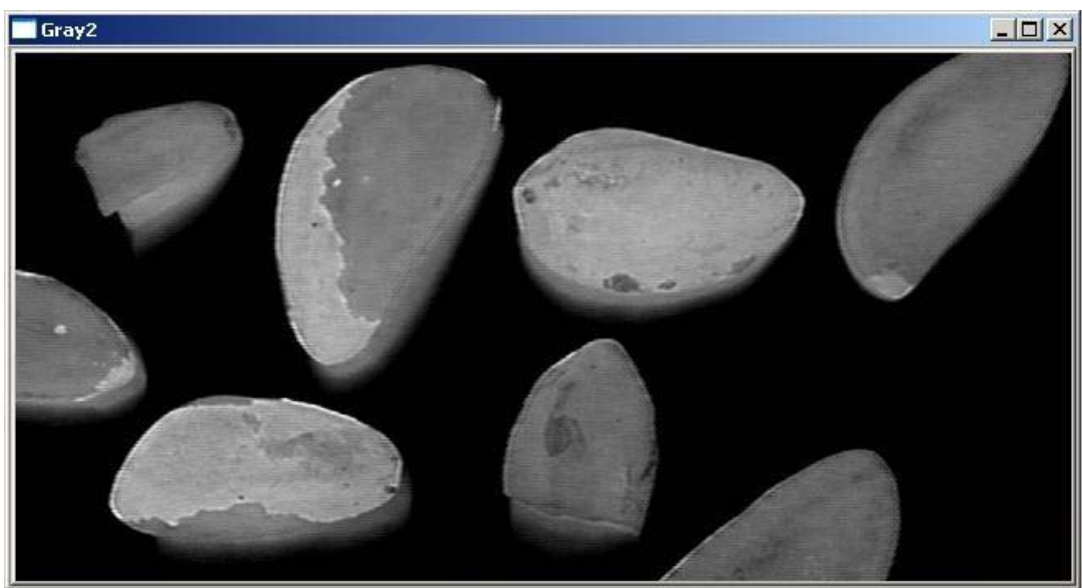

FIGURA 29 - RESULTADO DA SUBTRAÇÃO ENTRE O CANAL B DA IMAGEM DE FUNDO COM O CANAL B DO FRAME DA ANÁLISE.

O resultado dessa subtração é o isolamento dos objetos em relação ao fundo da imagem. As imagens resultantes foram binarizadas (threshold) e por limitações do sistema de 
aquisição em captar imagens de objetos em movimentos, foi necessário o ajuste das imagens. Esse ajuste foi feito através de morfologia matemática, comentada no Capítulo 3.

O elemento estruturante utilizado nas imagens tem formato em cruz e tamanho $3 \times 3$ pixels, estando a origem em seu centro. Com esse elemento estruturante, as imagens foram erodidas e depois dilatadas, sendo que essa operação é conhecida como Abertura. As Figuras 30 e 31 apresentam as imagens binarizadas antes e depois da utilização da morfologia matemática.

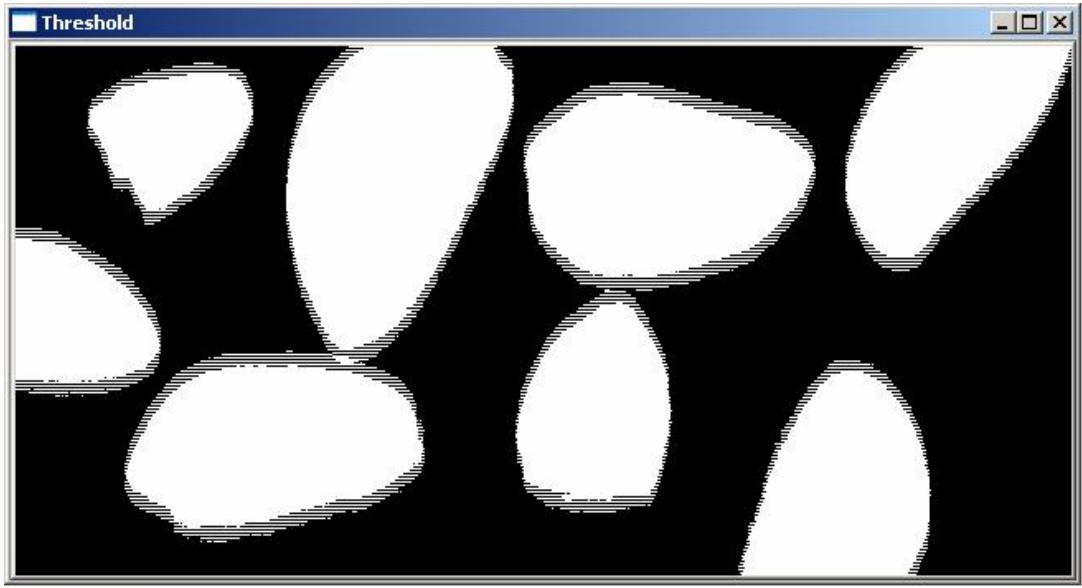

FIGURA 30 - IMAGEM BINARIZADA DAS AMÊNDOAS EM MOVIMENTO.

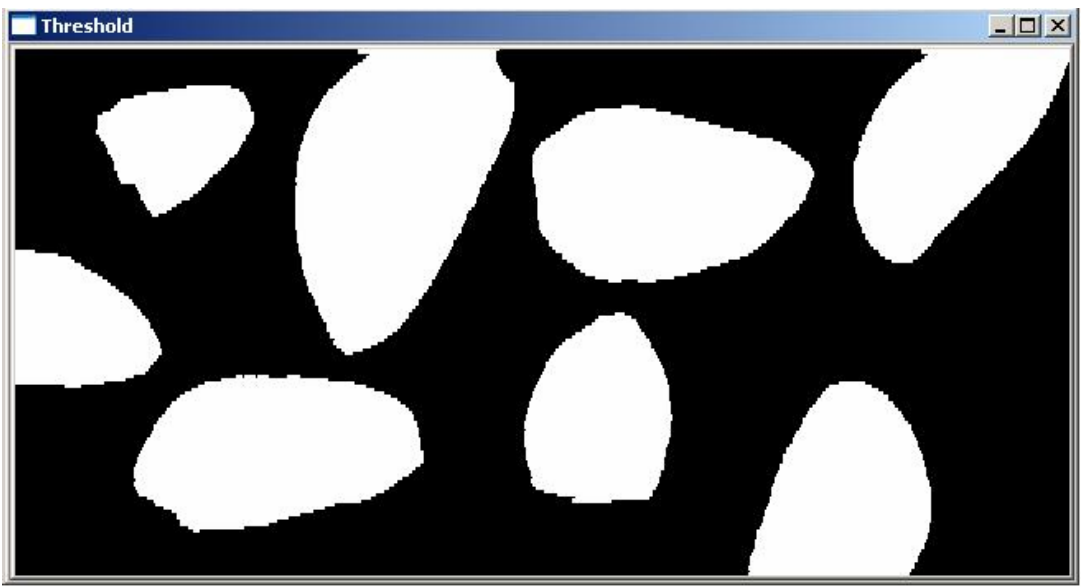

FIGURA 31 - IMAGEM DAS AMÊNDOAS EM MOVIMENTO APÓS A UTILIZAÇÃO DO PROCESSO DE ABERTURA.

Outra solução para essa limitação seria a suavização da imagem captada pela câmera, o que exigiria maior tempo de processamento. A Tabela 10 mostra os tempos de processamento quando a imagem foi suavizada por média com template de $5 \times 5$, com a operação de abertura e sem a utilização dos dois. 
TABELA 10 - TEMPO DE PROCESSAMENTO DAS METODOLOGIAS TESTADAS PARA MINIMIZAR RASTROS NA IMAGEM.

\begin{tabular}{cccccc}
\cline { 2 - 6 } & \multicolumn{5}{c}{ Tempo de Processamento (s) } \\
\cline { 2 - 6 } & Vídeo1 & Vídeo2 & Vídeo3 & Vídeo4 & Vídeo5 \\
\hline $\begin{array}{c}\text { Filtro de } \\
\text { Suavização }\end{array}$ & 35,094 & 34,219 & 19,234 & 17,25 & 18,234 \\
\hline $\begin{array}{c}\text { Morfologia } \\
\text { Matemática }\end{array}$ & 24,766 & 23,156 & 12,234 & 10,422 & 11,375 \\
\hline Sem Filtros & 20,907 & 19,219 & 11,219 & 9,563 & 10,641 \\
\hline
\end{tabular}

A partir da imagem resultante da morfologia matemática é possível a identificação de cada amêndoa na imagem, tornando-se possível a extração de suas características.

\subsection{Extração das características}

Com as amêndoas detectadas, foi possível extrair dados característicos de forma e dados de cores de cada amêndoa. As características de formas utilizadas nas análises podem ser vistas na Tabela 11.

A área e o perímetro foram utilizados para delimitar os objetos a serem reconhecidos, ou seja, a extração das outras características somente é feita se os objetos detectados atingirem a quantidade mínima de pixels na área e no perímetro, neste caso de 1250 e 200 pixels. O próximo passo é o cálculo do centro de massa utilizando as equações de momentos (21), (22) e (23).

$$
\begin{gathered}
M r s=\sum_{i=0}^{P} \sum_{j=0}^{Q} i^{r} j^{s} f(i, j) \\
x=\frac{M 10}{M 00} \\
y=\frac{M 01}{M 00}
\end{gathered}
$$

Sendo:

$\mathrm{P}$ e $\mathrm{Q}=\mathrm{A}$ largura e a altura da imagem; 
r e s = Índices do tipo de momento;

$\mathrm{x}$ e $\mathrm{y}=$ Coordenadas de centro de massa do objeto.

O centro de massa foi utilizado para adquirir a média da vizinhança (template de 5 x 5) dos canais de cores B (espaço RGB), H e S (espaço HSV). Também é utilizado como pixel inicial (semente) do preenchimento da cor de sua classificação. Essas utilizações serão comentadas no sub-itens de classificadores.

TABELA 11 - DESCRITORES DE FORMA UTILIZADOS PARA SELEÇÃO DAS AMÊNDOAS (COSTA; CESAR JUNIOR, 2001).

\begin{tabular}{|c|c|}
\hline Características & Expressões \\
\hline Área (A) & $\begin{array}{l}\qquad A=\sum_{i=0}^{P} \sum_{j=0}^{Q} f(i, j) \\
\text { *Para imagens binárias }\end{array}$ \\
\hline Perímetro $(\mathrm{Pe})$ & $\begin{array}{l}\qquad P e=\sum_{i=0}^{P} \sum_{j=0}^{Q} f(i, j) \\
\text { *Para imagens binárias } \\
\text { **Sendo } f(\mathrm{i}, \mathrm{j}) \text { pertencentes a borda do objeto }\end{array}$ \\
\hline Eixo Maior (EM) & $\begin{array}{c}E M=\operatorname{MAX}\left[d\left(p_{i}, p_{j}\right)\right] \\
* \text { Sendo } d(\text { pi,pj }) \text { a distância entre os pixels i e j }\end{array}$ \\
\hline Eixo Menor (Em) & $\begin{array}{l}\qquad E m=\operatorname{MAX}\left[d\left(q_{i}, q_{j}\right)\right] \\
\text { *Sendo } d(\text { qi,qj }) \text { a distância entre os pixels i e j } \\
\text { **Sendo Em perpendicular a EM }\end{array}$ \\
\hline Excentricidade (E) & $E=E M / E m$ \\
\hline Retangularidade (R) & $R=A /(E M * E m)$ \\
\hline Circularidade $(\mathrm{C})$ & $C=P e^{2} / A$ \\
\hline Razão de Afinamento (Ra) & $R a=(4 * \pi * A) / P e^{2}$ \\
\hline Razão Área-Perímetro (RAP) & $R A P=A / P e$ \\
\hline $\begin{array}{c}\text { Relação Afinamento-Circularidade } \\
\text { (RAC) }\end{array}$ & $R A C=P e-\sqrt{P e^{2}-4^{*} \pi^{*} A} / P e+\sqrt{P e^{2}-4^{*} \pi^{*} A}$ \\
\hline
\end{tabular}




\subsubsection{Peso das Amêndoas}

Como citado na introdução, as amêndoas tem sua classificação definida pelo MAPA. Hoje essa classificação é dada pela quantidade de amêndoas a cada 453 g, podendo haver amêndoas de diversos tamanhos em um conjunto definido como grande. Visando melhorar essa classificação, foram feitas relações do peso da amêndoa com as características extraídas das imagens. Também foram feitos cálculos considerando a aproximação das amêndoas a duas formas geométricas: elipsóide e prisma triangular.

Por se tratar de um sistema de imagens de duas dimensões, não é possível obter dados de profundidade. A falta desses dados foi crucial para os cálculos de relação entre as características e seu peso. Assim, a equação utilizada para o cálculo dos pesos das amêndoas foi a equação resultante da regressão linear entre o peso real e área da amêndoa na imagem. $\mathrm{O}$ erro da regressão foi de $3,9^{-14}$, calculado a partir dos resíduos dessa regressão. A média do peso das castanhas analisadas foi de 3,86 g sendo que a média do resíduo (independentemente se negativo ou positivo) foi de 0,24 g, ou seja, média de erro de 6,2\%. A Figura 32 mostra o gráfico da regressão e sua equação.

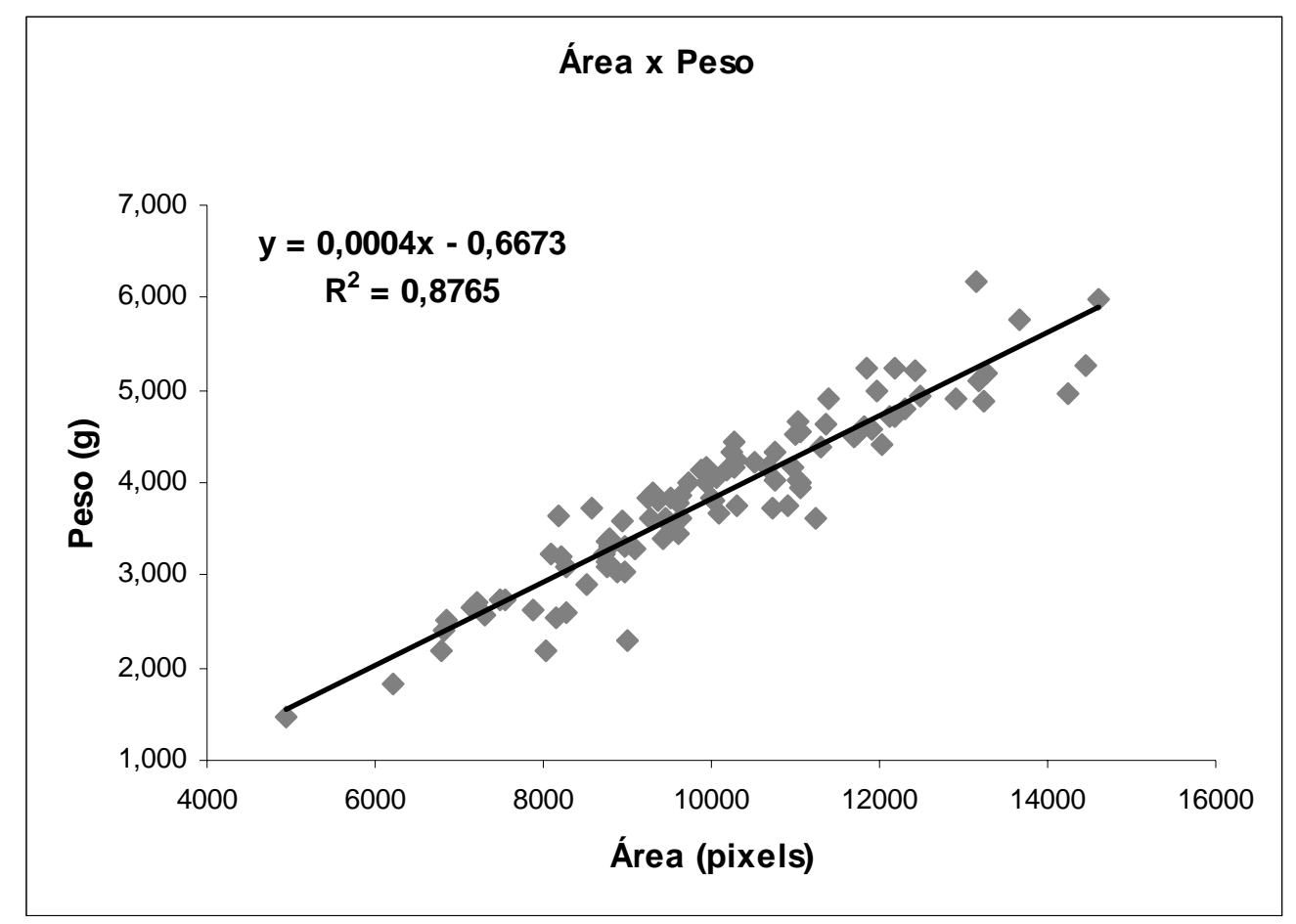

FIGURA 32 - GRÁFICO DA RELAÇÃO ENTRE A ÁREA DA AMÊNDOA NA IMAGEM E DO PESO REAL. 


\subsection{Classificadores}

A seleção da amêndoa no software desenvolvido é composta por duas etapas: identificação da forma (intacta ou quebrada) e identificação do estado (boa ou estragada). As amêndoas foram preenchidas com as cores definidas para cada situação, são elas:

- Verde - A amêndoa está intacta e boa.

- Roxo - A amêndoa está intacta e provavelmente estragada.

- Vermelho - A amêndoa está quebrada.

- Marrom Claro - A amêndoa não pode ser analisada por estar parcialmente fora da área de análise, ou seja, nas bordas da imagem.

- Azul - A amêndoa, independentemente de sua classificação, chegou ao fim da análise.

A Figura 33 mostra a imagem resultante das duas etapas que serão discutidas a seguir.

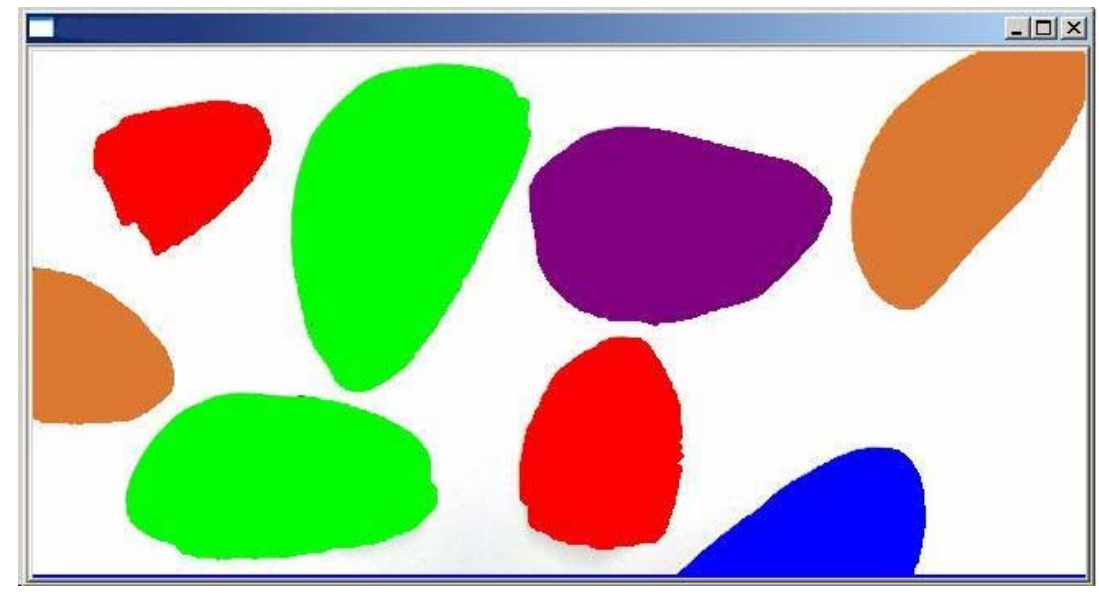

FIGURA 33 - IMAGEM RESULTANTE DAS DUAS ETAPAS DE SELEÇÃO.

\subsubsection{Identificação da Forma}

As características extraídas das amêndoas foram utilizadas como entrada para uma RNA. O processo de definição da RNA foi o mesmo utilizado no capítulo anterior. A diferença é a quantidade de amostras utilizadas, sendo que neste o arquivo de treinamento contém 100 amostras. Para os testes, foram criados 3 arquivos com 30, 19 e 24 amostras. Após vários testes, a arquitetura da MLP foi configurada com taxa de aprendizagem de 0.15 , fator de momentum de 0.9 e 100 épocas. Também foi utilizado o algoritmo de Wrapper na seleção das melhores variáveis para essa arquitetura.

A Figura 34 apresenta a arquitetura definida após os testes com Wrapper e a Tabela 12 mostra os resultados dos testes da MLP. 


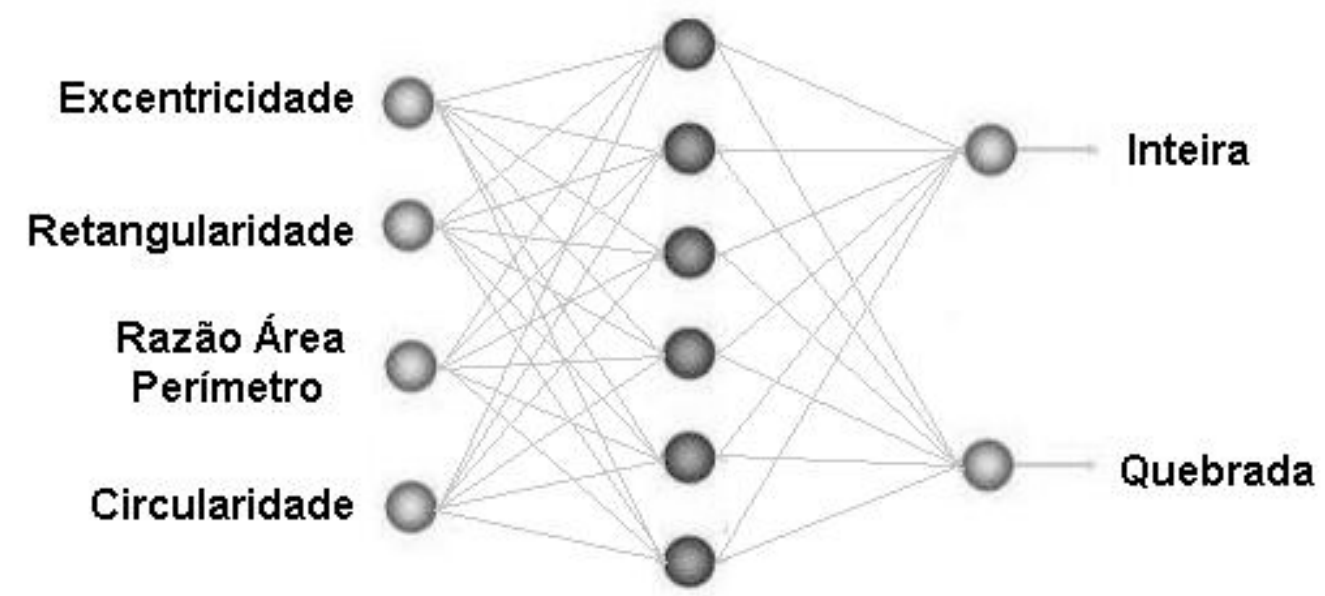

FIGURA 34 - ARQUITETURA INICIAL DA MLP (4 NEURÔNIOS NA CAMADA DE ENTRADA; 6 NEURÔNIOS NA CAMADA INTERMEDIÁRIA; 2 NEURÔNIOS NA CAMADA DE SAÍDA).

TABELA 12 - IDENTIFICAÇÕES CORRETAS (\%) DA CONDIÇÃO FÍSICA DAS AMÊNDOAS.

\begin{tabular}{cccccc} 
& \multicolumn{5}{c}{ Identificações Corretas (\%) } \\
\cline { 2 - 6 } Arquivo & $\begin{array}{c}\text { Validação } \\
\text { Cruzada }\end{array}$ & Treinamento & Teste 1 & Teste 2 & Teste 3 \\
\hline Todas as Variáveis & 77 & 86 & 93,33 & 94,74 & 100 \\
\hline $\begin{array}{c}\text { Variáveis } \\
\text { Selecionadas }\end{array}$ & 79 & 86 & 93,33 & 94,74 & 100 \\
\hline
\end{tabular}

Pode-se notar na Tabela acima, que não há diferença nos resultados entre os testes utilizando as duas arquiteturas de RNA. Pelo resultado do Wrapper, as outras variáveis não foram significativas, sendo desnecessárias para essa identificação. Mesmo que o resultado da identificação não tenha melhorado, a menor quantidade de variáveis corresponde a maior velocidade de processamento, por isso o sistema utilizou a arquitetura da MLP da Figura 34.

\subsubsection{Identificação da Aparência}

$\mathrm{Na}$ avaliação do estado da amêndoa são utilizados dados de cores adquiridos na vizinhança do centro de massa. As amêndoas sem películas têm contraste maior do que as com películas quando comparadas com as amêndoas estragadas. Quando as amêndoas sofrem algum tipo de choque mecânico, ficam expostas as condições de umidade e temperatura ou fungos, elas tendem a perder óleo. Sua aparência então é equivalente a das amêndoas estragadas. Esses são os casos críticos nos quais as amêndoas devem ser retiradas do sistema para não serem embaladas juntamente com as amêndoas boas.

Porém, há casos em que a variação de cores da película das amêndoas boas são similares as cores das amêndoas estragadas. Também existem amêndoas que não estão 
totalmente envolvidas pela película, dificultando a decisão do sistema. Na Figura 35 pode-se observar alguns desses casos citados. Outra informação importante é que entre as castanhas cedidas pelo projeto Kamukaia, não foram encontradas muitas amêndoas estragadas. Por esses motivos, foi utilizado um sistema nebuloso para estimar o estado da amêndoa.

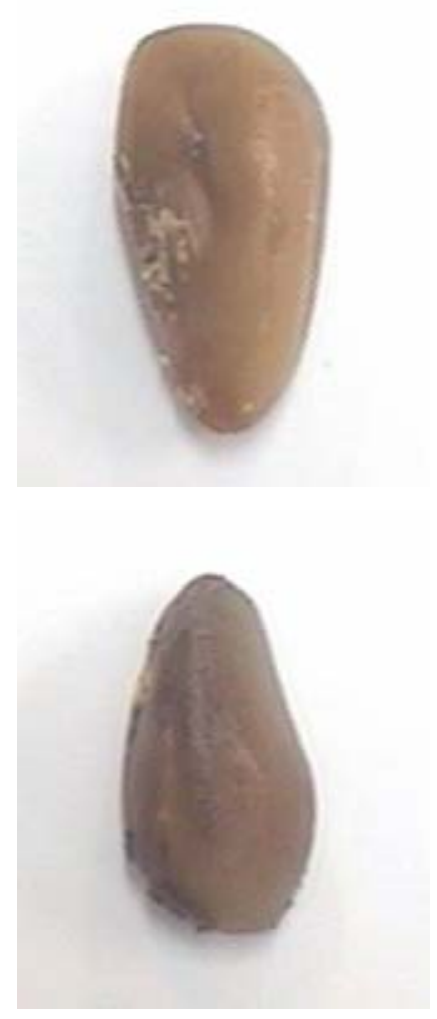

(a)
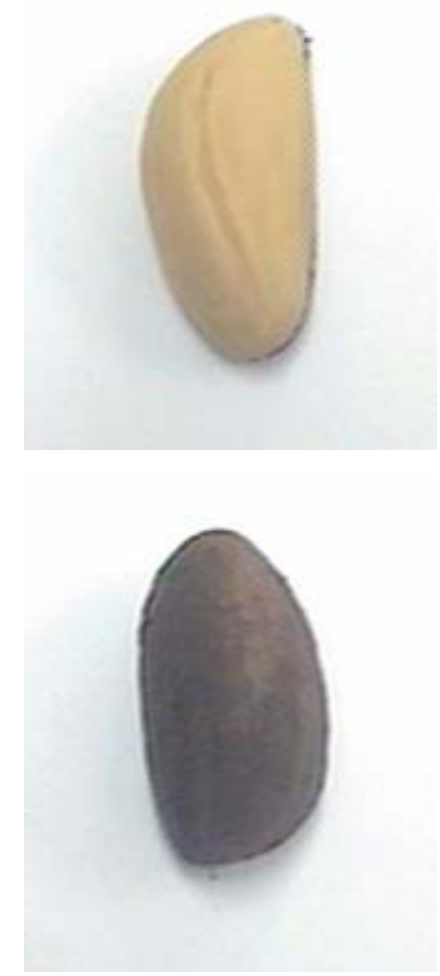

(b)

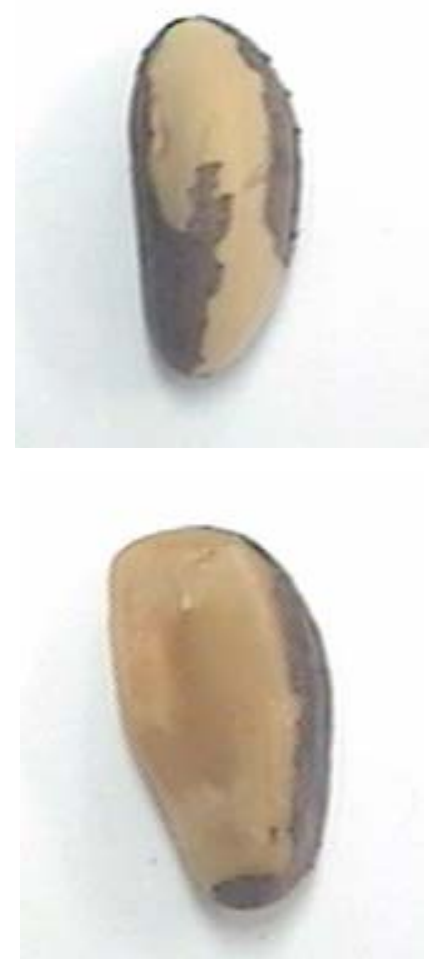

(c)

FIGURA 35 - IMAGENS DAS AMÊNDOAS: (A) ESTRAGADAS; (B) BOAS SEM E COM PELÍCULA; (C) BOA COM ALGUMA PELÍCULA E JÁ PERDENDO ÓLEO.

O sistema nebuloso aqui utilizado é composto por três canais de cores: B do espaço RGB, H e S do espaço HSV. Esses três foram utilizados como universos de discursos da entrada: valor de intensidade de $\mathrm{B}$ que varia de 0 até 255 , valor de $\mathrm{H}$ variando de 0 até 180 e valor de intensidade de $\mathrm{S}$ variando de 0 até 255. Cada uma delas tem duas funções de pertinência que podem ser vistas na Figura 36 juntamente com o universo de discurso de saída (estado da amêndoa). 


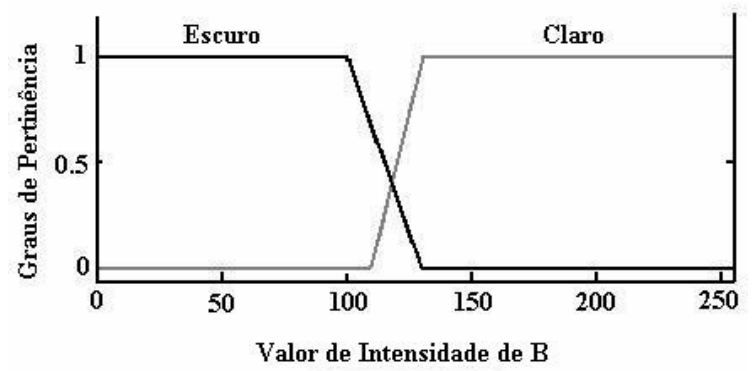

(a)

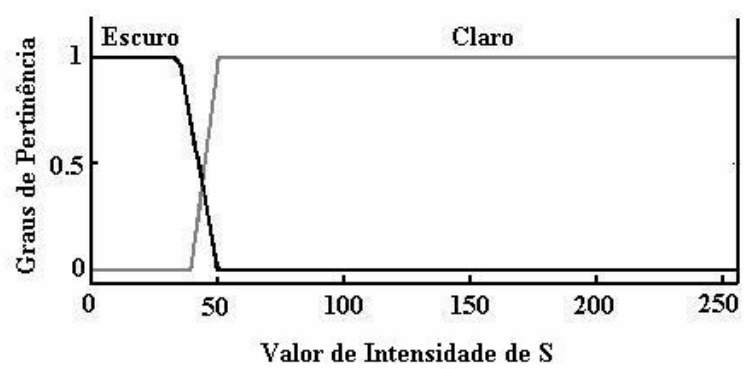

(c)

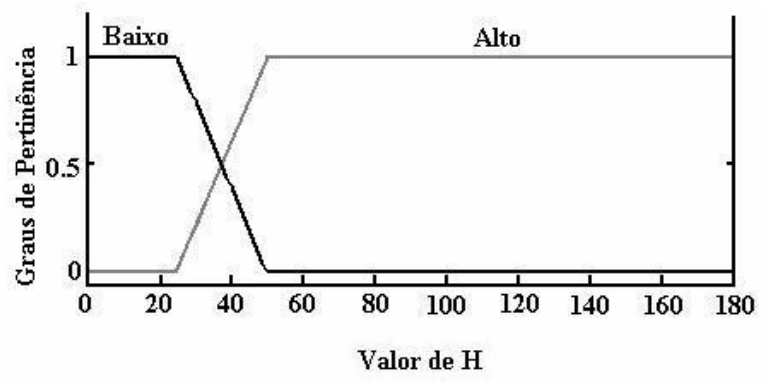

(b)

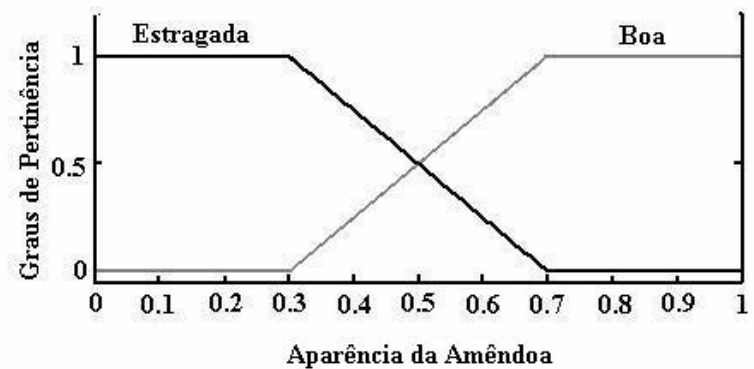

(d)

FIGURA 36 - UNIVERSOS DE DISCURSOS UTILIZADOS: (A) INTENSIDADE DE B; (B) VALOR DE H; (C) INTENSIDADE DE S; (D) APARÊNCIA DA AMÊNDOA.

Para essa configuração dos universos de discursos foram definidas e utilizadas as seguintes regras:

Regra 1: Se Valor de intensidade B é Claro

Então Estado Amêndoa é Boa

Se Valor de intensidade B é Escuro $e$ Valor H é Alto $e$

Regra 2: $\quad$ Valor de intensidade S é Escuro

Então Estado Amêndoa é Boa

Se Valor de intensidade B é Escuro $e$ Valor H é Baixo $e$

Regra 3: $\quad$ Valor de intensidade S é Claro

Então Estado Amêndoa é Estragada

$S e$ Valor de intensidade B é Escuro $e$ Valor H é Baixo $e$

Regra 4: Valor de intensidade S é Escuro

Então Estado Amêndoa é Boa

O sistema também utilizou o operador de implicação de Mandani, a agregação foi feita com valores de máximo, a composição com Max-Min e a defuzzyficação com CDA (Método do Centro de Área). Um exemplo feito com o Fuzzy Toolbox do Matlab R2006a é mostrado na Figura 37. 


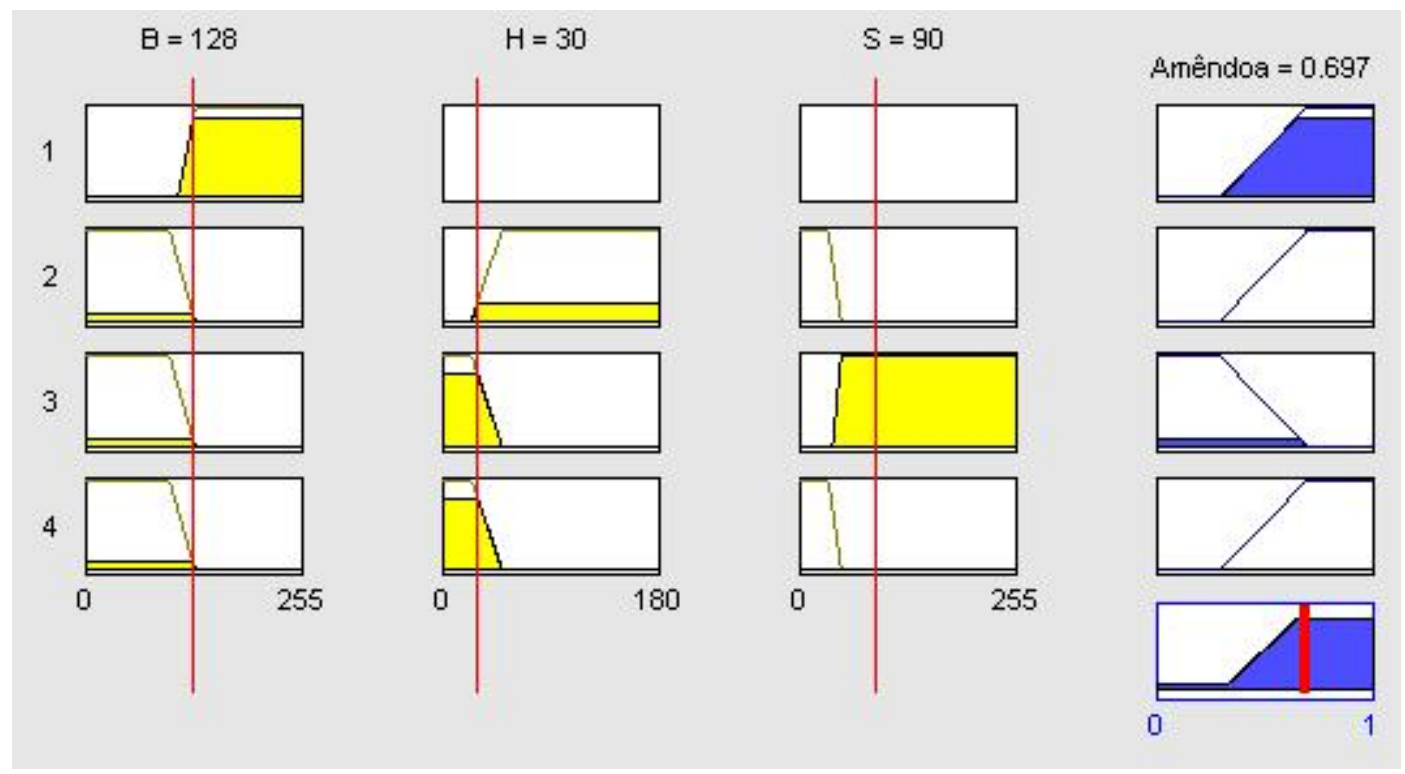

FIGURA 37 - EXEMPLO DAS ATIVAÇÕES DAS REGRAS.

Esse sistema foi testado com 10 imagens de amêndoas estragadas e 97 imagens de amêndoas boas. Com essas imagens o sistema apresentou um aproveitamento de 88,2 \% de identificações corretas.

\subsection{Considerações Finais}

Esse capítulo apresentou as técnicas utilizadas em cada etapa do software desenvolvido para a seleção das amêndoas. Mesmo com as limitações de hardware, o tempo total do processamento de cada frame foi em média de $50 \mathrm{~ms}$. Com a velocidade e o espaço utilizados na movimentação das amêndoas são analisadas cerca de 4 amêndoas por segundo ou seja, mais de 108000 amêndoas em 8 horas de trabalho. Se considerarmos um peso médio de 5 g por amêndoa, tem-se ao fim do dia (8 horas) mais de $540 \mathrm{Kg}$ de amêndoas analisadas.

Esses resultados podem ser melhorados com a utilização de outros dispositivos. Com o uso de lentes de filtros ópticos azuis acoplados, não seria preciso fazer a subtração do fundo. Além disso, um sistema de iluminação adequado é crucial para o bom desempenho do sistema, evitando assim sombras das amêndoas e a variação de luminosidade causada por uma lâmpada fluorescente (o que torna crítica a análise de cor). 
$-62-$ 


\section{CONCLUSÕES E TRABALHOS FUTUROS}

\subsection{Conclusão}

Este trabalho apresenta em sua introdução os motivos que tornam o Brasil apenas o segundo maior exportador de amêndoas de castanhas do Brasil. Então, com o objetivo de melhorar as etapas de classificação das castanhas e seleção de suas amêndoas, foram utilizadas técnicas de visão computacional e sistemas inteligentes. Os trabalhos relacionados, que podem ser encontrados na literatura, e os fundamentos das técnicas que foram utilizadas são descritos e discutidos nos capítulos que se seguiram.

No desenvolvimento da metodologia da classificação por origem foram utilizados descritores de textura e dados de cores. Essas características serviram como entrada de uma RNA que identificou sua origem depois de treinada com 90 e 240 imagens. Visando aumentar a eficácia da RNA foi utilizado algoritmo de seleção de variáveis Wrapper. Assim, a RNA foi mais eficaz quando utilizou as características selecionadas e utilizando o treinamento com maior número de imagens. As RNAs utilizadas para a classificação foram comparadas com uma análise visual utilizando o teste T Student. Como resultado do teste, as RNAs mostraram que é possível a identificação das castanhas por origem, sendo mais efetivo do que uma análise visual.

Já para a seleção das amêndoas foram utilizados descritores de forma e canais de cores também. Os descritores de forma foram utilizados como entrada de uma RNA que identificou se a amêndoa estava quebrada ou não. Os canais de cores ( $\mathrm{B}, \mathrm{H}$ e $\mathrm{S})$ foram utilizados como universo de discurso de um sistema nebuloso que identificou se a aparência da amêndoa é boa ou ruim. O erro na identificação da forma e da aparência foi abaixo da margem estipulada pelas indústrias que é de $15 \%$. Além disso, foi feita a estimativa do peso de cada amêndoa. Isso foi possível através da relação entre a área do objeto (amêndoa) na imagem e seu peso real. 
Os conceitos de visão computacional e sistemas inteligentes, aqui utilizados, garantiram a eficácia e a robustez necessária para um sistema industrial.

\subsection{Principais Contribuições}

As principais contribuições foram:

- Desenvolvimento de um software para seleção das amêndoas das castanhas do Brasil;

- Desenvolvimento de uma metodologia para classificação das castanhas do Brasil por sua região de origem utilizando dados de suas características físicas;

- Publicação do trabalho "Utilização de Redes Neurais Artificiais para Classificação por Origem de Castanhas do Brasil" no IX Congresso de Ecologia do Brasil;

- Publicação do trabalho "Seleção de amêndoas e Classificação das Castanhas do Brasil” no II Workshop da Pós Graduação da Engenharia Elétrica;

- Publicação do trabalho "Identificação da Condição Física da Amêndoa da Castanha do Brasil Utilizando Processamento de Imagens" na I Jornada Científica Embrapa.

\subsection{Trabalhos Futuros}

As sugestões para trabalhos futuros são:

- Construção de uma esteira composta por um sistema de iluminação controlada e blindada;

- Estudo para detecção das trincas e de carunchos nas amêndoas;

- Utilização de um sistema estéreo de câmeras para melhoria da estimativa do peso da amêndoa e melhor análise de forma e cor;

- Avaliação de novas características das castanhas do Brasil e análise de possíveis distinções entre castanhas de regiões do mesmo estado; 


\section{REFERÊNCIAS BIBLIOGRÁFICAS}

ANDRADE, E. T.; CORRÊA, P. C.; ALVARENGA, G. M.; ARTINS, J. J. Efeito do Impacto Mecânico Controlado Sobre a Qualidade Fisiológica de Sementes de Feijão. Engenharia na Agricultura, Viçosa, v.7, n.3, p. 148-159, 1999.

ANDRADE, R. G.; RODA, V. O.; PESSOA, J. D. C. Identificação da Condição Física da Amêndoa da castanha do Brasil Utilizando Processamento de Imagens. I Jornada Científica Embrapa. São Carlos - SP, 2009a.

ANDRADE, R. G.; RODA, V. O.; PESSOA, J. D. C. Utilização de Redes Neurais Artificiais para Classificação por Origem de Castanhas do Brasil. IX Congresso de Ecologia do Brasil. São Lourenço - MG, 2009 b.

BETANCUR, J.; PRIETO, F. Active Contour-Based Segmentation of Coffee Cherries Images. Signal Processing $9^{\text {th }}$ International Conference on Software Process - ICSP , p. 2738-2741, 2008.

BRAGA, A. P.; CARVALHO, A. P. L. F.; LUDERMIR, T. B. Redes Neurais Artificiais: Teoria e Aplicações. Rio de Janeiro: LTC Editora, 2000. 262p

CASTRO JORGE, L. A.; RUIZ, H. S.; FERREIRA, E. J. GONZAGA, A. Wrapper Approach to Select a Subset of Color Components for Image Segmentation with Photometric Variations. XX Brazilian Symposium on Computer Graphics and Image Processing. Belo Horizonte-MG, 2007.

CAVANI, F. A.; SOUSA, F. V.; PORTO, ARTHUR, J. V. Segmentação e Classificação de Imagens de Laranjeiras Utilizando JSEG e Perceptron Multicamadas. Minerva, v. 3, p. 189197, 2006.

CÍCERO, S. M.; BANZATTO JUNIOR, H. L. Avaliação do Relacionamento Entre Danos Mecânicos e Vigor, em Sementes de Milho, por Meio da Análise de Imagens. Revista Brasileira Sementes, Pelotas, v. 25, n. 1, 2003. 
COSLOVSKY, S. V. Determinantes de Sucesso na Indústria da Castanha. Junho, 2005.

Disponível em: <http://www.ebape.fgv.br/radma/doc/artigos/Salo-castanha\%20\%20FGV\%2031\%20maio\%202005.pdf>. Acesso em: 20 Abr. 2008.

COSTA, L. F.; CESAR JUNIOR., R. M. Shape Analysis and Classification Theory and Practice. RCR Press LLC, 2001

EASYRGBCOLOR. Conversion Math and Formulas. [2008]. Disponível em: $<$ http://www.easyrgb.com/index.php?X=MATH>. Acesso em: 20 Ago. 2009.

FERNANDES, R. A. S.; SILVA, I. N.; OLESKOVICZ, M. Identificação de Fontes Harmônicas por Redes Neurais Artificiais. VIII Conferência Internacional de Aplicações Industriais (Induscon). Poços de Caldas - SP, 2008.

FLOR, E. P. O.; CICERO, S. M.; FRANÇA NETO, J. de B.; KRZYZANOWSKI, F. C. Avaliação de Danos Mecânicos em Sementes de Soja por Meio da Análise de Imagens. Revista Brasileira Sementes, Pelotas, v. 26, n. 1, 2004.

FORTI, V. A.; CICERO, S. M.; PINTO, T. L. F. Análise de Imagens na Avaliação de Danos Mecânicos e Causados por Percevejos em Semente de Feijão. Revista Brasileira Sementes, Pelotas, v. 30, n. 1, 2008.

GONZAGA, A.; FRANÇA, C. A.; SLAETS, A. F.F. A Neuro-Fuzzy Approach for Automatic Classification of Wooden Plates. Revista Engenharia \& Arquitetura, São Carlos, p. 38 - 49, 01 Jan. 2000.

GONZALEZ, R. C.; WOODS, R. E. Digital Image Processing. $2^{\text {a }}$ Edição. Prentice Hall, 2001.

GONZALEZ, R. C.; WOODS, R. E.; EDDINS, S. L. Digital Image Processing Using MATLAB. $1^{\text {a }}$ Edição. Prentice Hall, 2004.

HALL, M.; FRANK, E.; HOLMES, G.; REUTEMANN, P.; WITTEN, I. H. The WEKA Data Mining Software: An Update; SIGKDD Explorations, Volume 11, Issue 1. 2009. 
HENRIQUES, L. O. de A. Implementação de Estratégia de Minimização de Oscilações de Torque e Remoção de Sensor de Posição para um Acionamento de Relutância Variável Usando Técnica Neuro-Fuzzy. Tese de Doutorado, Universidade Federal do Rio de Janeiro, Rio de Janeiro - RJ, 2004.

JÄHNE, B.; HAUBECKER, H.; GEIBLER, P. Handbook of Computer Vision and Applications - Volume 3 - Systems and Applications. Academic Press, 1999

JAIN, A. K. Fundamentals of Digital Image Processing. Prentice Hall, 1989.

KOENIGKAN, V. L. Método para Análise do Contorno de Aglomerados de Gotas de Chuva Artificial em Imagem Digital. Dissertação de Mestrado, Universidade de São Paulo, São Carlos-SP, 2005.

KOHAVI, R.; JOHN, G. H. Wrapper for Feature Subset Selection. Artificial Intelligence. 97(1-2): 273-324, 1997.

KOVÁCS, L. Z. Redes Neurais Artificiais: Fundamentos e Aplicações. $2^{\mathrm{a}}$ Edição. Collegium Cognitio, 1996.

LOURO, A. H. F.; MENDONÇA, M. M.; GONZAGA, A. Classificação de Tomates Utilizando Redes Neurais Artificiais. Anais do WVC'2006 - II Workshop de Visão Computacional. 16 a 18 de Outubro de 2006, São Carlos - SP, p.239 - 244.

MANUAL de segurança e qualidade para a cultura da Castanha-do-Brasil. Brasília, DF: CampoPAS, 2004. 60 p. (Série de Qualidade e segurança dos Alimentos).

McDONALD, M.; EVANS, A.; BENNETT, M. Using Scanners to Improve Seed/Seedling Evaluations Internationally. In: Reports of Department of Horticulture and Crop Science. Ohio State University, USA, p.6-9, July 2000.

MELlO, F. R. Avaliação da Qualidade da Castanha do Brasil (Bertholletia Excelsa H. B. K.), Sua Relação Com o Processo de Seleção e Contaminação Por Aflatoxinas. Dissertação Mestrado, Universidade Federal de Santa Catarina, Florianópolis - SC, 2007. 
PASCALE, D. RGB Coordinates of the Macbeth ColorChecker. Disponível em: < http://www.babelcolor.com/download/RGB\%20Coordinates\%20of\%20the\%20Macbeth\%20C olorChecker.pdf >, Acesso em: 28 Maio 2008.

PENNACCHIO, H. L. Castanha do Brasil, período até 28/04/2006. Disponível em: $<$ http://www.conab.gov.br/conabweb/download/cas/semanais/semana24a28042006/conj24_a _28042006_castanha_do_brasil.pdf>. Acesso em: 12 Abr. 2008a.

PENNACCHIO, H. L. Castanha do Brasil, Proposta de Preço Mínimo. Disponível em: $<$ http://www.conab.gov.br/conabweb/download/precos_minimos/proposta_de_precos_minim os_safra_2006_07_castanha_do_brasil.pdf>. Acesso em: 12 Abr. 2008b.

PINHEIRO, J. I. D.; CUNHA, S. B.; CARVAJAL; GOMES, G. C. Estatística Básica - A Arte de Trabalhar Com Dados. Campus. 2009.

PINTO, T. L. F.; CICERO, S. M.; FORTI, V. A. Avaliação de Danos por Umidade, em Sementes de Soja, Utilizando a Técnica da Análise de Imagens. Revista Brasileira Sementes, Pelotas, v. 29, n. 3, 2007.

PROJETO FLORESTA VIVA. Castanha do Brasil: produção e beneficiamento. Manaus, [2009]. Disponível em:

$<\mathrm{http}$ ://www.florestavivaextrativismo.org.br/src_externo/consumo_castanha.php?dest=consu mo_castanha>. Acesso em: 20 Nov. 2009.

PROJETO KAMUKAIA. Manejo Sustentável de Produtos Florestais Não Madeireiros na Amazônia. [2009]. Disponível em:

$<$ http://www.kamukaia.com.br/>. Acesso em: 13 Jan. 2010.

REIS, M. M. Testes de Diferenças Entre Médias. Disponível em: $<$ http://www.inf.ufsc.br/ marcelo/testes2.html>. Acesso em: 15 Dez. 2009.

RIBEIRO, H. L. Reconhecimento de Gestos Usando Segmentação de Imagens Dinâmicas de Mãos Baseada no Modelo de Mistura de Gaussianas e Cor de Pele. Dissertação Mestrado, Universidade São Paulo, São Carlos - SP, 2006. 
RUZ, G. A.; ESTÉVEZ, P. A.; PEREZ, C. A. A Neuro-Fuzzy Color Image Segmentation Method for Wood Surface Defect Deteciton. Forest Products Journal, v. 55, n. 4, p. 52-68, 2005 .

SHAHIN, M. A.; SYMONS, S. J.; POYSA, V. W. Determining Soya Bean Seed Size Uniformity with Image Analysis. Biosystems Engineering, p. 191-198, Fevereiro, 2006.

SILVA, C. B. S. Processamento de Sinais de Ressonância Magnética Nuclear Usando Classificador Neural para Reconhecimento de Carne Bovina. Dissertação de Mestrado, Universidade de São Paulo, São Carlos - SP, 2007.

SILVA, F. A. Aplicação de Microondas no Processo de Beneficiamento da Castanha do Brasil (Bertholletia excelsa). Dissertação de Mestrado. Unicamp, Campinas - SP, 2002.

SIMÕES, A. S.; COSTA, A. H. R. Classificação de Laranjas Baseadas em Padrões

Visuais. VI Simpósio Brasileiro de Automação Inteligente. Bauru - SP, 2003.

SIMÕES, A. S.; COSTA, A. H. R.; ANDRADE, M. T. C. Utilizando um Classificador

Fuzzy para a Seleção Visual de Laranjas. Workshop de Computação - Instituto

Tecnológico da Aeronáutica. São José dos Campos - SP, 2001.

SISTEMA de Análise das Informações de Comércio Exterior via Internet. [S.1.]:

Ministério do Desenvolvimento, Indústria e Comércio Exterior, [1989?]. Disponível em: <http://aliceweb.desenvolvimento.gov.br/alice.asp>. Acesso em: 27 Abr. 2008.

TEIXEIRA, E. F.; DOURADO NETO, D.; CÍCERO, S. M. MARTIN, T. N. Análise da Uniformidade de Sementes de Milho Via Processamento de Imagens Digitais. Revista Faculdade de Zootecnia, Veterinária e Agronomia - FZVA, Uruguaiana, v.14, n.1, p.14 24, 2007.

VILELA, P. Castanha do Brasil. Disponível em: $<$ http://www.sebrae.com.br/setor/fruticultura/o-setor/frutas-de-a-a-f/castanha-do-brasil $>$. Acesso em: 05 Mai. 2008. 
- 1xx - 


\section{APÊNDICE A - Gráficos das Diversidades das Variáveis Para Cada Região}

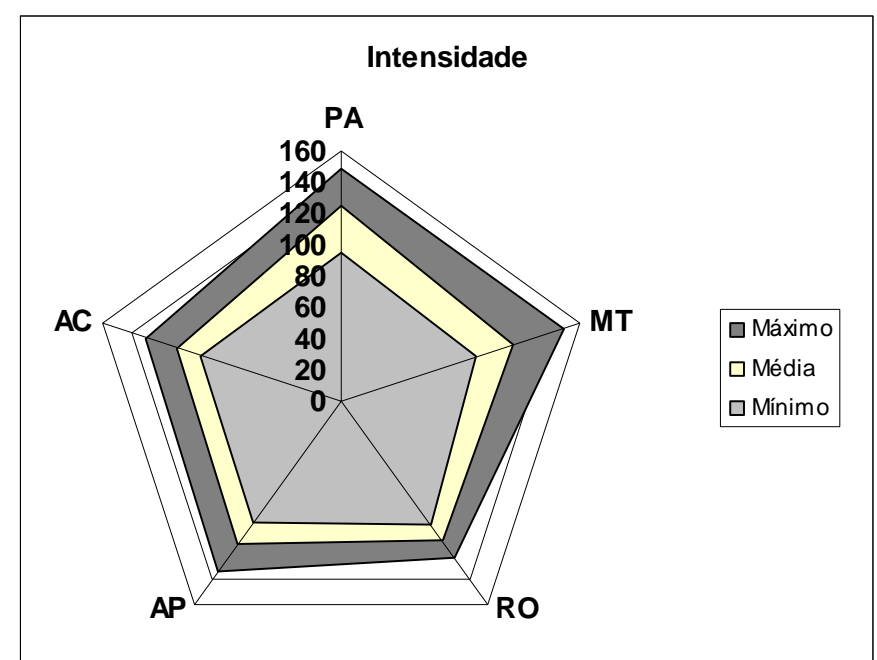

FIGURA 38 - GRÁFICO DA DIVERSIDADE DAS AMOSTRAS EM RELAÇÃO AOS VALORES DE INTENSIDADE.

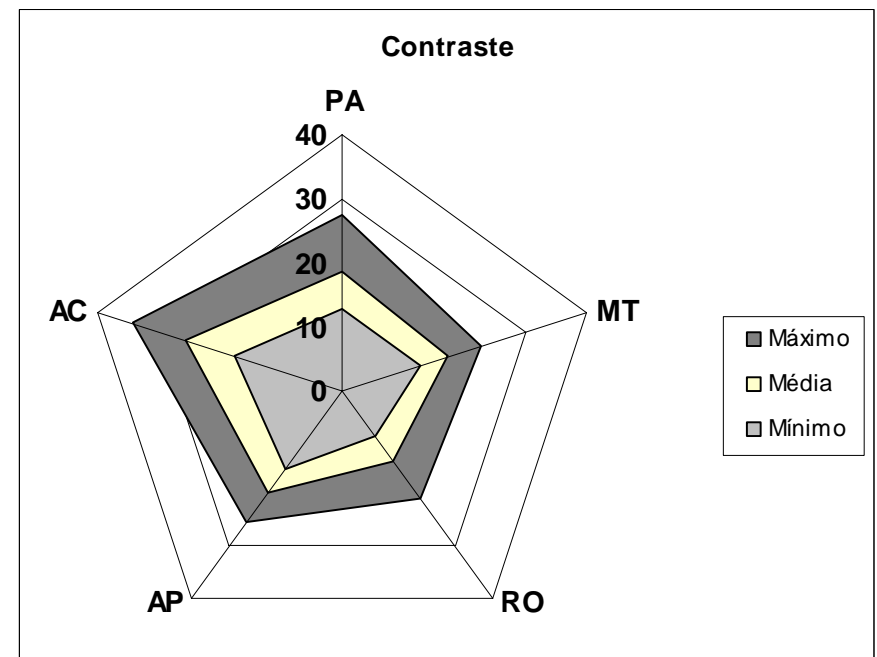

FIGURA 39 - GRÁFICO DA DIVERSIDADE DAS AMOSTRAS EM RELAÇÃO AOS VALORES DE CONTRASTE. 


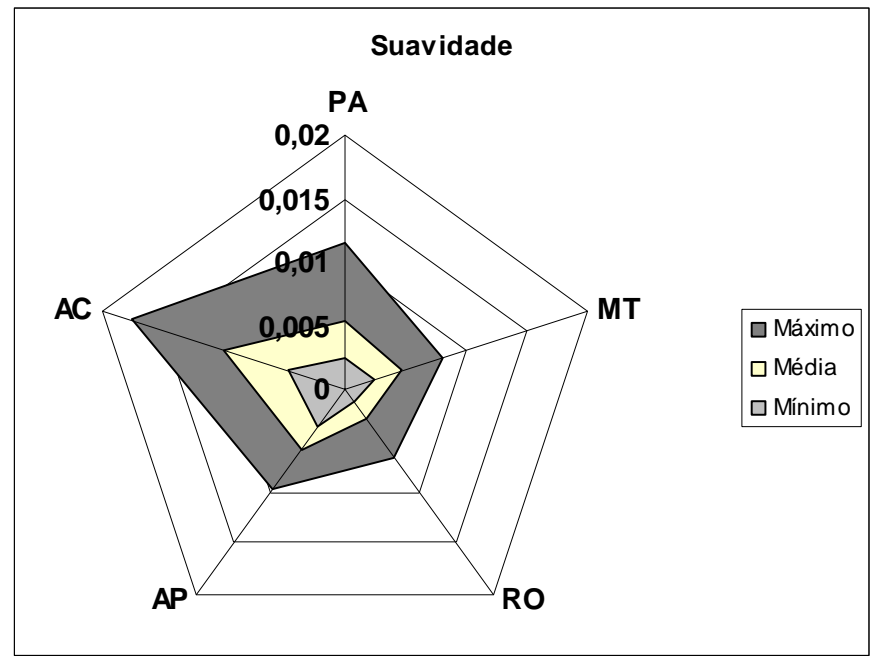

FIGURA 40 - GRÁFICO DA DIVERSIDADE DAS AMOSTRAS EM RELAÇÃO AOS VALORES DE SUAVIDADE.

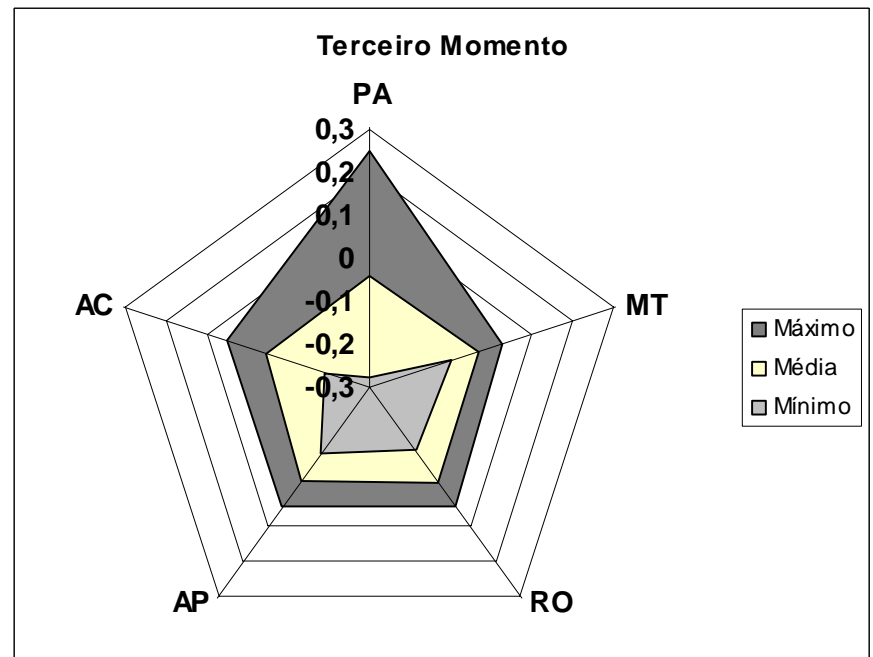

FIGURA 41 - GRÁFICO DA DIVERSIDADE DAS AMOSTRAS EM RELAÇ̃̃O AOS VALORES DE TERCEIRO MOMENTO.

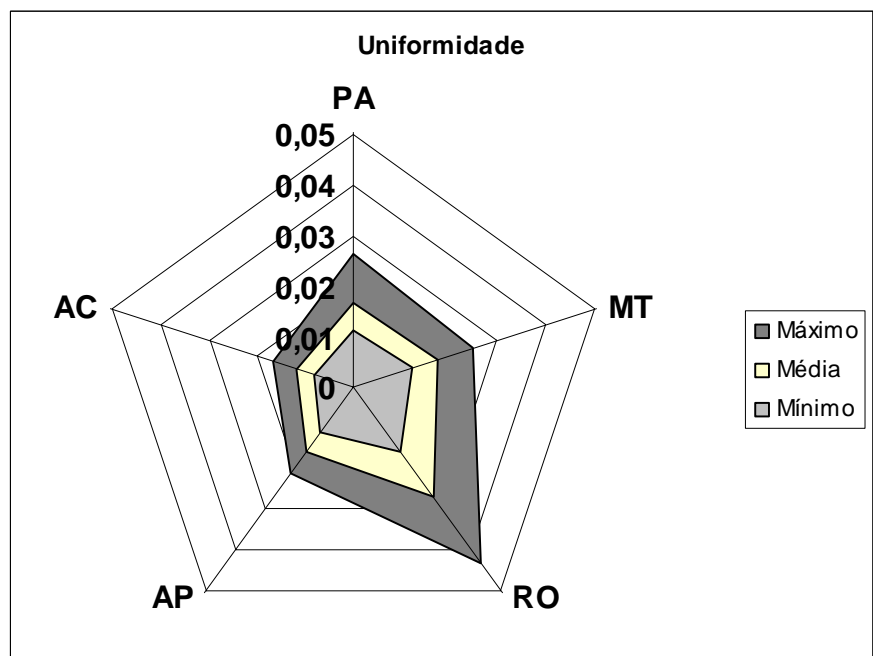

FIGURA 42 - GRÁFICO DA DIVERSIDADE DAS AMOSTRAS EM RELAÇ̃̃o AOS VALORES DE UNIFORMIDADE. 


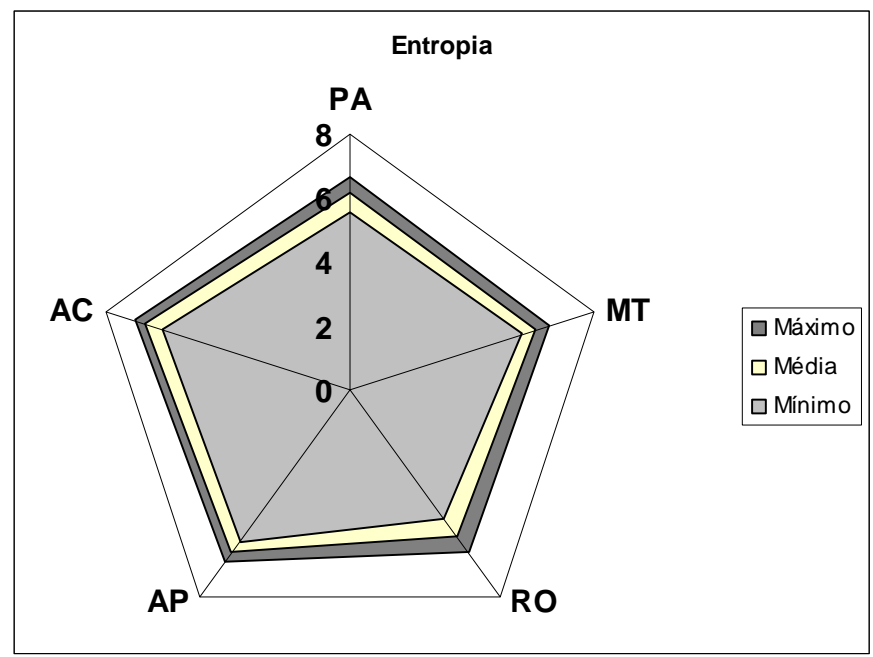

FIGURA 43 - GRÁFICO DA DIVERSIDADE DAS AMOSTRAS EM RELAÇÃO AOS VALORES DE ENTROPIA.

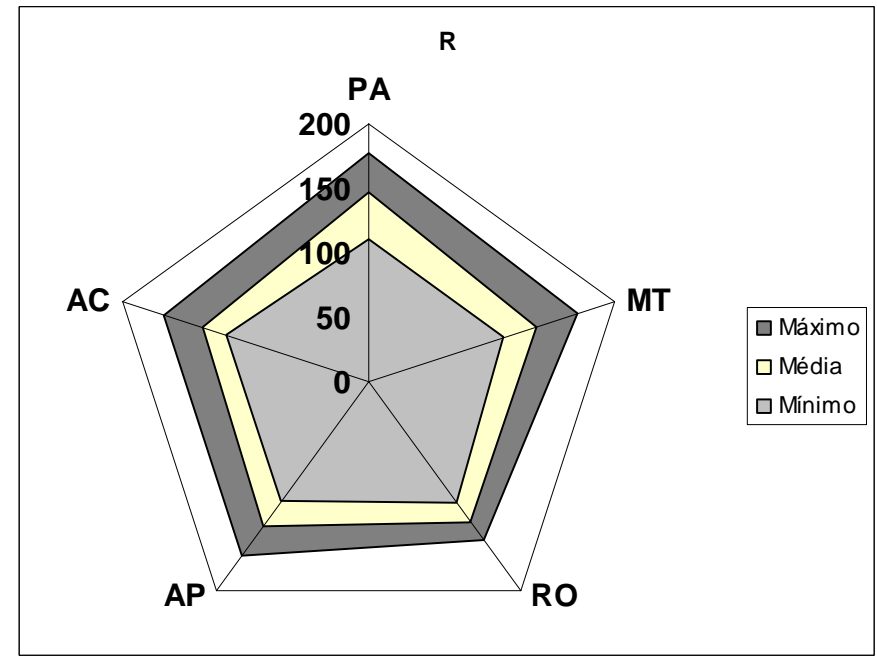

FIGURA 44 - GRÁFICO DA DIVERSIDADE DAS AMOSTRAS EM RELAÇÃO AOS VALORES DE R DO ESPAÇO RGB.

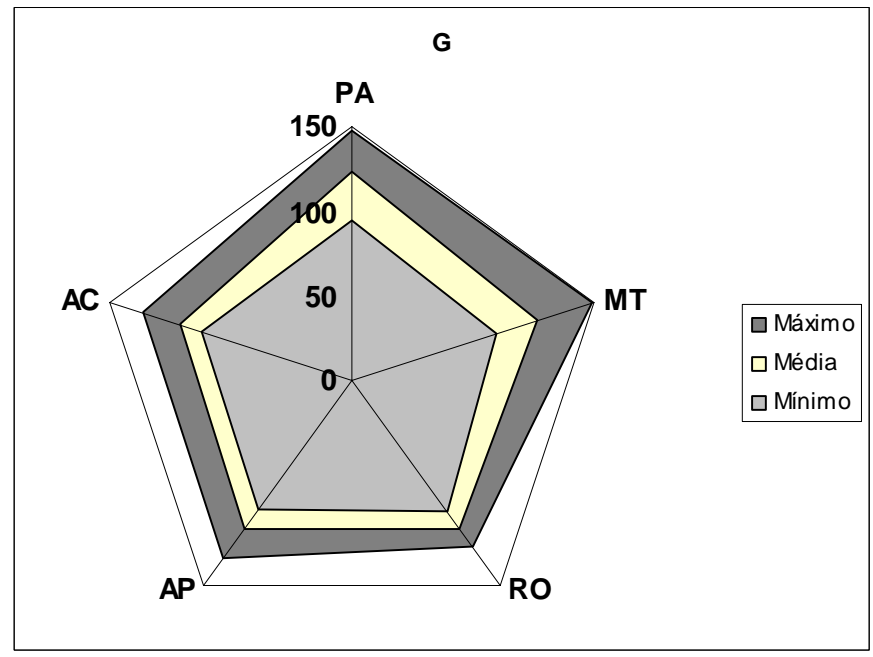

FIGURA 45 - GRÁFICO DA DIVERSIDADE DAS AMOSTRAS EM RELAÇÃO AOS VALORES DE G DO ESPAÇO RGB. 


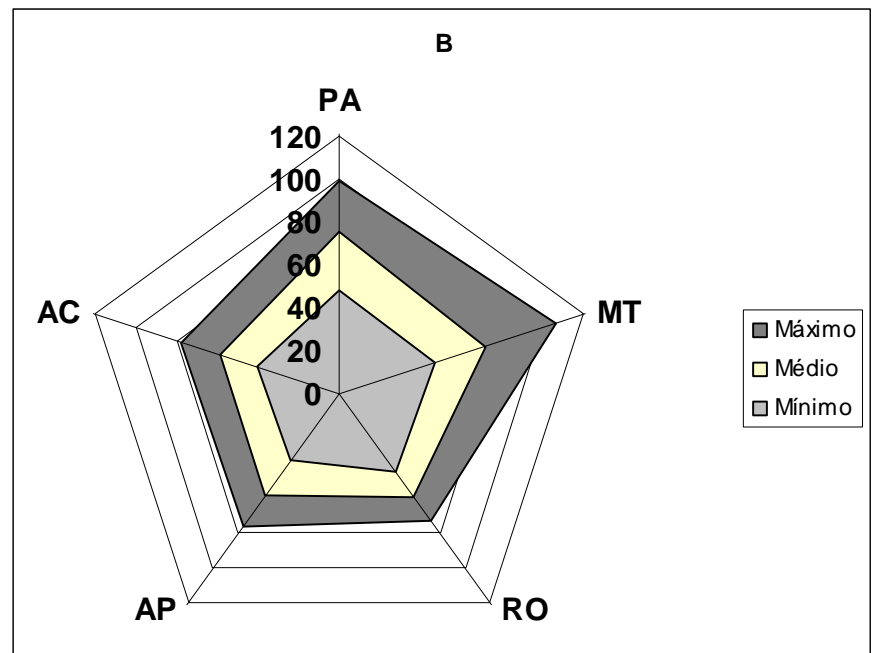

FIGURA 46 - GRÁFICO DA DIVERSIDADE DAS AMOSTRAS EM RELAÇÃO AOS VALORES DE B DO ESPAÇO RGB.

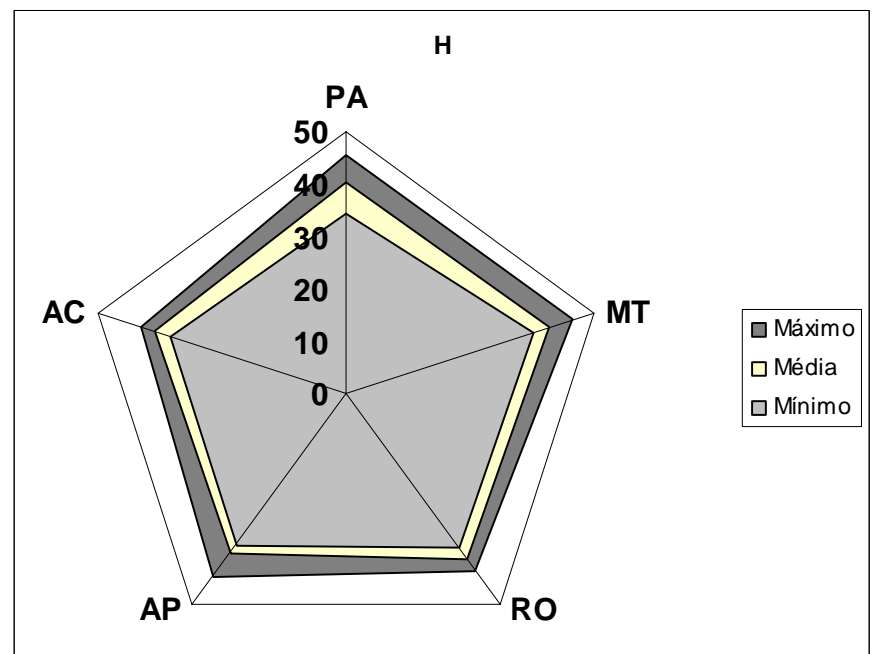

FIGURA 47 - GRÁFICO DA DIVERSIDADE DAS AMOSTRAS EM RELAÇÃO AOS VALORES DE H DO ESPAÇO HSV.

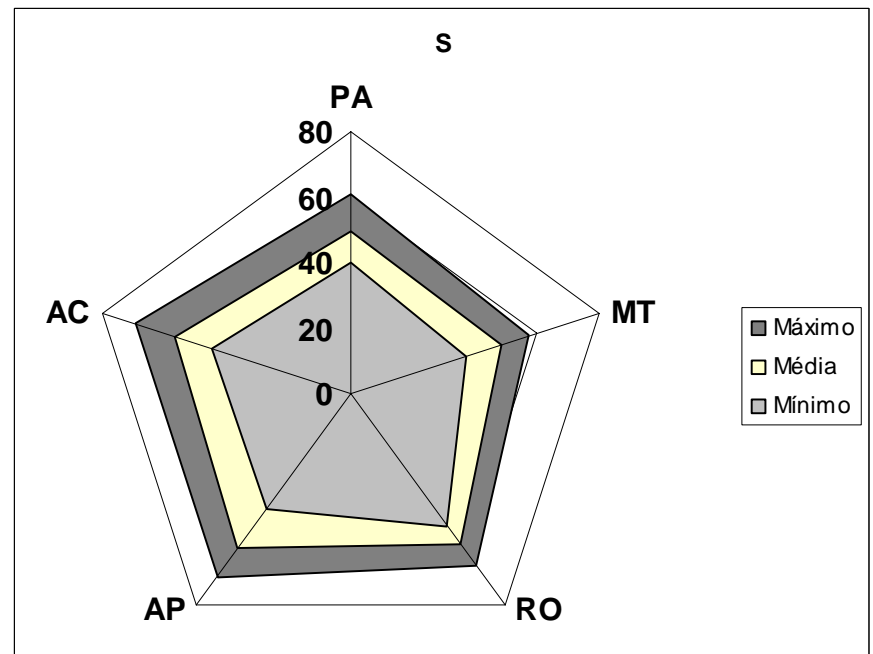

FIGURA 48 - GRÁFICO DA DIVERSIDADE DAS AMOSTRAS EM RELAÇÃO AOS VALORES DE S DO ESPAÇO HSV. 


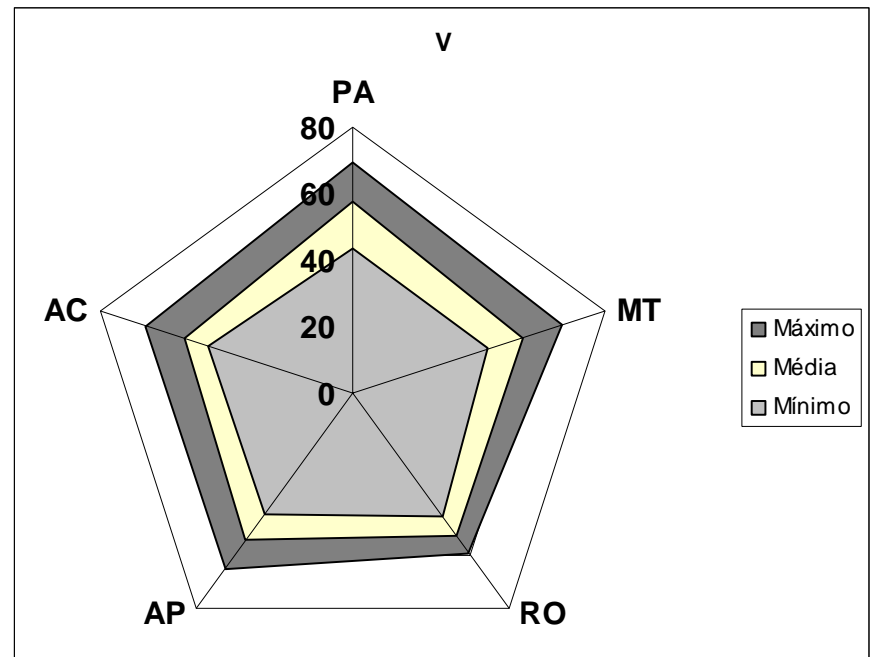

FIGURA 49 - GRÁFICO DA DIVERSIDADE DAS AMOSTRAS EM RELAÇÃO AOS VALORES DE V DO ESPAÇO HSV.

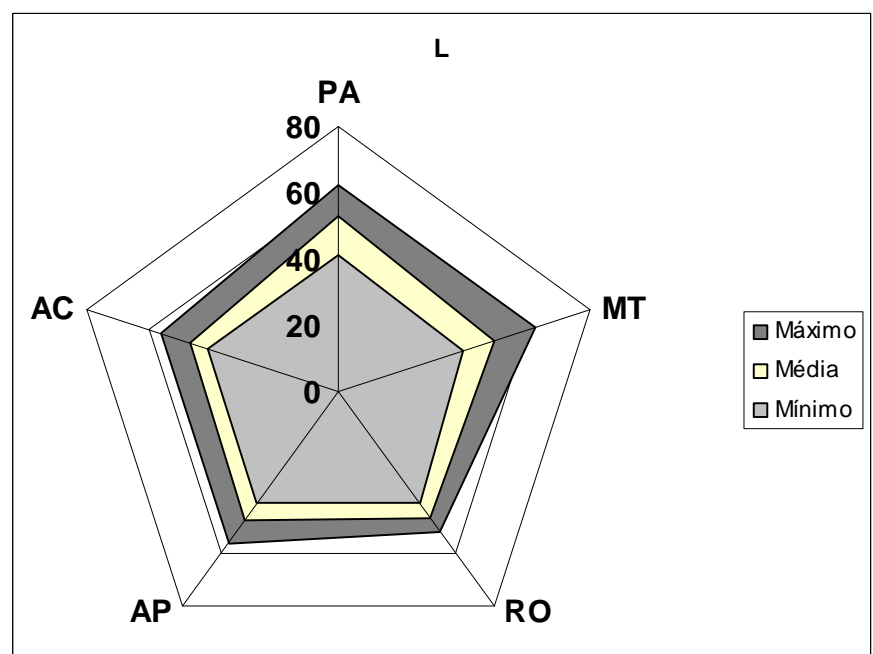

FIGURA 50 - GRÁFICO DA DIVERSIDADE DAS AMOSTRAS EM RELAÇ̃̃O AOS VALORES DE L DO ESPAÇO L*A*B.

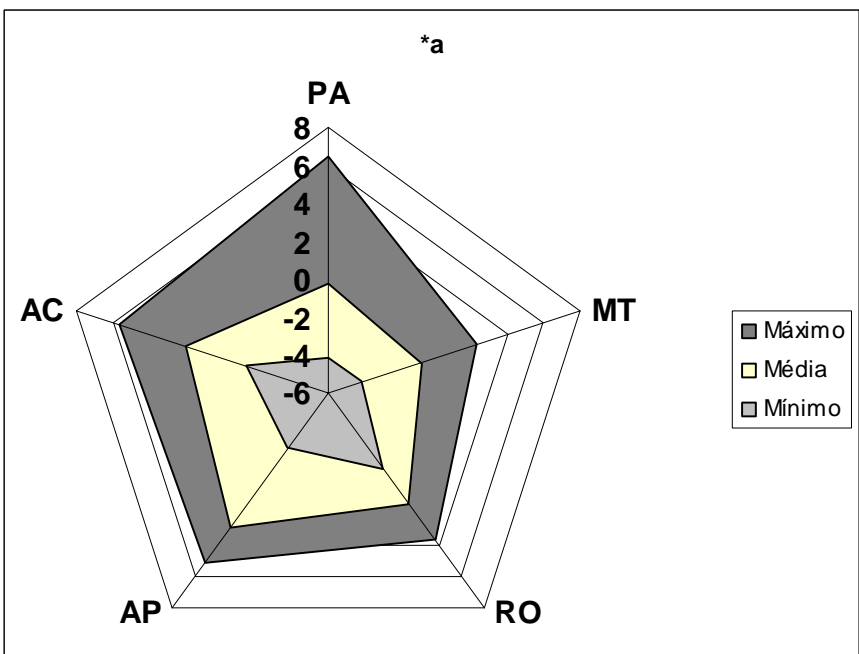

FIGURA 51 - GRÁFICO DA DIVERSIDADE DAS AMOSTRAS EM RELAÇ̃̃O AOS VALORES DE *A DO ESPAÇO L*A*B. 
- lxxvi -

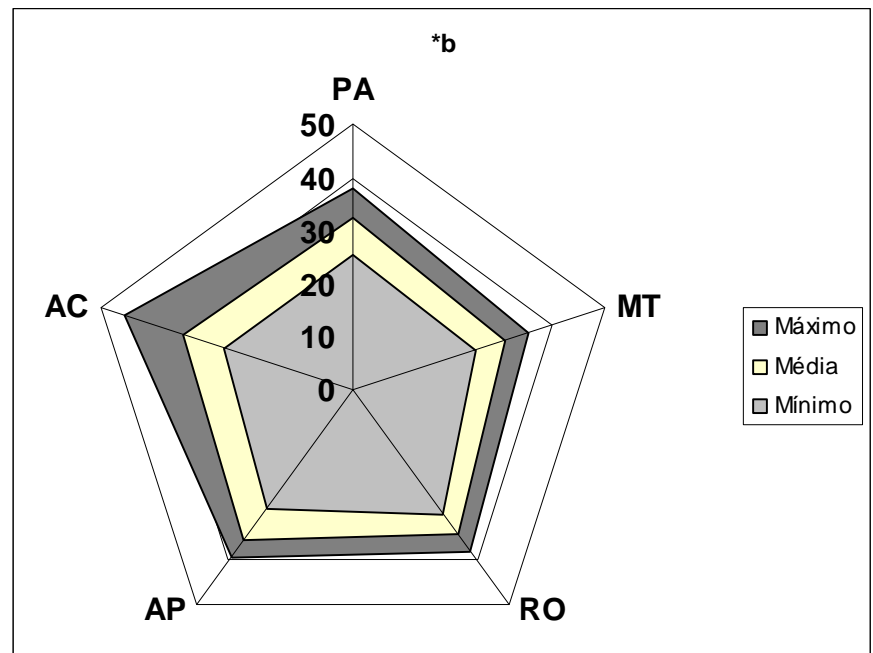

FIGURA 52 - GRÁFICO DA DIVERSIDADE DAS AMOSTRAS EM RELAÇ̃̃O AOS VALORES DE *B DO ESPAÇO L*A*B. 


\section{APÊNDICE B - Imagens das Telas do Software Desenvolvido}

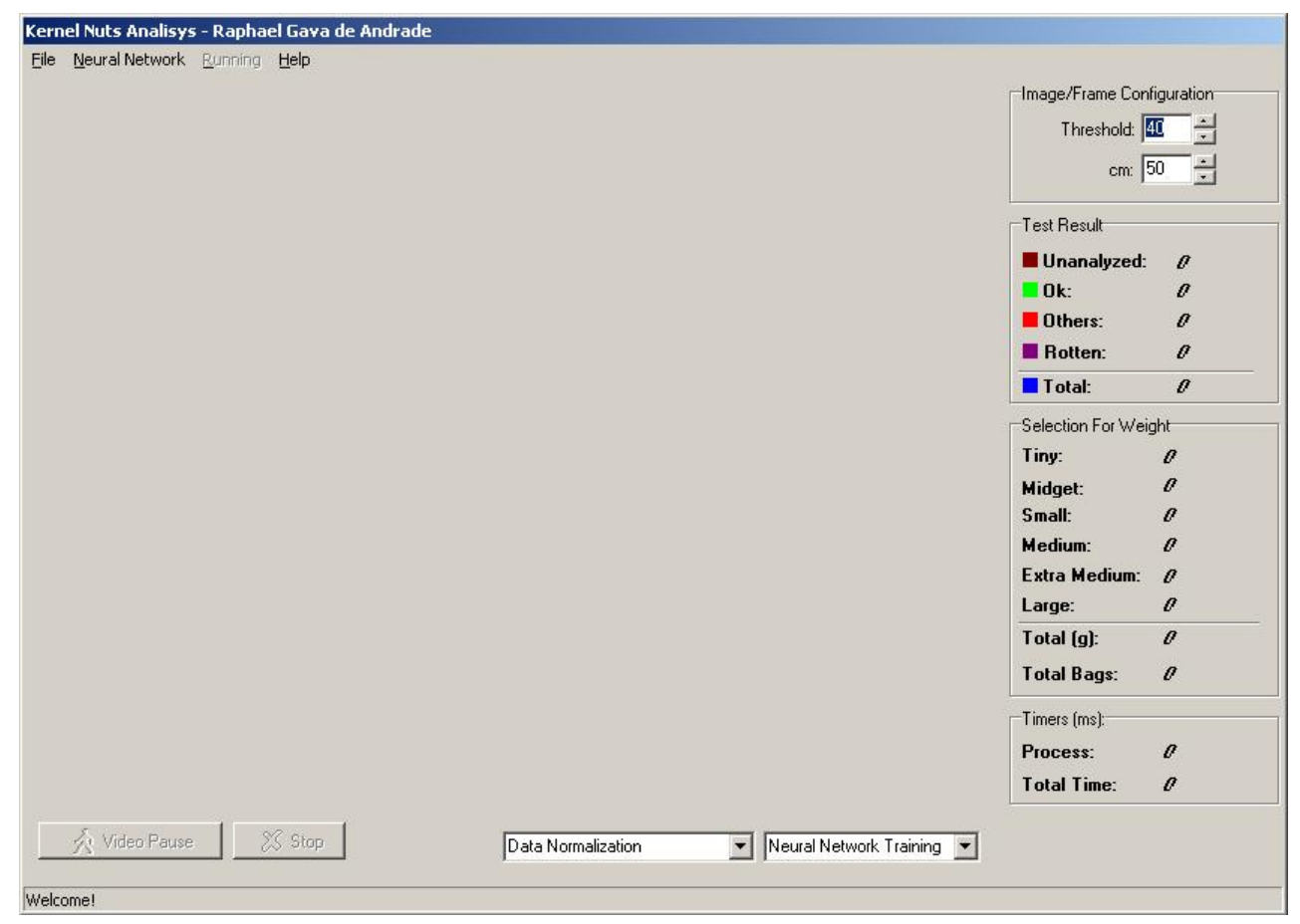

FIGURA 53 - TELA INICIAL DO SOFTWARE.

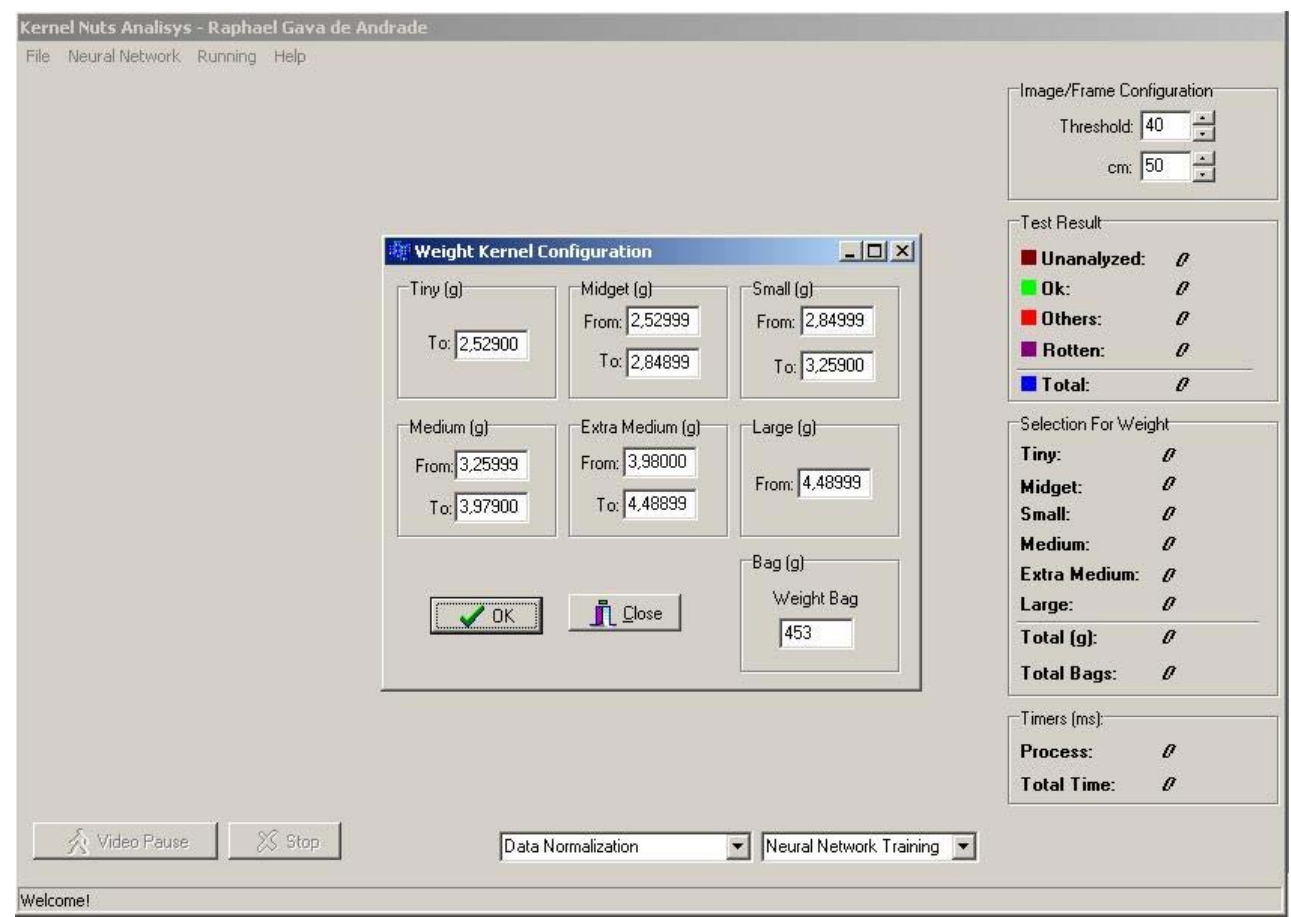

FIGURA 54 - TELA DE CONFIGURAÇÃO DOS PESOS. 


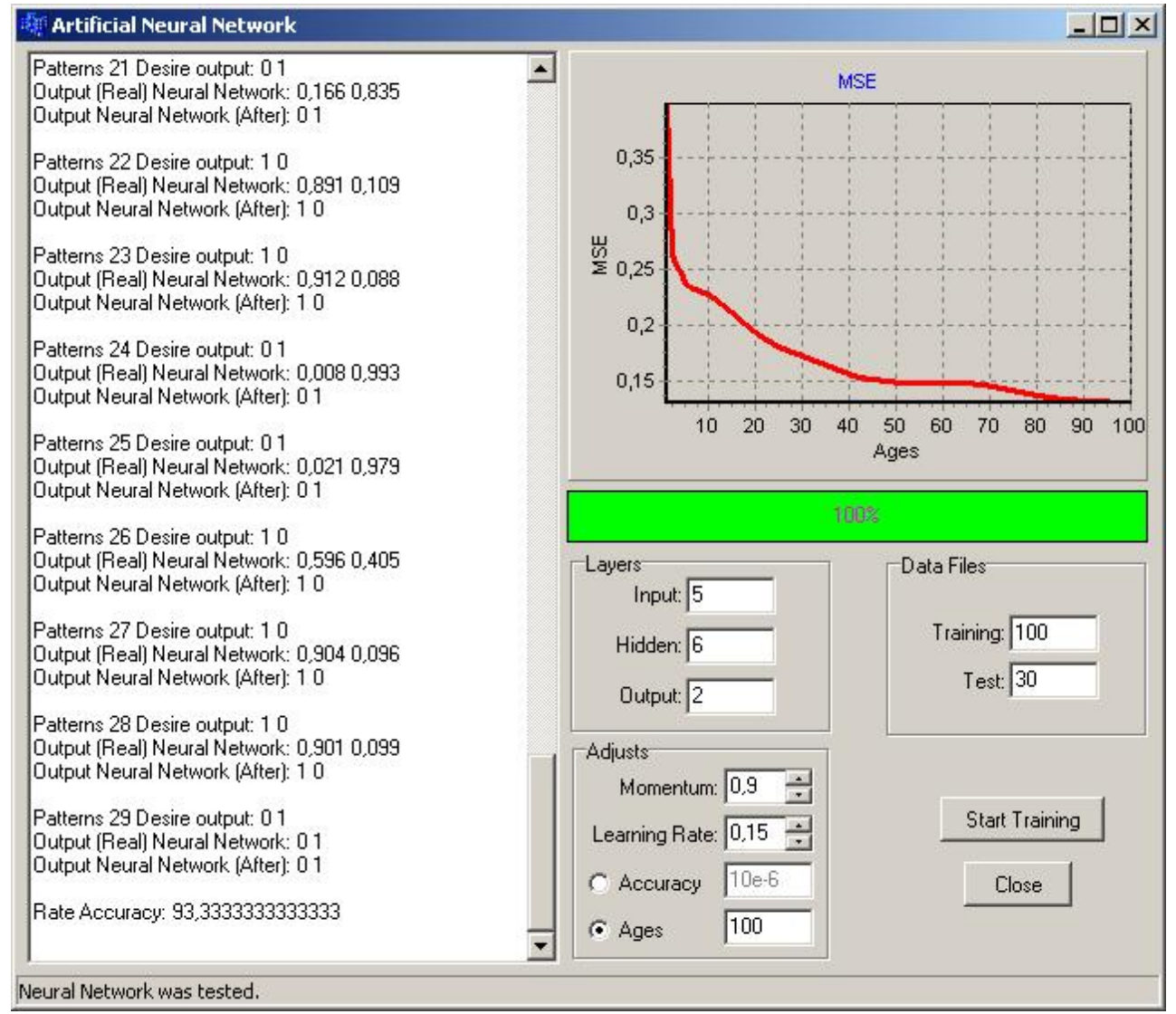

FIGURA 55 - TELA DE CONFIGURAÇÃO DA MLP.

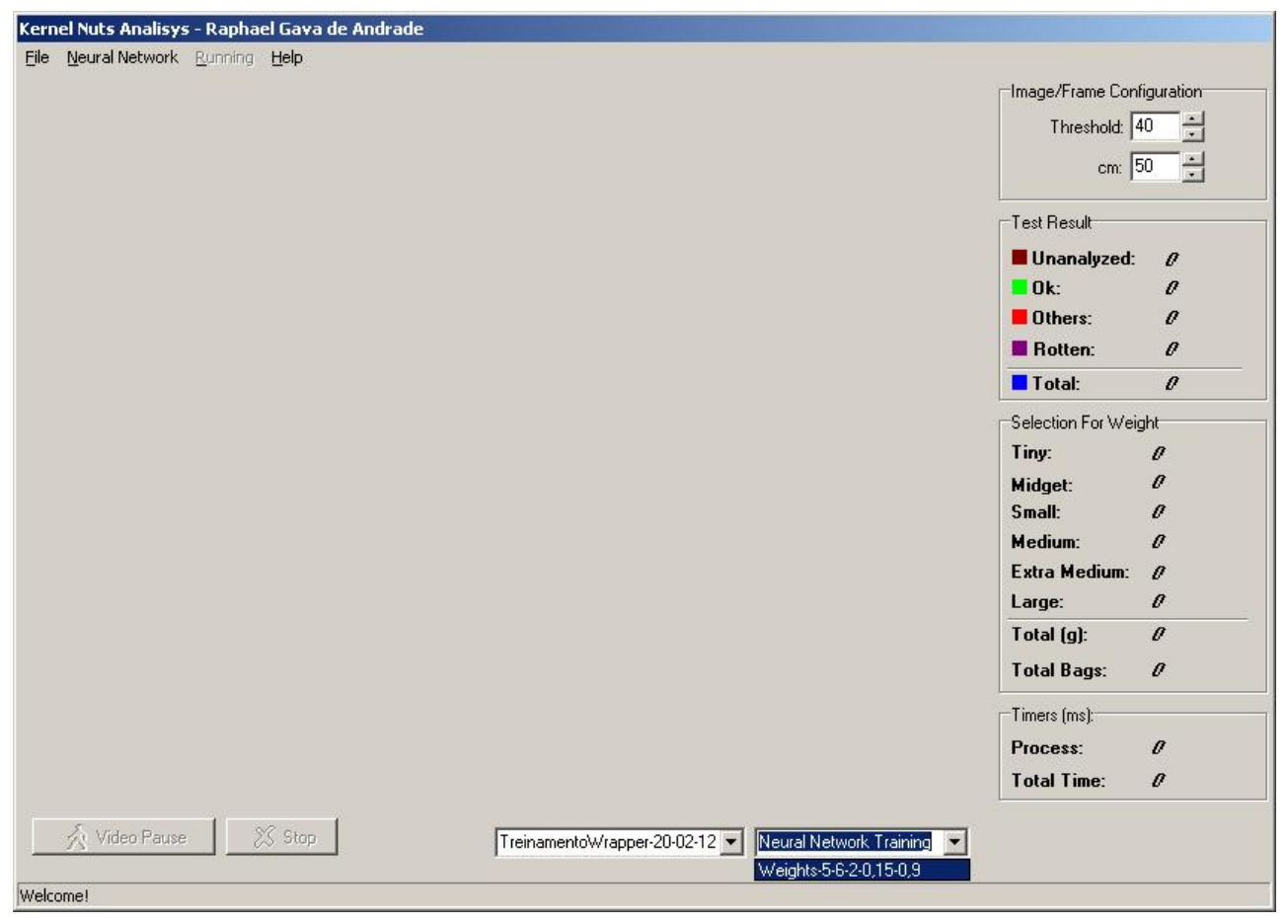

FIGURA 56 - SELECIONANDO A MLP QUE SERÁ UTILIZADA E O ARQUIVO DE MÍNIMOS E MÁXIMOS GERADOS NO TREINAMENTO DA RNA. 


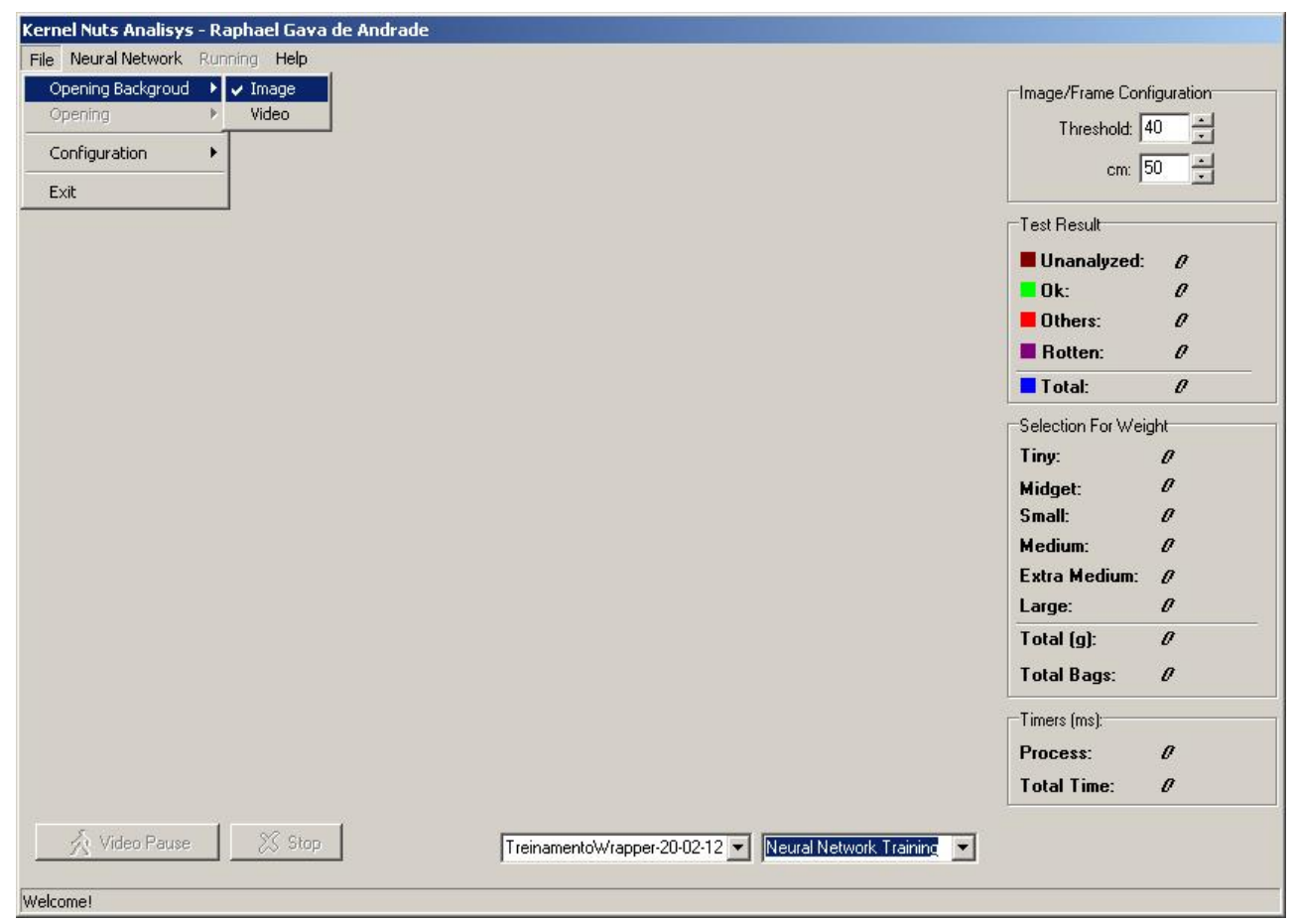

FIGURA 57 - ABRINDO ARQUIVO DA IMAGEM DO FUNDO.

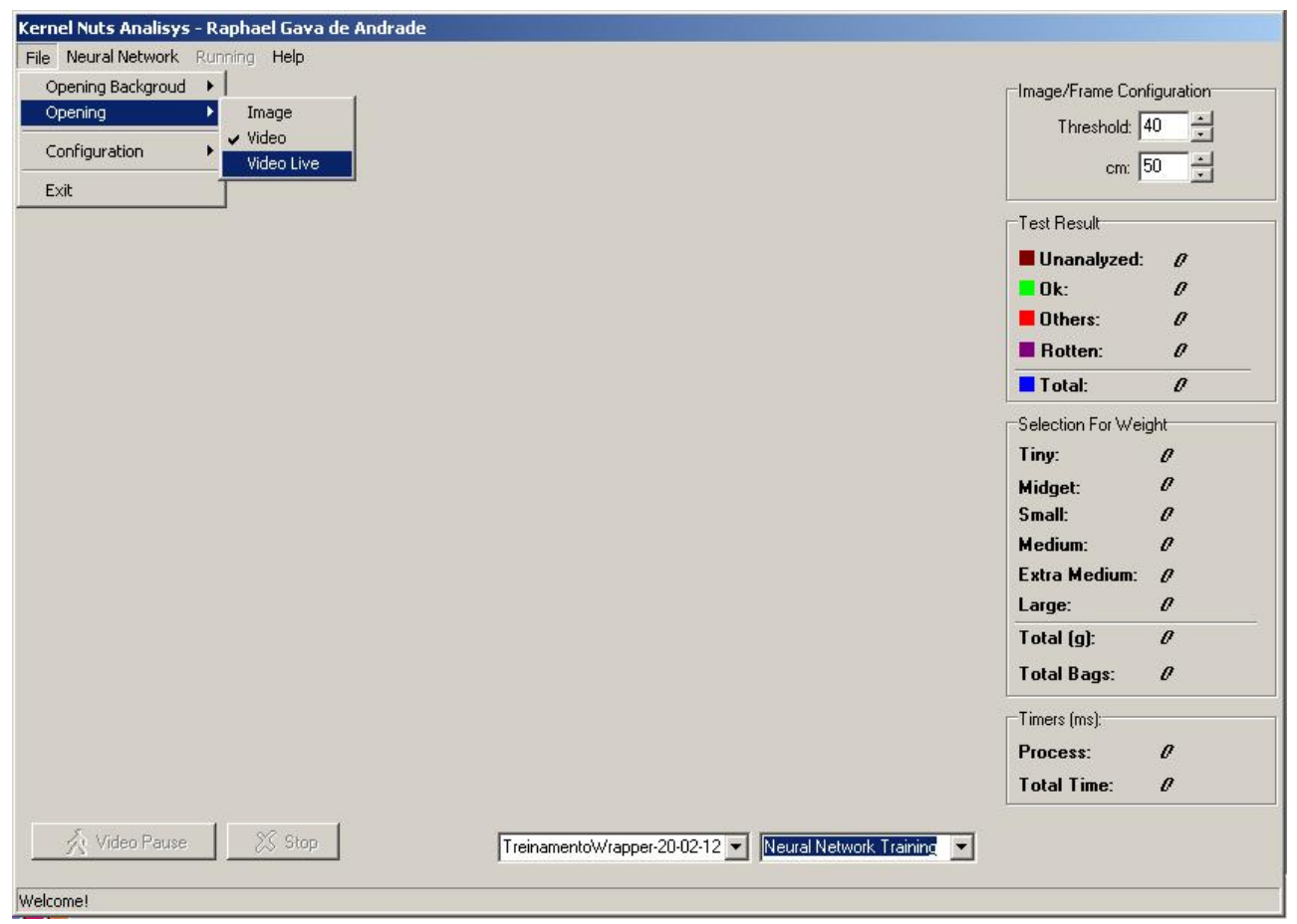

FIGURA 58 - ABRINDO A CÂMERA PARA ANÁLISE AO VIVO. 


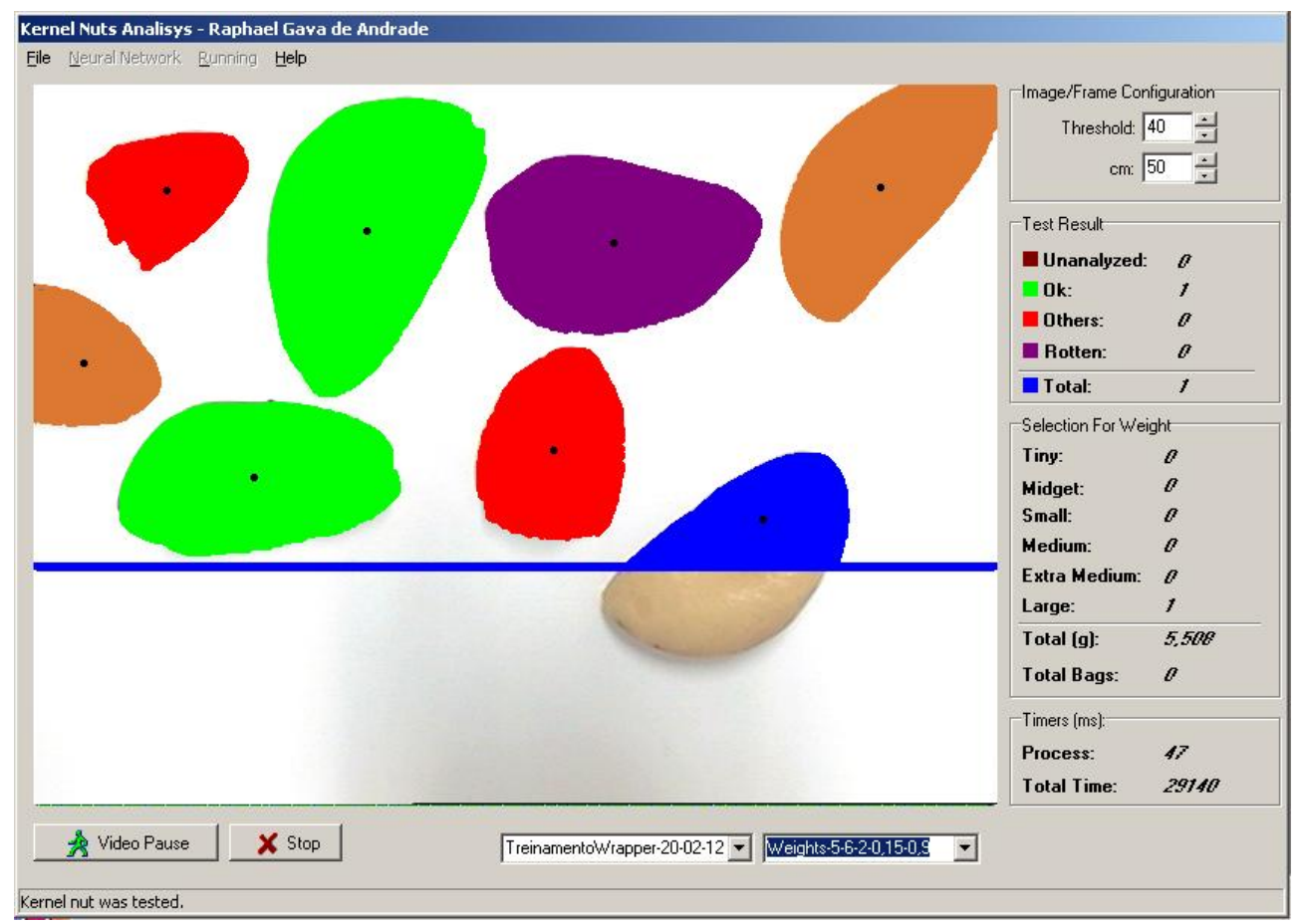

FIGURA 59 - TELA DO SISTEMA EM FUNCIONAMENTO.

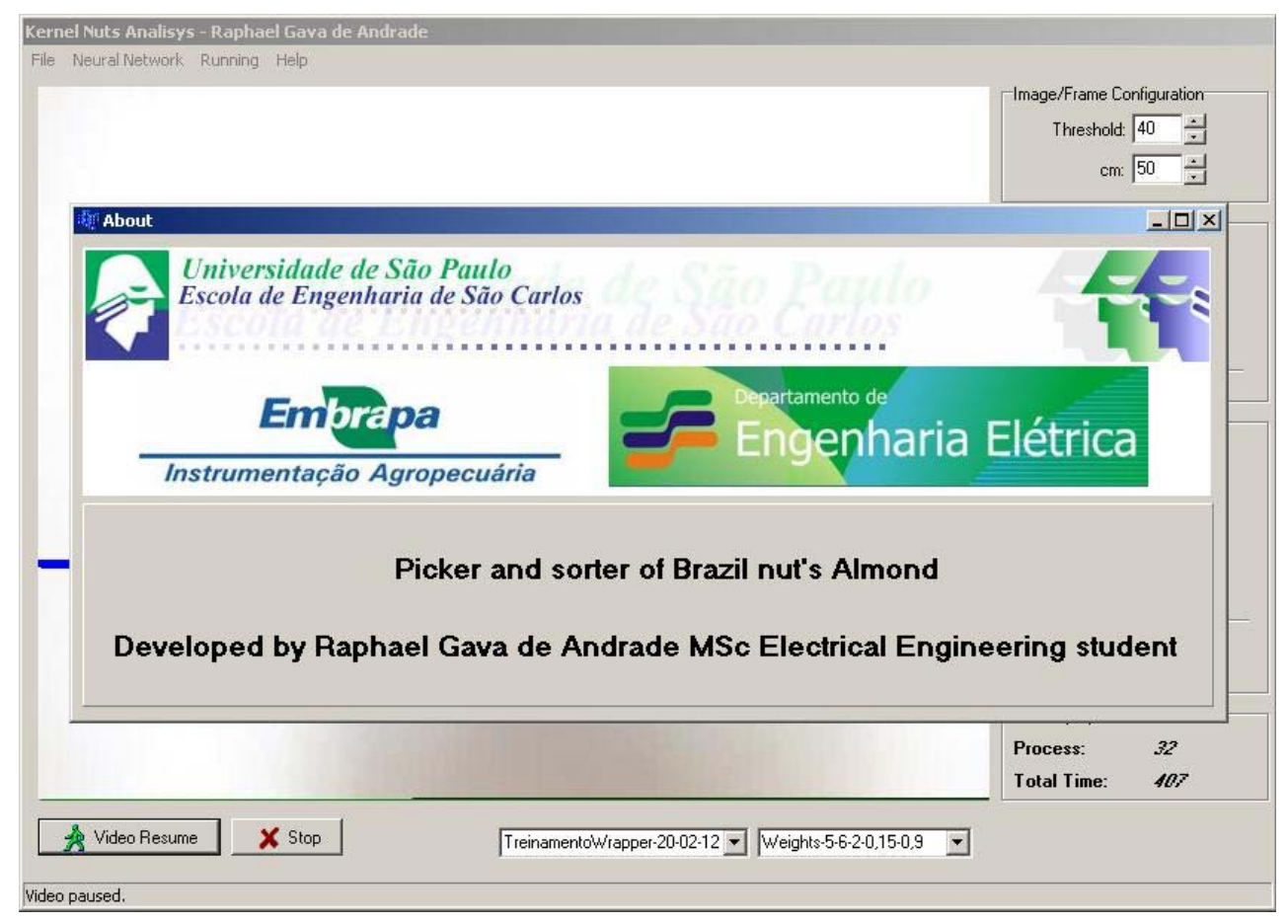

FIGURA 60 - TELA DO ABOUT DO SISTEMA. 


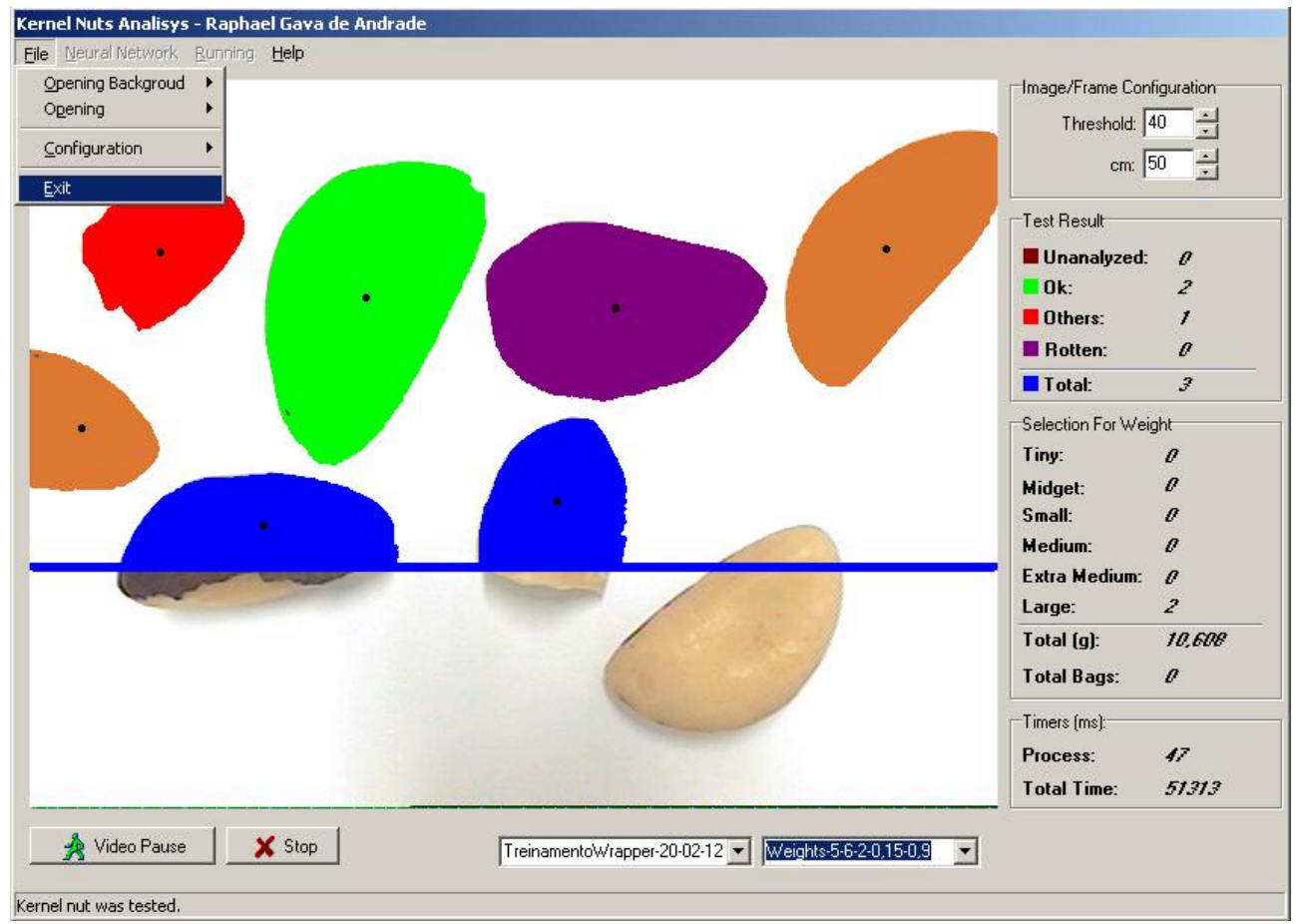

FIGURA 61 - FINALIZANDO O SOFTWARE. 


\section{APÊNDICE C - Imagens da Montagem Utilizada nos Testes Para Seleção das Amêndoas}

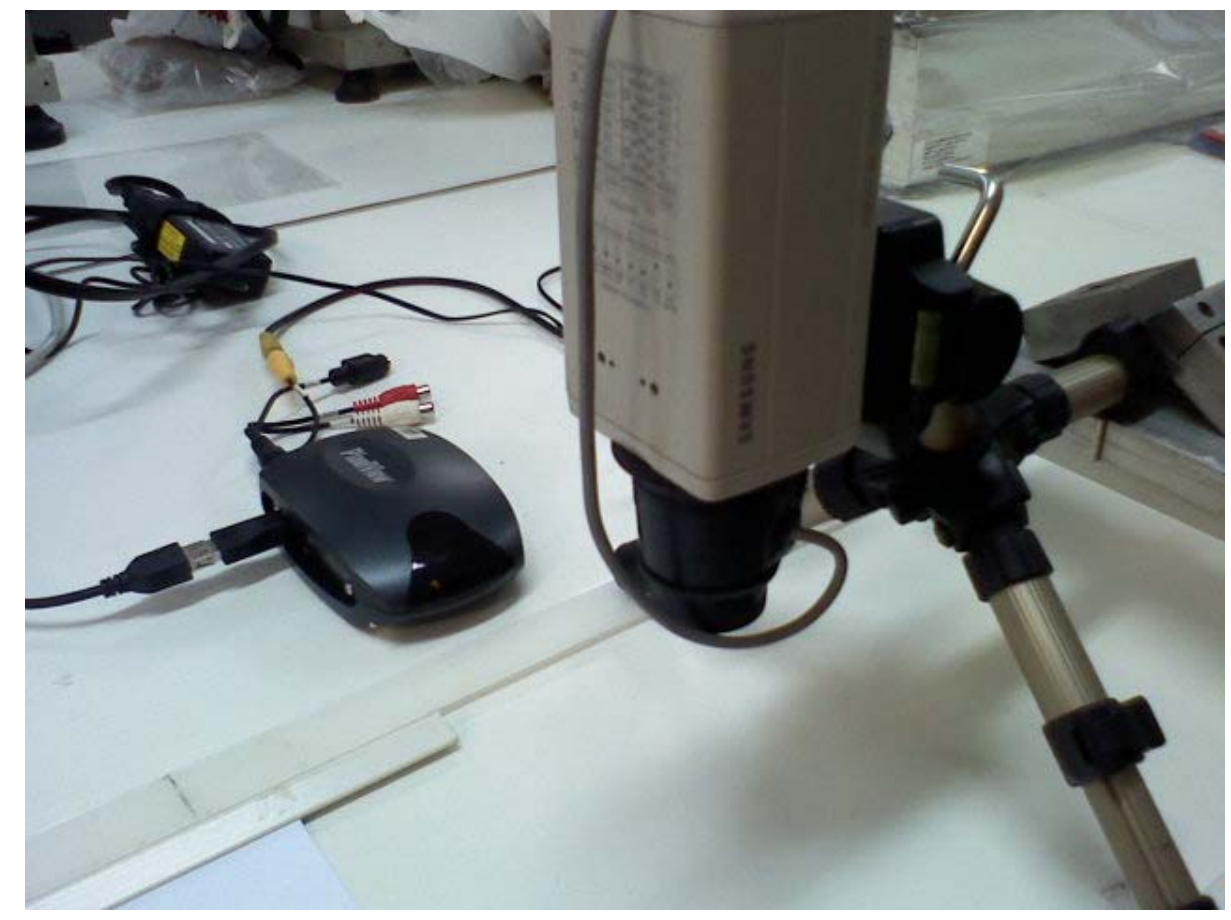

FIGURA 62 - VISTA 1 DA MONTAGEM FEITA PARA A SELEÇÃO DAS AMÊNDOAS.

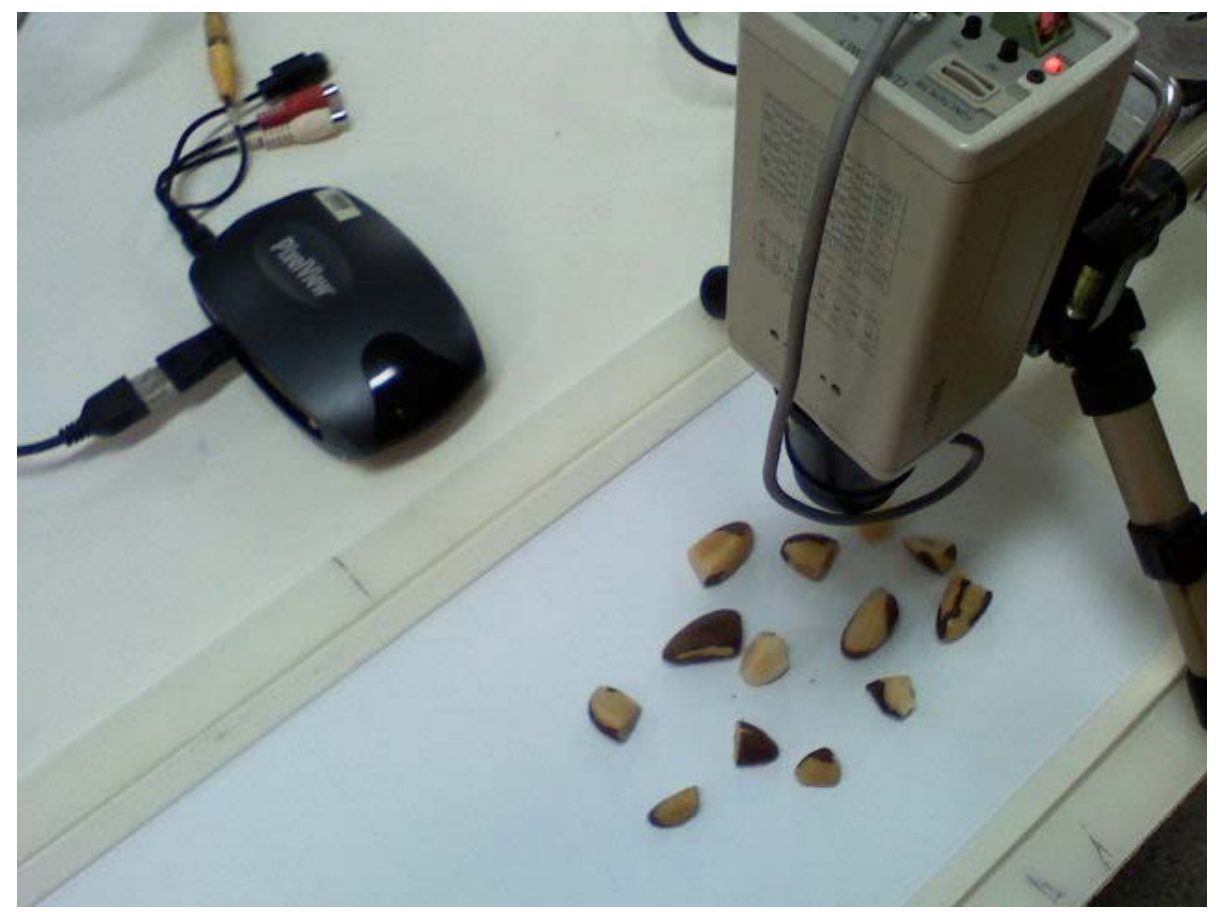

FIGURA 63 - VISTA 2 DA MONTAGEM FEITA PARA SELEÇÃO DAS AMÊNDOAS. 


\section{APÊNDICE D - Fluxograma do Funcionamento do Software de Seleção das Amêndoas}

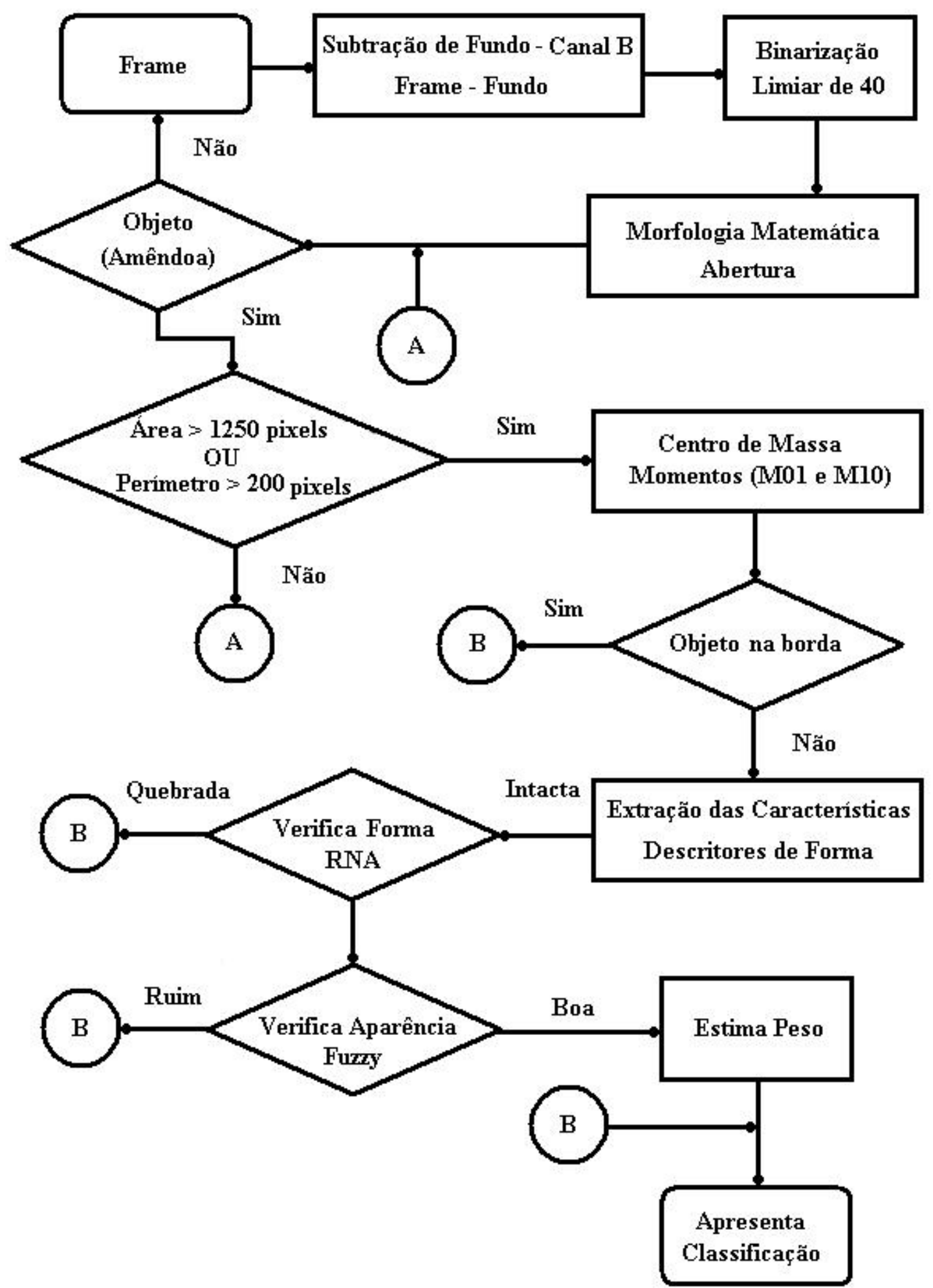

FIGURA 64 - FLUXOGRAMA DO FUNCIONAMENTO DO SOFTWARE DE SELEÇÃO DAS AMÊNDOAS. 
- 1xxxvi - 


\title{
ANEXO A - Pseudocódigo de Conversão Entre os Espaços de Cores RGB e HSV
}

\author{
RGB para HSV \\ var_R $=(\mathrm{R} / 255)$ \\ //RGB de 0 até 255 \\ var_G $=(\mathrm{G} / 255)$ \\ $\operatorname{var} B=(B / 255)$ \\ var_Min $=\min ($ var_R, var_G, var_B $) \quad / /$ Min. valor de RGB \\ var_Max $=\max (\operatorname{var} R$, var_G, var_B $) \quad / / M a x$. valor de RGB \\ del_Max $=$ var_Max - var_Min \\ //Delta de RGB \\ $\mathrm{V}=$ var_Max \\ if $($ del_Max $==0)\{$ \\ //Nível de cinza \\ $\mathrm{H}=0$ \\ //resultado HSV de 0 até 1 \\ $\mathrm{S}=0$ \\ \}else \{ \\ //Colorido.

$$
\begin{aligned}
& \mathrm{S}=\text { del_Max / var_Max } \\
& \text { del_R }=(((\text { var_Max }- \text { var_R }) / 6)+(\text { del_Max / 2) }) / \text { del_Max } \\
& \text { del_G }=(((\operatorname{var} \text { _Max }- \text { var_G }) / 6)+(\text { del_Max / 2) }) / \text { del_Max } \\
& \text { del_B }=\left(\left(\left(\operatorname{var} \_M a x-v a r \_B\right) / 6\right)+(\text { del_Max / } 2)\right) / \text { del_Max } \\
& \text { if (var_R == var_Max) } \mathrm{H}=\text { del_B - del_G } \\
& \text { else if (var_G== var_Max) } \mathrm{H}=(1 / 3)+\text { del_R - del_B } \\
& \text { else if (var_B == var_Max) } \mathrm{H}=(2 / 3)+\text { del_G - del_R } \\
& \text { if }(\mathrm{H}<0) \quad \mathrm{H}+=1 \\
& \text { if }(\mathrm{H}>1) \quad \mathrm{H}-=1
\end{aligned}
$$




\section{HSV para RGB}

if $(\mathrm{S}==0)\{/ / \mathrm{HSV}$ from 0 to 1

$$
\begin{aligned}
& \mathrm{R}=\mathrm{V} * 255 \\
& \mathrm{G}=\mathrm{V} * 255 \\
& \mathrm{~B}=\mathrm{V} * 255
\end{aligned}
$$

\}else \{

$$
\begin{aligned}
& \text { var_h }=\mathrm{H} * 6 \\
& \text { if }(\text { var_ } h==6) \quad \text { var_h }=0 \quad \text { //H deve ser }<1 \\
& \text { var_i }=\text { int(var_h) } \\
& \text { var_1 }=\mathrm{V} *(1-\mathrm{S}) \\
& \text { var_2 }=\mathrm{V} *\left(1-\mathrm{S} *\left(\operatorname{var} \_\mathrm{h}-\mathrm{var} \_\mathrm{i}\right)\right) \\
& \text { var_3 }=\mathrm{V} *\left(1-\mathrm{S} *\left(1-\left(\operatorname{var} \_\mathrm{h}-\mathrm{var} \mathrm{i}\right)\right)\right) \\
& \text { if }\left(\operatorname{var} \_\mathrm{i}==0\right)\{ \\
& \text { var_r }=\mathrm{V} \quad \text { var_g }=\text { var_3 } \quad \text { var_b }=\text { var_1 }
\end{aligned}
$$

\}else if $($ var_ $\mathrm{i}==1)\{$

$$
\text { var_r }=\text { var_2 var_g }=\mathrm{V} \quad \text { var_b }=\text { var_1 }
$$

\}else if $($ var_ $\mathrm{i}==2)\{$

$$
\text { var_r }=\text { var_1 var_g }=\mathrm{V} \quad \text { var_b }=\text { var_3 }
$$

\}else if $($ var_i $==3)\{$

$$
\text { var_r }=\text { var_1 var_g }=\text { var_2 var_b }=\mathrm{V}
$$

\}else if (var_i $==4)\{$

$$
\text { var_r }=\text { var_3 var_g }=\text { var_1 var_b }=\mathrm{V}
$$

\}else \{

$$
\text { var_r }=\mathrm{V} \quad \text { var_g }=\text { var_1 var_b }=\text { var_2 }
$$

\}

$\mathrm{R}=$ var_ $\mathrm{r} * 255$

$\mathrm{G}=$ var_g * 255

$\mathrm{B}=\operatorname{var} \mathrm{b} * 255$ 